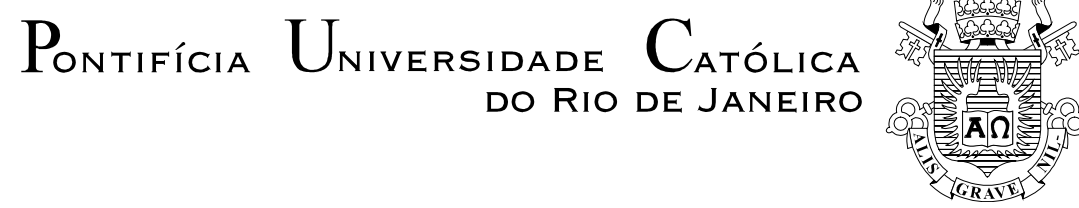

Himer Alberto Mieles Pinto

Estudo numérico do processo de cimentação em poços erodidos.

Dissertação de Mestrado

Dissertação apresentada ao Programa de Pósgraduação em Engenharia Mecânica da PUC-Rio como requisito parcial para obtenção do título de Mestre em Engenharia Mecânica.

Orientadora: Prof. Mônica Feijó Naccache

Rio de Janeiro Abril de 2016 


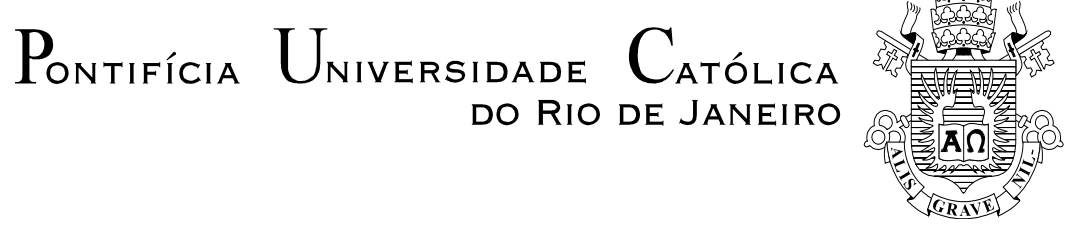

Himer Alberto Mieles Pinto

\section{Estudo numérico do processo de cimentação em poços erodidos}

Dissertação apresentada como requisito parcial para obtenção do grau de Mestre pelo Programa de Pós-Graduação em Engenharia Mecânica da PUC-Rio. Aprovada pela Comissão Examinadora abaixo assinada.

Profa. Mônica Feijó Naccache

Orientadora

Departamento de Engenharia Mecânica - PUC-Rio

Prof. Sérgio Frey

Universidade Federal do Rio Grande do Sul

Dra. Cristiane Richard

PETROBAS

Prof. Márcio da Silveira Carvalho

Coordenador Setorial do Centro Técnico Científico - PUC-Rio

Rio de Janeiro, 25 de abril de 2016 
Todos os direitos reservados. É proibida a reprodução total ou parcial do trabalho sem autorização da universidade, do autor e do orientador.

Himer Alberto Mieles Pinto

Graduou-se em Engenharia Mecatrônica pela Universidade Autónoma de Bucaramanga - Bucaramanga - Colômbia 2010 .

Ficha Catalográfica

Pinto, Himer Alberto Mieles

Estudo numérico do processo de cimentação em poços erodidos / Himer Alberto Mieles Pinto ; orientadora: Mônica Feijó Naccache. - 2016.

89 f. : il. color. ; $30 \mathrm{~cm}$

Dissertação (mestrado)-Pontifícia Universidade Católica do Rio de Janeiro, Departamento de Engenharia Mecânica, 2016.

Inclui bibliografia

1. Engenharia Mecânica - Teses. 2. Fluidos viscoplásticos. 3. Poços erodidos. 4. Deslocamento de fluidos. I. Naccache, Mônica Feijó. II. Pontifícia Universidade Católica do Rio de Janeiro. Departamento de Engenharia Mecânica. III. Título. 


\section{Agradecimentos}

A Capes e à PUC-Rio, pelos auxílios concedidos, sem os quais este trabalho não poderia ter sido realizado.

A todos os professores e funcionários do Departamento de Engenharia Mecânica pelos ensinamentos e pela ajuda.

À minha orientadora Professora Mônica, pela paciência, apoio e ajuda para a realização deste trabalho.

A minha mãe Fanny Pinto e meu pai Manuel Mieles pela educação, empenho, apoio e amor incondicional.

A meus irmãos Camilo, Andrés e Fidel pela ajuda e apoio, que foram para mim de valor inestimável.

A todos meus colegas do GReo que me brindaram sua ajuda, apoio e amizade.

A todos os amigos e familiares que de uma forma ou de outra me estimularam e me ajudaram.

Aos professores que participaram da Comissão examinadora. 


\section{Resumo}

Pinto, Himer Alberto Mieles. Naccache, Mônica Feijó. Estudo numérico do processo de cimentação em poços erodidos. Rio de Janeiro, 2016. 89p. Dissertação de Mestrado - Departamento de Engenharia Mecânica, Pontifícia Universidade Católica do Rio de Janeiro.

Atualmente na indústria do petróleo a simulação numérica é frequentemente usada para avaliar diferentes processos através de poderosas ferramentas de software que ajudam a evitar uma pesquisa experimental, que pode ser uma tarefa cara e às vezes impraticáveis. O objetivo deste estudo é apresentar uma investigação numérica para encontrar uma melhor eficiência no processo de cimentação em poços erodidos. Neste processo, um fluido desloca um outro fluido através de um tubo com secção transversal de área variável. Ambos os fluidos podem ter um comportamento não-newtoniano. A análise é feita pela solução numérica das equações governantes, utilizando o método de volumes finitos. Estudos anteriores mostraram que os processos de deslocamento através dos poços verticais são governados principalmente pela relação de viscosidades e densidades dos fluidos, pela excentricidade do espaço anular, e pelo número de Reynolds do escoamento. Além disso, outras variáveis tais como a rotação da parede e a geometria do poço podem influenciar a eficiência do deslocamento. Dessa forma, serão analisados o efeito de alguns destes parâmetros no escoamento ao longo do poço e na eficiência de remoção nos poços erodidos, a fim de ajudar na otimização dos processos de limpeza e de remoção.

\section{Palavras-chave}

Fluidos viscoplásticos; poços erodidos; deslocamento de fluidos. 


\section{Abstract}

Pinto, Himer Alberto Mieles. Naccache, Mônica Feijó (Advisor). Numerical study of cementation process in eroded wells. Rio de Janeiro, 2016. 89p. MSc. Dissertation - Departamento de Engenharia Mecânica, Pontifícia Universidade Católica do Rio de Janeiro.

Currently in the oil industry, the numerical simulation is often used to evaluate different processes through powerful software tools that help to prevent an experimental research in a real well, which can be an expensive and sometimes impractical task. The purpose of this study is to present a numerical investigation to find a better efficiency in the cementation process in eroded wells. In this process, one fluid displaces another through a tube with variable cross sectional area. Both fluids may have non-Newtonian behavior. The analysis is done by the numerical solution of the governing equations, using the finite volume method. Previous studies showed that the displacement process through vertical wells are ruled primarily by the viscosity and density ratios of the fluids, the eccentricity of the annulus, and the Reynolds number. In addition, other variables such as the casing rotation and well geometry can influence the displacement efficiency. Then, the analysis of the influence of these parameters in the flow pattern through the well and removal efficiency in eroded wells will be performed, and will help to optimize the cleaning and removal processes.

\section{Keywords}

Viscoplastic fluids; eroded wells; displacement of fluids. 


\section{Sumário}

1 Introdução 14

1.1 Objetivos e Metodologia do Trabalho 15

$\begin{array}{ll}1.2 \text { Revisão Bibliográfica } & 16\end{array}$

$\begin{array}{ll}1.3 \text { Organização do Trabalho } & 20\end{array}$

2 Modelagem matemática $\quad 21$

$\begin{array}{ll}2.1 \text { Geometria da área erodida } & 21\end{array}$

2.2 Equações governantes 23

2.2.1 Equações de conservação 23

2.2.2 Equações constitutivas 25

2.3 Condições de contorno e inicial 28

2.3.1 Adimensionalização 28

$\begin{array}{ll}\text { 2.3.2 Parâmetros adimensionais relevantes } & 28\end{array}$

3 Método numérico 34

3.1 Método dos Volumes Finitos 34

3.3 Método VOF (Volume of fluid) 35

3.3 Teste de malha 36

$\begin{array}{ll}3.4 \text { Malhas utilizadas } & 39\end{array}$

4 Resultados $\quad 41$

4.1 Carbopol deslocando Água 42

4.1.1 Carbopol deslocando Água - geometria $1(\mathrm{~L} / \mathrm{D}=0,5) \quad 44$

4.1.2 Carbopol deslocando Água - geometria $2(L / D=1,0) \quad 48$

4.1.3 Carbopol deslocando Água - geometria $3(\mathrm{~L} / \mathrm{D}=1,5)$

4.1.4 Eficiências do caso Carbopol deslocando Água 55

4.2 Glicerina deslocando Carbopol 59

4.2.1 Glicerina deslocando Carbopol - geometria $1(\mathrm{~L} / \mathrm{D}=0,5) \quad 62$

4.2.2 Glicerina deslocando Carbopol - geometria $2(\mathrm{~L} / \mathrm{D}=1,0)$

4.2.3 Glicerina deslocando Carbopol - geometria $3(\mathrm{~L} / \mathrm{D}=1,5) \quad 67$ 
4.2.4 Eficiências do caso Glicerina deslocando Carbopol

4.3 Cimento deslocando Fluido de perfuração

4.3.1 Cimento deslocando Fluido de perfuração - geometria 1

$(\mathrm{L} / \mathrm{D}=0,5)$

4.3.2 Cimento deslocando Fluido de perfuração - geometria 2 $(\mathrm{L} / \mathrm{D}=1,0)$

4.3.3 Cimento deslocando Fluido de perfuração - geometria 3 $(\mathrm{L} / \mathrm{D}=1,5)$

4.3.4 Eficiências do caso Cimento deslocando Fluido de perfuração

5 Conclusões e trabalhos futuros 85

5.1 Conclusões 85

5.2 Trabalhos futuros $\quad 85$ 


\section{Lista de Figuras}

Figura 1 - Principio de deslocamento da pasta de cimento entre o casing e a formação num poço comum e um poço com uma área erodida (Plank 2000).

Figura 2 - Descrição da área erodida e seus limites. 22

Figura 3 - As três geometrias utilizadas nos testes. 22

Figura 4 - Modelo proposto por Bingham para o tratamento da viscosidade de um fluido não Newtoniano.

Figura 5 - Definições da eficiência na cavidade.

Figura 6 - Descrição da área erodida e seus limites.

Figura 7 - Perfis de velocidade das malhas testadas para escoamento desenvolvido.

Figura 8 - Número de nós usados em cada coordenada para as três geometrias.

Figura 9 - Razões de viscosidades entre a Água e o Carbopol para os números Herschel-Bulkley HB 1, HB 2, HB 3 e HB 4.

Figura 10 - Deslocamento de Água pelo Carbopol para diferentes Reynolds e números HerschelBulkley na geometria 1.

Figura 11 - Deslocamento de Água pelo Carbopol para diferentes Reynolds e números HerschelBulkley na geometria 1.

Figura 12 - Linhas de corrente do Carbopol deslocando Água em diferentes Reynolds e números Herschel-Bulkley na geometria 1.

Figura 13 - Linhas de corrente do Carbopol deslocando Água em diferentes Reynolds e números Herschel-Bulkley na geometria 1.

Figura 14 - Deslocamento de Água pelo Carbopol para diferentes Reynolds e números Herschel-Bulkley na geometria 2.

Figura 15 - Deslocamento de Água pelo Carbopol para diferentes Reynolds e números Herschel-Bulkley na geometria 2.

Figura 16 - Linhas de corrente do Carbopol deslocando Água em diferentes Reynolds e números Herschel-Bulkley na geometria 2.

Figura 17 - Linhas de corrente do Carbopol deslocando Água em diferentes Reynolds e números Herschel-Bulkley na geometria 2.

Figura 18 - Deslocamento de Água pelo Carbopol para diferentes e números Herschel-Bulkley na geometria 3.

Figura 19 - Deslocamento de Água pelo Carbopol para diferentes Reynolds e números Herschel-Bulkley na geometria 3.

Figura 20 - Linhas de corrente do Carbopol deslocando Água em diferentes Reynolds e números Herschel-Bulkley na geometria 3. 
Figura 21 - Linhas de corrente do Carbopol deslocando Água em diferentes Reynolds e números Herschel-Bulkley na geometria 3.

Figura 22 - Eficiência total nas três geometrias (preto: geometria 1; vermelho: geometria 2; azul: geometria 3) para diferentes

Reynolds e números Herschel-Bulkley.

Figura 23 - Eficiência na cavidade nas três geometrias para diferentes Reynolds.

Figura 24 - Eficiência na cavidade da área 1 nas três geometrias para diferentes Reynolds.

Figura 25 - Eficiência na cavidade da área 2 nas três geometrias para diferentes Reynolds.

Figura 26 - Eficiência na cavidade com relação ao comprimento e diâmetro para Reynolds muito baixos $(R e=0,001)$.

Figura 27 - Eficiência na cavidade com relação ao comprimento e diâmetro para Reynolds alto $(R e=50)$.

Figura 28 - Razões de viscosidades entre o Carbopol e a Glicerina para números Herschel-Bulkley HB 1, HB 2 e HB 3.

Figura 29 - Deslocamento do Carbopol pela Glicerina para diferentes Reynolds e números Herschel-Bulkley na geometria 1.

Figura 30 - Deslocamento do Carbopol pela Glicerina para diferentes Reynolds e números Herschel-Bulkley na geometria 1.

Figura 31 - Linhas de corrente da Glicerina deslocando Carbopol em diferentes Reynolds e números Herschel-Bulkley na geometria 1.

Figura 32 - Linhas de corrente da Glicerina deslocando Carbopol em diferentes Reynolds e números Herschel-Bulkley na geometria 1.

Figura 33 - Deslocamento do Carbopol pela Glicerina para diferentes Reynolds e números Herschel-Bulkley na geometria 2.

Figura 34 - Deslocamento do Carbopol pela Glicerina para diferentes Reynolds e números Herschel-Bulkley na geometria 2.

Figura 35 - Linhas de corrente da Glicerina deslocando Carbopol em diferentes Reynolds e números Herschel-Bulkley na geometria 2.

Figura 36 - Linhas de corrente da Glicerina deslocando Carbopol em diferentes Reynolds e números Herschel-Bulkley na geometria 2.

Figura 37 - Deslocamento do Carbopol pela Glicerina para diferentes Reynolds e números Herschel-Bulkley na geometria 3.

Figura 38 - Deslocamento do Carbopol pela Glicerina para diferentes Reynolds e números Herschel-Bulkley na geometria 3. 
Figura 39 - Linhas de corrente da Glicerina deslocando Carbopol em diferentes Reynolds e números Herschel-Bulkley na geometria 3.

Figura 40 - Linhas de corrente da Glicerina deslocando Carbopol em diferentes Reynolds e números Herschel-Bulkley na geometria 3.

Figura 41 - Eficiência total nas três geometrias para diferentes Reynolds.

Figura 42 - Eficiência na cavidade nas três geometrias para diferentes Reynolds.

Figura 43 - Eficiência na cavidade da área 1 nas três geometrias para diferentes Reynolds.

Figura 44 - Eficiência na cavidade da área 2 nas três geometrias para diferentes Reynolds.

Figura 45 - Razões de viscosidades entre o Fluido de perfuração e o Cimento para tensões limite de escoamento característico Ty ${ }^{*}$ $=15 \mathrm{~Pa}, \mathrm{Ty}^{*}=30 \mathrm{~Pa}$ е ту ${ }^{*}=60 \mathrm{~Pa}$.

Figura 46 - Deslocamento do Fluido de perfuração pelo Cimento para diferentes Reynolds e tensões limites de escoamento característico na geometria 1.

Figura 47 - Deslocamento do Fluido de perfuração pelo Cimento para diferentes Reynolds e tensões limites de escoamento característico na geometria 1 .

Figura 48 - Linhas de corrente do Cimento deslocando Fluido de perfuração em diferentes Reynolds e tensões limites de escoamento característico na geometria 1.

Figura 49 - Linhas de corrente do Cimento deslocando Fluido de perfuração em diferentes Reynolds e tensões limites de escoamento característico na geometria 1.

Figura 50 - Deslocamento do Fluido de perfuração pelo Cimento para diferentes Reynolds e tensões limites de escoamento característico na geometria 2.

Figura 51 - Deslocamento do Fluido de perfuração pelo Cimento para diferentes Reynolds e tensões limites de escoamento característico na geometria 2 .

Figura 52 - Linhas de corrente do Cimento deslocando Fluido de perfuração em diferentes Reynolds e tensões limites de escoamento característico na geometria 2 .

Figura 53 - Linhas de corrente do Cimento deslocando Fluido de perfuração em diferentes Reynolds e tensões limites de escoamento característico na geometria 2 .

Figura 54 - Deslocamento do Fluido de perfuração pelo Cimento para diferentes Reynolds e tensões limites de escoamento característico na geometria 3 . 
Figura 55 - Deslocamento do Fluido de perfuração pelo Cimento para diferentes Reynolds e tensões limites de escoamento característico na geometria 3.

Figura 56 - Linhas de corrente do Cimento deslocando Fluido de perfuração em diferentes Reynolds e tensões limites de escoamento característico na geometria 3 .

Figura 57 - Linhas de corrente do Cimento deslocando Fluido de perfuração em diferentes Reynolds e tensões limites de escoamento característico na geometria 3 .

Figura 58 - Eficiência total nas três geometrias para diferentes Reynolds.

Figura 59 - Eficiência na cavidade nas três geometrias para diferentes Reynolds.

Figura 60 - Eficiência na cavidade da área 1 nas três geometrias para diferentes Reynolds.

Figura 61 - Eficiência na cavidade da área 2 nas três geometrias para diferentes Reynolds. 


\section{Lista de Tabelas}

Tabela 1 - Número de nós em cada direção da geometria e espaçamentos mínimos das malhas.

Tabela 2 - Valores para o coeficiente de fricção f e erros relativos. $\quad 39$

Tabela 3 - Listado de casos testados neste trabalho.

Tabela 4 - Números Herschel-Bulkley para o caso entre a Água e - Carbopol.

Tabela 5 - Razões de viscosidades entre a Água e o Carbopol. 43

Tabela 6 - Números Herschel-Bulkley para o caso entre o Carbopol e a Glicerina.

Tabela 7 - Razões de viscosidades entre o Carbopol e a Glicerina.

Tabela 8 - Razões de viscosidades entre o Fluido de perfuração e o Cimento. 


\section{Introdução}

Atualmente na indústria do petróleo a exploração e a perfuração são processos muito importantes para manter a competitividade no mercado energético mundial. Dentre os grandes objetivos da indústria de petróleo estão estabelecer as jazidas existentes, determinar a localização dos reservatórios e assim poder fazer a extração e posterior produção do petróleo.

Para realizar a produção são muitos os obstáculos que devem ser vencidos antes de se aprovar a viabilidade de qualquer projeto. Assim, no momento que seja aprovado o projeto, e atinge-se a etapa de produção, se faz necessário garantir a eficiência e segurança operacional do escoamento ao longo das tubulações, para evitar qualquer parada na produção, que poderia acarretar um aumento nos custos inerentes já elevados.

Ao longo do desenvolvimento e construção de um poço de petróleo existem três tarefas muito importantes que são a perfuração, a introdução da tubulação de revestimento e a cimentação.

A perfuração é feita através de uma sonda em diversas fases até atingir determinada profundidade. Na medida que se atinge uma profundidade maior, os diâmetros das brocas são menores e é necessário revestir o poço para proteger as formações.

Logo, os cascalhos derivados e produzidos pela perfuração devem ser removidos, usando um fluido de perfuração que se injeta no interior da coluna de perfuração e retorna à superfície através do espaço anular formado pelas paredes do poço e a coluna.

Após a descida do revestimento no poço, uma nova etapa é necessária para evitar a migração de fluidos não desejados entre as formações e fornecer suporte estrutural à tubulação de revestimento. Esta etapa é a cimentação, e este é um dos processos que requer maior e melhor planejamento porque está diretamente relacionada com a vida útil do poço. 
Entre as principais funções da cimentação está evitar o desmoronamento das paredes do poço, proteger as formações de fluidos não compatíveis, e também proteger a tubulação de revestimento da corrosão produzida pelos fluidos de formação.

Devido à importância desta etapa é necessário levar em conta os fatores que influenciam numa cimentação bem-feita, os quais são:

- Geometria do poço

- Propriedades do fluido de perfuração

- Remoção dos fluidos de perfuração

- Projeto, preparo e bombeio da pasta de cimento

- Execução das obras

A limpeza do poço se torna então numa atividade crítica para considerar a cimentação uma operação bem-sucedida. Assim, é necessário assegurar a remoção da maior quantidade possível de fluido de perfuração e dos cascalhos produzidos pela perfuração da região anular.

O alto custo envolvido nas operações leva a necessidade de estudos de viabilidade. Como a avaliação experimental também é cara e muitas vezes inviável, a simulação numérica dos escoamentos que ocorrem nestes processos de perfuração e cimentação é uma alternativa importante a ser considerada.

\section{1}

\section{Objetivos e Metodologia do Trabalho}

Em função do exposto anteriormente, este trabalho teve como objetivo principal apresentar uma investigação numérica do escoamento no processo da cimentação em poços erodidos ou arrombados, a fim de avaliar a influência de parâmetros relevantes do problema na eficiência da operação. No processo de cimentação, ocorre o deslocamento de um fluido por outro em tubulações que podem possuir seção reta variável. Ambos fluidos podem ter comportamento Newtoniano ou não Newtoniano. Esta investigação é feita a partir da solução numérica das equações governantes, usando o método de volumes finitos.

Deste modo, a análises da influência dos parâmetros na eficiência da remoção vai ser realizada com detalhes a fim de se determinar quão boa é a limpeza e qual é a eficiência da remoção. Os efeitos da relação de viscosidades 
dos fluidos, relação de densidades, geometria e vazão serão investigados e discutidos ao longo do presente trabalho.

$\mathrm{Na}$ Figura 1 apresentam-se as diferenças entre um poço comum e um poço que devido à presença de formações instáveis pode gerar uma área erodida. $\mathrm{O}$ presente trabalho tem como foco avaliar a eficiência de deslocamento em poços erodidos.

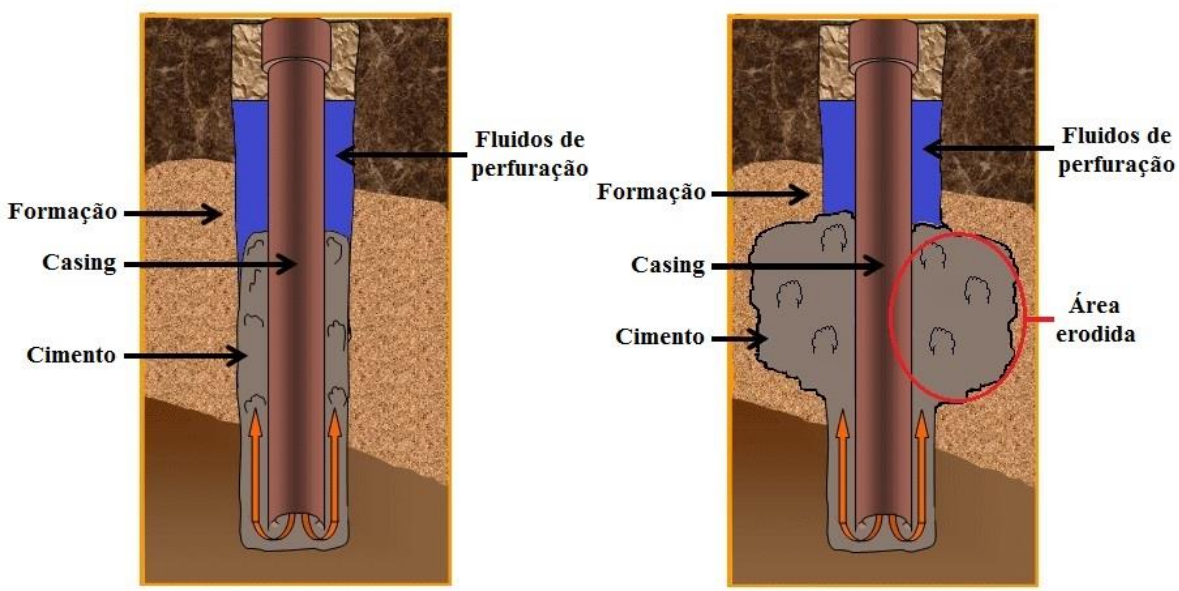

Figura 1 - Principio de deslocamento da pasta de cimento entre o casing e a formação num poço comum e um poço com uma área erodida (Plank 2000).

\section{2 \\ Revisão Bibliográfica}

Os estudos anteriores sobre o processo de deslocamento de fluidos através de poços verticais avaliam a influência de parâmetros importantes do problema, tais como a relação entre a viscosidade dos fluidos, a excentricidade do espaço anular entra a coluna e o casing (ou revestimento), o fluxo de massa e a taxa de densidade (Haut \& Crook, 1979; Sauer, 1987; Lockyear \& Hibbert, 1989). Observou-se também que as propriedades reológicas e padrões de escoamento, especialmente nas interfaces entre os fluidos de deslocamento são fatores importantes que afetam a eficiência de deslocamento (Pelipenko \& Frigaard, 2004; Szabo \& Hassager, 1992; Wachs, 2007). Além disso, outras variáveis como a centralização do casing, a taxa de bombeio, a movimentação do casing por rotação ou reciprocidade, e a geometria do poço podem influenciar na eficiência do deslocamento e consequentemente na eficiência da limpeza do poço (Haut \& Crook, 1982; Smith \& Ravi, 1991; Pelipenko \& Frigaard, 2004). 
Dutra et al., (2005) fizeram uma simulação numérica de três fluidos adjacentes (cimento, fluido espaçador e fluido de perfuração) através do anular de um poço, onde foram investigados os efeitos dos parâmetros reológicos e do volume bombeado do fluido espaçador. Os resultados obtidos mostram que uma boa estratégia para aumentar a eficiência do deslocamento em situações críticas pode ser o uso de um fluido espaçador mais viscoso. Além disso, se mostram algumas zonas de recirculação, onde o fluido de perfuração se mantem estagnado, diminuindo assim a eficiência do processo de deslocamento.

Em um trabalho posterior, Sousa et al., (2007) apresentaram o estudo experimental e numérico de escoamentos de líquidos viscoplásticos através de dutos axi-simétricos com expansões e contrações abruptas, onde a escala das equações de movimento mostrou que esse escoamento é regido por cinco parâmetros adimensionais principais, dois dos quais estão apenas relacionados com as propriedades reológicas do material, os quais são o número de salto $\mathrm{J}$ (que fornece uma medida do comportamento viscoplástico do fluido) e o exponente Power-Law, n. Citam-se também dois parâmetros geométricos que são a relação de raios ou diâmetros do anular, $\mathrm{R}_{0} / \mathrm{R}$, e a relação comprimento-raio da seção maior do tubo, $\mathrm{L}_{0} / \mathrm{R}_{0}$. O último é um parâmetro de fluxo $\tau_{\mathrm{R}}^{*}$, que representa a tensão de cisalhamento adimensional totalmente desenvolvida na parede do tubo. Os autores observaram a eficiência de deslocamento (volume de líquido na cavidade maior do tubo/volume total da cavidade) ao aumentar o parâmetro de fluxo $\tau_{\mathrm{R}}^{*}$ e mostraram que a eficiência aumenta levemente com o número de salto $\mathrm{J}$, e diminui quando o exponente Power-Law aumenta. A dependência com os parâmetros geométricos é tal que a eficiência de deslocamento diminui com a relação $\mathrm{R}_{0} / \mathrm{R}$ e aumenta com $\mathrm{L}_{0} / \mathrm{R}_{0}$. Os autores também fizeram uma comparação entre as previsões numéricas e alguns ensaios experimentais, que sugere que a intensidade da tensão limite de escoamento na superfície é realmente maior do que a tensão limite de escoamento $\left(r^{*}=r / R \cong 1,5\right)$, porque as tensões abaixo desse valor fazem o valor da viscosidade ainda demasiado elevado, e daí a velocidade permanece insignificante baixa.

No ano seguinte, Deawwanich et al. (2008) estudaram o desenvolvimento de um dispositivo de laboratório para a análise de um fluxo helicoidal com excentricidade ajustável e rotação no tubo interno, para estudos de visualização do 
escoamento de fluidos miscíveis no anular. As experiências de deslocamento foram realizadas com uma variedade de fluidos viscoplásticos em várias geometrias no anular e com diferentes condições de escoamento, para obter dados que podem ser comparados e utilizados para avaliar as simulações numéricas produzidas por um novo modelo de deslocamento 3-D. Os resultados obtidos da visualização do escoamento mostram que as propriedades reológicas e as características de ambos os fluidos tem efeitos significativos sobre o comportamento de deslocamento. A reologia dos fluidos interage com outras variáveis que afetam o desempenho do processo de deslocamento. Além disso, o efeito da rotação do cilindro interno tornou-se mais significativo em graus mais elevados de excentricidade do cilindro, onde se reduziu o desequilíbrio entre as velocidades do escoamento nas regiões de seções mais amplas e mais estreitas do anular. A rotação do cilindro afeta o deslocamento de ambos os fluidos devido ao fluxo tangencial que conduz mais fluido para a parte mais estreita do anular, e pela agitação convectiva dos fluidos na interface. O estudo indica também que a rotação do cilindro interno pode não ser eficaz em deslocamentos de fluidos com tensões limite de escoamento. No entanto, é evidente que o efeito da rotação do cilindro é mais significativo no anular altamente excêntrico, onde a velocidade azimutal induzida pela rotação do cilindro ajuda a distribuir o fluido deslocado através de todo o anular. $\mathrm{O}$ papel da excentricidade anular na eficiência do deslocamento diminui quando existe deslocamento com fluxo rotativo no anular. Assim, a rotação do cilindro interno serve efetivamente para compensar o desequilíbrio de fluxo causado pela excentricidade anular.

Savery et al. (2008) apresentaram um novo simulador computacional (CFD) da dinâmica dos fluidos em três dimensões (3-D) que modela múltiplos aspectos do deslocamento do fluido de perfuração durante a cimentação. Os autores encontraram a necessidade de centralizar sempre o casing, pois na situação não centralizada o fluxo na região mais ampla do anular sempre vai dominar, deixando regiões não cimentadas na região mais estreita. Com o anular excêntrico, nunca há garantia do que cimento chegue ao topo desejado, o que significa uma cobertura incompleta ao redor do casing. A capacidade de prever a localização da pasta de cimento no espaço 3-D é inestimável, especialmente em situações onde o casing esteja descentralizado. Alguns casos também forneceram uma visualização dos efeitos da rotação do casing, mostrando a compensação das variações drásticas 
entre a região mais ampla do anular excêntrico em comparação com a região mais estreita. Com todos esses ensaios, os autores confirmaram com CFD o que durante anos tem sido observado em operações de campo, por exemplo o passo do fluxo helicoidal e os fenômenos de mistura durante a rotação do casing. No final, os autores desenvolveram um simulador que pode ajudar ao projetista da cimentação na estimativa do impacto da rotação do casing durante o deslocamento, e na elaboração de uma avaliação mais precisa de onde está o topo do cimento ao longo do processo. Desenhada

Outro dos estudos foi realizado por Groesbeck \& Jordan (2009), onde descrevem o desenvolvimento de uma sapata de revestimento em águas profundas, que garante que as colunas de revestimento submergível planejadas para a cabeça do poço possam ser executadas na totalidade da profundidade sem o rat hole (ou buraco de rato). Com esse estudo descobriram que os problemas associados ao excesso do rat hole tornaram-se mais evidentes à medida que os poços em águas profundas aumentaram seu alvo e complexidade. Em poços desviados, a circulação e as taxas de rotação necessárias para a adequada limpeza do poço e condicionamento tendem a ampliar e desestabilizar as seções com o rat hole antes e depois da sapata. Isto leva ao risco de que as ferramentas de registro fiquem juntas, a pobre colocação de cimento e o deficiente isolamento entre zonas, junto com os problemas de bombeamento dos cascalhos tornam-se então numa preocupação primordial. Além disso, o projeto e o sucesso na implantação em campo da sapata de revestimento retrátil demonstram que esta tecnologia é capaz de resolver tais problemas do rat hole. Ao colocar a sapata de revestimento na parte inferior do poço, os cascalhos e os resíduos são efetivamente deslocados com a pasta de cimento, assegurando simultaneamente que o casing submergível esteja firmemente fixado na cabeça do poço. Assim, os riscos envolvidos durante a perfuração e revestimento dos intervalos subsequentes são mitigados, reduzindo o tempo potencial de inatividade do equipamento, e fornecendo um benefício de valor acrescentado significativo.

Por último, Chin et al. (2010), trabalharam em uma análise exata de fluidos não Newtonianos com tensão limite de escoamento em anulares altamente excêntricos com translação e rotação no casing. Os autores apresentaram novos recursos para a modelagem de fluidos não Newtonianos em anulares excêntricos, 
Capítulo 1 - Introdução

com ou sem zonas de plugs associados a fluidos com tensões limite de escoamento.

\section{3}

\section{Organização do Trabalho}

Esta dissertação está organizada da seguinte forma. No próximo Capítulo são apresentados alguns fundamentos teóricos relevantes e uma descrição da modelagem matemática com suas equações governantes. Além disso são mostradas as principais características da geometria a utilizar e as condições de contorno do problema.

O Capítulo 3 descreve o método numérico utilizado, seguido dos testes de validação para averiguar o nível de refinamento da malha a usar, para atingir níveis altos de precisão nas simulações.

Os resultados dos estudos numéricos e a análise paramétrica do problema são mostrados e discutidos no Capítulo 4. Para diferentes pares de fluidos, é feita a análise da influência dos parâmetros na eficiência da remoção. São discutidos e avaliados os efeitos da relação de viscosidade, relação de densidade e a razão de aspecto (L/D) para diferentes valores de número de Reynolds.

As conclusões do presente trabalho e sugestões para trabalhos futuros são, finalmente, apresentadas no Capítulo 5. 


\section{2 Modelagem matemática}

No capítulo anterior foi apresentado o estado da arte do problema analisado, fazendo referência a artigos e trabalhos da literatura que tem desde um enfoque geral na parte teórica até simulações avançadas de deslocamentos de fluidos não Newtonianos.

Em seguida será apresentada a modelagem matemática e a geometria que caracteriza o problema em questão. Serão descritas as equações governantes: equações de conservação de massa e quantidade de movimento e equações constitutivas dos fluidos. Diferentes pares de fluidos foram analisados, sendo considerados fluidos Newtonianos e viscoplásticos. Os fluidos viscoplásticos são fluidos que possuem como principal característica a existência de uma tensão limite de escoamento, e serão modelados pela equação de Herschel Bulkley Regularizada. Por último, são apresentadas as condições de contorno do problema e os parâmetros adimensionais mais relevantes.

\section{1 \\ Geometria da área erodida}

Em primeiro lugar é preciso delimitar o problema e assim a região de estudo desta pesquisa. A área erodida consiste de uma região anular de alargamento de comprimento L, situada entre dois tubos anulares de menor área transversal. Foram analisadas três geometrias diferentes e fluidos com diferentes propriedades. A geometria escolhida teve como base uma bancada experimental desenvolvida no laboratório de mecânica dos fluidos não Newtonianos na PUC-Rio. Da mesma forma, as propriedades dos fluidos utilizados basearam-se em dados experimentais medidos no laboratório de caracterização de fluidos da PUC-Rio. A geometria analisada é bi-dimensional, axi-simétrica, e é mostrada na Figura 2. 


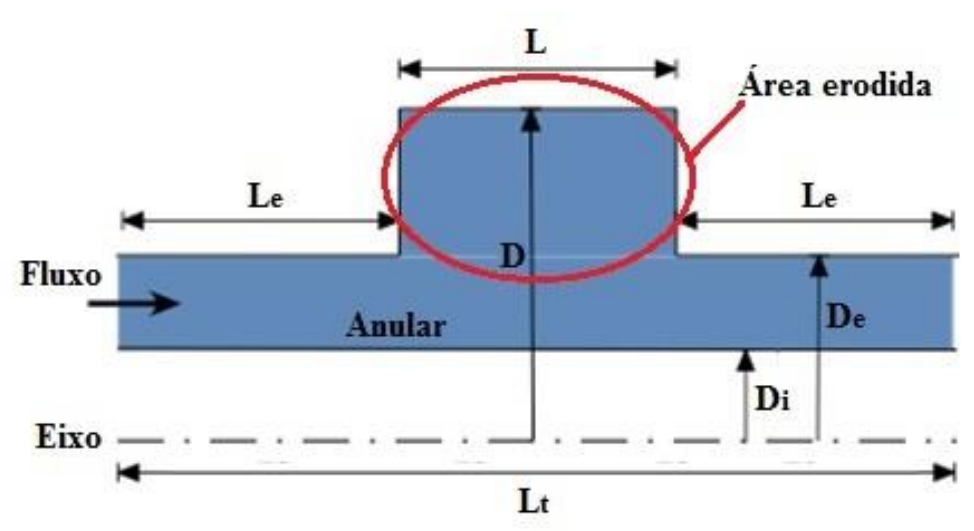

Figura 2 - Descrição da área erodida e seus limites.

- Comprimento dos tubos de entrada e saída: $\mathrm{L}_{\mathrm{e}}=0,110$ milímetros;

- Diâmetro do casing: $\mathrm{D}_{\mathrm{i}}=0,016$ milímetros;

- Diâmetro da parede do poço: $\mathrm{D}_{\mathrm{e}}=0,024$ milímetros;

- Diâmetro da parede da área erodida $\mathrm{D}=0,032$ milímetros;

- Comprimento da área erodida $\mathrm{L}$ e o comprimento total do tubo $\mathrm{L}_{\mathrm{t}}$ são variáveis.

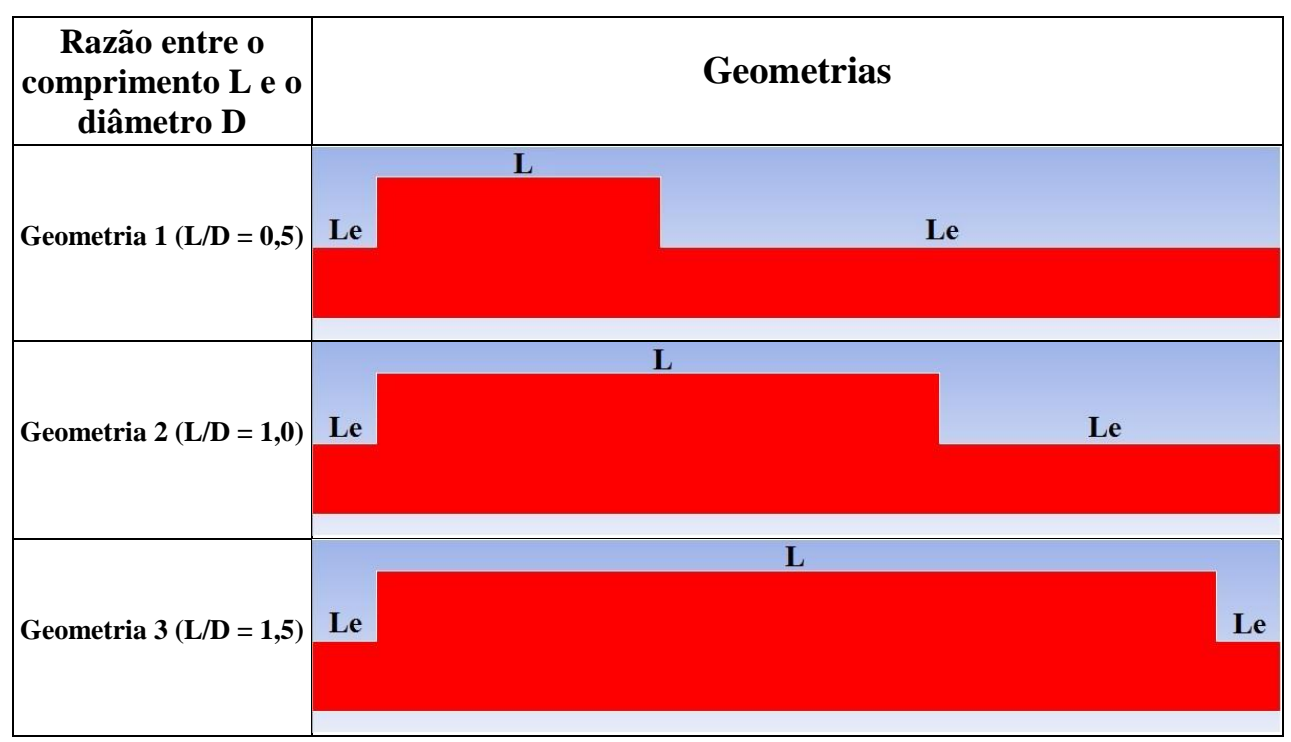

Figura 3 - As três geometrias utilizadas nos testes.

Como se mostra na Figura 3 acima, os comprimentos da zona erodida são:

- Para a geometria $1, \mathrm{~L}=0,016$ milímetros $(\mathrm{L} / \mathrm{D}=0,5)$; então $\mathrm{L}_{\mathrm{t}}=0,236$ milímetros.

- Para a geometria 2, $\mathrm{L}=0,032$ milímetros $(\mathrm{L} / \mathrm{D}=1,0)$; então $\mathrm{L}_{\mathrm{t}}=0,252$ milímetros. 
- Para a geometria 3, $\mathrm{L}=0,048$ milímetros $(\mathrm{L} / \mathrm{D}=1,5)$; então $\mathrm{L}_{\mathrm{t}}=0,268$ milímetros.

Em cada simulação, o espaço anular encontra-se preenchido com o fluido a ser deslocado (fluido 1). No início da simulação (tempo $t=0$ ), injeta-se o fluido deslocador (fluido 2), até atingir um volume bombeado igual ao volume do espaço anular. Portanto, os volumes totais bombeados do fluido deslocador em cada caso foram:

- Geometria 1, o volume total bombeado foi $\mathrm{V}=6,4943 \times 10^{-5} \mathrm{~m}^{3}$.

- Geometria 2, o volume total bombeado foi $\mathrm{V}=7,4594 \times 10^{-5} \mathrm{~m}^{3}$.

- Geometria 3, o volume total bombeado foi $\mathrm{V}=8,4245 \times 10^{-5} \mathrm{~m}^{3}$.

\section{2}

\section{Equações governantes}

Hoje em dia muitos estudos usam a simulação numérica CFD para a análise de problemas envolvendo dinâmica dos fluidos. Neste trabalho foi utilizado o programa comercial Fluent (Ansys Inc.), que resolve as equações de NavierStokes e de conservação de massa, junto com as condições de contorno apropriadas para o problema, usando o método de volumes finitos.

A seguir apresentam-se mais detalhadamente as equações que governam o problema analisado.

\subsection{1 \\ Equações de conservação}

O programa Fluent (Ansys Inc.) é um programa de CFD (Computação em Dinâmica de Fluidos) bastante amplo, sendo uma das possibilidades a simulação de escoamentos multifásicos transientes, envolvendo fluidos não Newtonianos puramente viscosos, e geometrias muito complexas. O problema analisado envolve o escoamento de dois fluidos com diferentes propriedades, sendo tratado então como um escoamento multicomponente. Nos casos analisados, os fluidos são considerados imiscíveis, e por este motivo foi utilizado o método de volume de fluido (VOF) na sua modelagem. O método consiste na solução da equação de conservação de quantidade de movimento para as fases (que tem a mesma velocidade) e na determinação da interface entre os fluidos a partir da solução da 
equação de conservação de massa das fases, que fornece a fração mássica de cada fase.

As equações resolvidas no VOF são descritas a seguir. A equação da conservação de massa geral ou equação da continuidade pode ser expressa pela equação 1:

$$
\frac{\partial \rho}{\partial \mathrm{t}}+\nabla \cdot(\rho \overline{\mathrm{v}})=0
$$

Onde,

- $\rho$ é a densidade da mistura;

- $\quad \overline{\mathrm{V}}$ é o vetor velocidade da mistura;

- t é o tempo.

As propriedades da mistura são calculadas pela relação: $\varphi=\varphi_{1} \alpha_{1}+\varphi_{2} \alpha_{2}$, onde $\varphi_{i}$ são as propriedades de cada fase $i, \varphi$ é a propriedade da mistura e $\alpha_{i}$ são as frações volumétricas de cada fase $i$.

A fração volumétrica da fase 1 é calculada por:

$$
\frac{\partial \alpha_{1}}{\partial \mathrm{t}}+\nabla \cdot\left(\alpha_{1} \overline{\mathrm{v}}\right)=0
$$

A fração volumétrica da fase 2 é calculada pela seguinte equação de restrição: $\alpha_{1}+\alpha_{2}=1$.

As equações de quantidade de movimento, escritas segundo o sistema inercial não acelerado, são dadas por:

$$
\frac{\partial}{\partial \mathrm{t}}(\rho \overline{\mathrm{v}})+\nabla \cdot(\rho \overline{\mathrm{v}} \overline{\mathrm{v}})=-\nabla \mathrm{p}+\nabla \cdot(\overline{\bar{\tau}})+\rho \overline{\mathrm{g}}+\overline{\mathrm{F}}
$$

Onde $\rho$ é a densidade da mistura, $\overline{\mathrm{g}}$ é a força de corpo gravitacional, $\overline{\mathrm{F}}$ são as forças de corpo externas (da interação entre as fases) e $\overline{\bar{\tau}}$ é o tensor extra-tensão, que pode ser escrito como:

$$
\overline{\bar{\tau}}=p I+\overline{\bar{T}}
$$


Sendo I a matriz identidade, $\mathrm{p}$ é a pressão média e $\overline{\bar{T}}$ é o tensor das tensões, que representa a parte viscosa do tensor das tensões, dado pela equação constitutiva. Quando cessa o movimento, este termo cai a zero.

\subsection{2}

\section{Equações constitutivas}

Para modelar os fluidos Newtonianos e não Newtonianos tem-se a seguinte equação de Fluido Newtoniano Generalizado para o tensor extra-tensão:

$$
\overline{\bar{\tau}}=2 \eta(\dot{\gamma}) \overline{\bar{D}}
$$

$\operatorname{Com} \overline{\overline{\mathrm{D}}}$

$$
\overline{\overline{\mathrm{D}}}=\left(\frac{\partial \mathrm{u}_{\mathrm{j}}}{\partial \mathrm{x}_{\mathrm{i}}}+\frac{\partial \mathrm{u}_{\mathrm{i}}}{\partial \mathrm{x}_{\mathrm{j}}}\right) \cdot \frac{1}{2}
$$

Em geral $\eta$ é a viscosidade, que é função do módulo do tensor taxa de deformações $\overline{\overline{\mathrm{D}}}$, definido como $\dot{\gamma}$ :

$$
\dot{\gamma}=\sqrt{2 \overline{\overline{\mathrm{D}}}: \overline{\overline{\mathrm{D}}}}
$$

No sistema de coordenadas cilíndricas, as equações de conservação da quantidade de movimento linear se tornam, então:

$$
\begin{gathered}
\rho\left(\frac{\partial \mathrm{u}_{\mathrm{r}}}{\partial \mathrm{t}}+\mathrm{u}_{\mathrm{r}} \frac{\partial \mathrm{u}_{\mathrm{r}}}{\partial \mathrm{r}}+\frac{\mathrm{u}_{\theta}}{\mathrm{r}} \frac{\partial \mathrm{u}_{\mathrm{r}}}{\partial \theta}-\frac{\mathrm{u}_{\theta}^{2}}{\mathrm{r}}+\mathrm{u}_{\mathrm{z}} \frac{\partial \mathrm{u}_{\mathrm{r}}}{\partial \mathrm{z}}\right)= \\
-\frac{\partial \mathrm{p}}{\partial \mathrm{r}}-\left|\frac{1}{\mathrm{r}} \frac{\partial\left(\mathrm{r} \tau_{\mathrm{rr}}\right)}{\partial \mathrm{r}}+\frac{1}{\mathrm{r}} \frac{\partial\left(\mathrm{r} \tau_{\theta \mathrm{r}}\right)}{\partial \theta}+\frac{\partial\left(\tau_{\mathrm{zr}}\right)}{\partial \mathrm{z}}-\frac{\tau_{\theta \theta}}{\mathrm{r}}\right|+\rho \mathrm{g}_{\mathrm{r}} \\
\rho\left(\frac{\partial \mathrm{u}_{\theta}}{\partial \mathrm{t}}+\mathrm{u}_{\mathrm{r}} \frac{\partial \mathrm{u}_{\theta}}{\partial \mathrm{r}}+\frac{\mathrm{u}_{\theta}}{\mathrm{r}} \frac{\partial \mathrm{u}_{\theta}}{\partial \theta}-\frac{\mathrm{u}_{\theta} \mathrm{u}_{\mathrm{r}}}{\mathrm{r}}+\mathrm{u}_{\mathrm{z}} \frac{\partial \mathrm{u}_{\theta}}{\partial \mathrm{z}}\right)= \\
-\frac{1}{\mathrm{r}} \frac{\partial \mathrm{p}}{\partial \theta}-\left|\frac{1}{\mathrm{r}^{2}} \frac{\partial\left(\mathrm{r}^{2} \tau_{\mathrm{r} \theta}\right)}{\partial \mathrm{r}}+\frac{1}{\mathrm{r}} \frac{\partial\left(\mathrm{r} \tau_{\theta \theta}\right)}{\partial \theta}+\frac{\partial\left(\tau_{\mathrm{zr}}\right)}{\partial \mathrm{z}}-\frac{\tau_{\theta \mathrm{r}}-\tau_{\mathrm{r} \theta}}{\mathrm{r}}\right|+\rho g_{\theta}
\end{gathered}
$$




$$
\begin{gathered}
\rho\left(\frac{\partial \mathrm{u}_{\mathrm{z}}}{\partial \mathrm{t}}+\mathrm{u}_{\mathrm{r}} \frac{\partial \mathrm{u}_{\mathrm{z}}}{\partial \mathrm{r}}+\frac{\mathrm{u}_{\theta}}{\mathrm{r}} \frac{\partial \mathrm{u}_{\mathrm{z}}}{\partial \theta}+\mathrm{u}_{\mathrm{z}} \frac{\partial \mathrm{u}_{\mathrm{z}}}{\partial \mathrm{z}}\right)= \\
-\frac{\partial \mathrm{p}}{\partial \mathrm{z}}-\left|\frac{1}{\mathrm{r}} \frac{\partial\left(\mathrm{r} \tau_{\mathrm{rz}}\right)}{\partial \mathrm{r}}+\frac{1}{\mathrm{r}} \frac{\partial\left(\tau_{\theta \mathrm{z}}\right)}{\partial \theta}+\frac{\partial\left(\tau_{\mathrm{zz}}\right)}{\partial \mathrm{z}}\right|+\rho \mathrm{g}_{\mathrm{z}}
\end{gathered}
$$

Onde $\rho$ é a densidade do fluido, $\mathrm{u}_{\mathrm{r}}, \mathrm{u}_{\theta}$ e $\mathrm{u}_{\mathrm{z}}$ são os componentes do vetor velocidade, $g_{r}, g_{\theta}$ e $g_{z}$ são os componentes do vetor gravidade e $\frac{\partial p}{\partial r}, \frac{\partial p}{\partial \theta}$ e $\frac{\partial p}{\partial z}$ são os componentes do gradiente de pressão, nas direções $\mathrm{r}, \theta$ e z, respectivamente.

A viscosidade $\eta$ é avaliada para cada tipo de fluido. No caso de fluido Newtoniano e problema isotérmico, a viscosidade é considerada constante. No caso de fluido viscoplástico, os modelos mais utilizados na literatura são os modelos de Bingham e de Herschel-Bulkley. Os comportamentos qualitativos destes modelos podem ser observados na Figura 4. Os fluidos viscoplásticos tem como principal característica a existência de uma tensão limite de escoamento. Abaixo desta tensão limite o fluido se comporta como um corpo rígido e teria viscosidade infinita. Quando a tensão imposta ao fluido excede o valor da tensão limite de escoamento, o fluido escoa, podendo ter então comportamento Newtoniano (i.e., viscosidade constante) ou não Newtoniano (i.e., viscosidade dependente da taxa de deformação do escoamento). O modelo proposto por Bingham ocorre para o índice $n=1$. Quando o índice de potência é maior do que 1, o fluido tem comportamento dilatante, i.e., após o início do escoamento, a viscosidade cresce com a taxa de deformação. Quando o índice de potência é menor do que um o fluido é chamado pseudoplástico, e a viscosidade cai com o aumento da taxa de deformação.

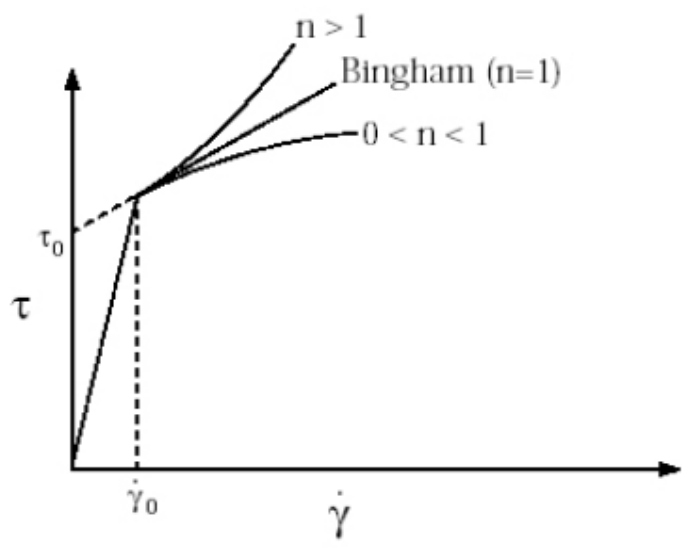

Figura 4 - Modelo proposto por Bingham para o tratamento da viscosidade de um fluido não Newtoniano. 
O modelo de Herschel-Bulkley combina os efeitos do comportamento plástico de Bingham e do modelo Power-Law. Para baixas taxas de deformação $\left(\tau \leq \tau_{0}\right)$, o material é "rígido", e a viscosidade é infinita. Quando a tensão aumenta e atinge a tensão de escoamento, $\tau_{0}$, o comportamento do fluido é descrito pelo modelo Power-Law. Assim, a viscosidade no modelo de Herschel-Bulkley é dada por:

$$
\begin{cases}\eta=\infty & \tau<\tau_{0} \\ \eta(\dot{\gamma})=\frac{\tau_{0}}{\dot{\gamma}}+K \dot{\gamma}^{\mathrm{n}-1} & \tau>\tau_{0}\end{cases}
$$

Onde,

- $\tau_{0}$ é a tensão limite de escoamento;

- K é o índice de consistência;

- $\mathrm{n}$ é o índice de potência.

Quando $\mathrm{n}=1$, esta equação se reduz à equação de Bingham:

$$
\begin{cases}\eta=\infty & \tau<\tau_{0} \\ \eta(\dot{\gamma})=\tau_{0}+\mu_{\mathrm{P}} \dot{\gamma} & \tau>\tau_{0}\end{cases}
$$

Onde $\mu_{\mathrm{P}}$ é a viscosidade plástica. As duas equações preveem uma viscosidade infinita para as situações onde a tensão está abaixo da tensão limite de escoamento. Dessa forma, nas simulações numéricas são necessários artifícios numéricos para o tratamento das regiões onde as tensões estão abaixo da tensão limite de escoamento. Estes são os chamados métodos de regularização. No método empregado no Fluent é utilizada a seguinte equação para a função viscosidade:

$$
\begin{gathered}
\eta=\frac{\tau_{\mathrm{y}}}{\dot{\gamma}}+\mathrm{K}\left[\frac{\dot{\gamma}}{\dot{\gamma}_{\mathrm{cr}}}\right]^{\mathrm{n}-1} \text { se } \dot{\gamma} \geq \dot{\gamma}_{\mathrm{cr}} \\
\eta=\eta_{0}=\frac{\tau_{\mathrm{y}}}{\dot{\dot{\gamma}}}\left[\frac{2-\frac{\dot{\gamma}}{\dot{\gamma}_{\mathrm{cr}}}}{\dot{\gamma}_{\mathrm{cr}}}\right]+\mathrm{K}\left[(2-\mathrm{n})+(\mathrm{n}-1) \frac{\dot{\gamma}}{\dot{\gamma}_{\mathrm{cr}}}\right] \text { se } \dot{\gamma}<\dot{\gamma}_{\mathrm{cr}}
\end{gathered}
$$


Nas equações acima, $\dot{\gamma}_{\text {cr }}$ é o valor da taxa de deformação crítica. É um valor pequeno, em geral da ordem de 1000 vezes menor do que o valor de uma taxa de deformação característica do escoamento (Alexandrou et al., 2001).

\section{3}

\section{Condições de contorno e inicial}

O escoamento analisado no anular é transiente, isotérmico e incompressível, além de ter uma tensão interfacial desprezível entre os dois fluidos (Newtoniano ou não Newtoniano), ou seja, os dois fluidos são considerados imiscíveis.

Nas simulações, a velocidade é considerada uniforme na entrada, e a condição de escoamento desenvolvido é considerada na saída. O casing e a parede do poço foram consideradas como contorno rígido, e a condição de impermeabilidade e as condições de não-deslizamento foram aplicadas (i.e., velocidades tangencial e normal nulas nas paredes).

Como condição inicial utilizou-se o tubo preenchido com o fluido a ser deslocado e velocidade nula.

\subsection{1}

\section{Adimensionalização}

Agora se faz necessário reescrever as equações básicas que governam o problema de forma adimensional, descrevendo os fenômenos independentemente da magnitude das escalas, e facilitando a determinação dos parâmetros mais relevantes. Assim, os parâmetros de nosso problema são obtidos através da adimensionalização das principais variáveis presentes nas equações da quantidade de movimento linear, de conservação de massa e da equação de fração volumétrica.

\subsection{2}

\section{Parâmetros adimensionais relevantes}

Os parâmetros dimensionais relevantes para o problema analisado são: diâmetro do casing $\mathrm{D}_{\mathrm{i}}$, o diâmetro da parede da área erodida $\mathrm{D}$, o diâmetro da parede do poço $\mathrm{D}_{\mathrm{e}}$, o comprimento $\mathrm{L}$ da área erodida, as massas especificas do 
fluido deslocador $\rho_{2}$ e deslocado $\rho_{1}$, as viscosidades dinâmicas desses fluidos, $\mu_{1}$ e $\mu_{2}$, respectivamente, a gravidade g e a velocidade média do escoamento $\overline{\mathrm{u}}$.

Neste trabalho, os fluidos são considerados incompressíveis. Assim, são considerados os seguintes parâmetros adimensionais:

$$
\begin{gathered}
\overline{\mathrm{v}}^{*}=\frac{\overline{\mathrm{v}}}{\overline{\mathrm{u}}} \\
\mathrm{x}^{*}=\frac{\mathrm{x}}{\mathrm{D}_{\mathrm{h}}}
\end{gathered}
$$

Onde $\mathrm{D}_{\mathrm{h}}=\mathrm{D}-\mathrm{D}_{\mathrm{e}}$, é o diâmetro hidráulico para o espaço anular.

$$
\rho^{*}=\frac{\rho}{\rho_{2}}
$$

$$
\mathrm{t}^{*}=\frac{\mathrm{t}}{\mathrm{t}_{\mathrm{c}}}
$$

Onde $t_{c}=\frac{D_{h}}{\bar{u}}$

$$
\begin{aligned}
\tau^{*} & =\frac{\tau}{\tau_{\mathrm{y}}} \\
\mathrm{p}^{*} & =\frac{\mathrm{p}}{\mathrm{p}_{\mathrm{c}}}
\end{aligned}
$$

Onde $\mathrm{p}_{\mathrm{c}}=\rho_{2} \cdot \overline{\mathrm{u}}^{2}$

$$
\mathrm{g}^{*}=\frac{\mathrm{g}}{\mathrm{g}_{\mathrm{c}}}
$$

Onde $g_{c}=\frac{\bar{u}^{2}}{D_{h}}$

O número de Reynolds está dado por:

$$
\operatorname{Re}=\frac{\rho_{2} D_{h} \bar{u}}{\mu_{2}}
$$


Desta forma, fazendo as substituições respectivas dos parâmetros adimensionais definidos acima e reordenando podemos também adimensionalizar as equações dimensionais (1) (2) e (3) apresentadas no início deste capitulo, obtendo o seguinte conjunto de equações adimensionais:

$$
\begin{gathered}
\frac{\partial \rho^{*}}{\partial \mathrm{t}^{*}}+\nabla^{*} \cdot\left(\rho^{*} \overline{\mathrm{v}}^{*}\right)=0 \\
\frac{\partial \alpha_{1}}{\partial \mathrm{t}^{*}}+\nabla^{*} \cdot\left(\alpha_{1} \overline{\mathrm{v}}^{*}\right)=0 \\
\frac{\partial}{\partial \mathrm{t}^{*}}\left(\rho^{*} \overline{\mathrm{v}}^{*}\right)+\nabla^{*} \cdot\left(\rho^{*} \overline{\mathrm{v}}^{*} \overline{\mathrm{v}}^{*}\right)=-\nabla^{*} \mathrm{p}^{*}+\frac{\mathrm{HB}}{\mathrm{Re}} \nabla^{*} \cdot\left(\overline{\bar{\tau}}^{*}\right)+\rho^{*} \overline{\mathrm{g}}^{*}
\end{gathered}
$$

Onde HB é o número Herschel-Bulkley e é um dos parâmetros adimensionais mais importante na apresentação dos resultados, e se define assim:

$$
\mathrm{HB}=\frac{\tau_{\mathrm{y}} \mathrm{D}_{\mathrm{h}}}{\mu_{2} \overline{\mathrm{u}}}
$$

Onde $\tau_{\mathrm{y}}$ é a tensão limite de escoamento, $\mu_{2}$ é viscosidade do fluido e $\overline{\mathrm{u}}$ é a velocidade na entrada. $\mathrm{O}$ valor do número Herschel-Bulkley sempre depende da velocidade na entrada, da tensão limite de escoamento e da viscosidade do fluido.

Para a análise do processo de deslocamento é importante também definir dois parâmetros do problema: a razão de densidades entre os fluidos e a razão de viscosidades.

A razão de densidade entre o fluido deslocado e o fluido deslocador é dada pela seguinte equação:

$$
\rho^{*}=\frac{\rho_{2}}{\rho_{1}}
$$

Onde,

- Razão de densidade: $\rho^{*}$; 
- Densidade do fluido deslocado: $\rho_{1}$;

- Densidade do fluido deslocador: $\rho_{2}$;

A razão de viscosidade entre os dois fluidos é dada pela equação (2), assim:

$$
\mu^{*}=\frac{\mu_{2}}{\mu_{1}}
$$

Onde,

- Razão de viscosidade: $\mu^{*}$;

- Viscosidade do fluido deslocado: $\mu_{1}$;

- Viscosidade do fluido deslocador: $\mu_{2}$;

Outros parâmetros adimensionais que são necessários para fazer uma análise melhor do efeito da geometria no escoamento das duas fases através da seção anular são: a razão de aspecto na região erodida $\mathrm{L} / \mathrm{D}$, e a razão entre os diâmetros do anular $\mathrm{D} / \mathrm{D}_{\mathrm{i}}$ e $\mathrm{D}_{\mathrm{e}} / \mathrm{D}_{\mathrm{i}}$.

Para a análise dos resultados, definem-se as eficiências de deslocamento na área erodida, que chamaremos também como a região de estudo.

Assim, conforme mostrado na Figura 5, definimos a eficiência de deslocamento na cavidade (parte erodida do poço) como $\beta_{\mathrm{c}}$. Definimos também as eficiências de deslocamento à esquerda (cor amarela) e à direita (cor azul) como $\beta_{\mathrm{c}_{1}}$ e $\beta_{\mathrm{c}_{2}}$, respectivamente.

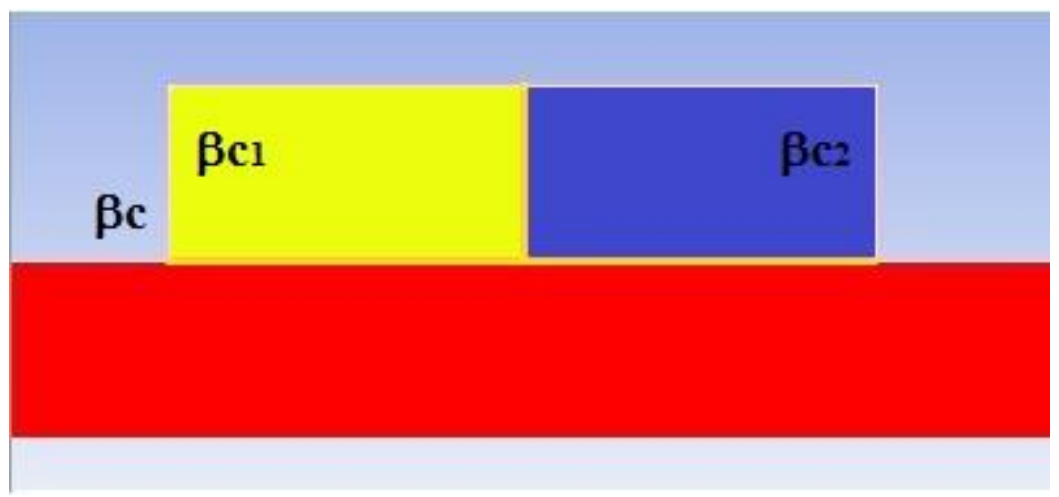

Figura 5 - Definições da eficiência na cavidade.

A análise da eficiência no deslocamento em cada caso é um dos objetivos da nossa pesquisa, então se faz necessário definir as condições com as quais vamos a medir a eficiência no tubo todo, na cavidade e nas áreas 1 e 2 da cavidade. 
A eficiência total no tubo é definida como a razão entre o volume total ocupado pelo fluido a ser deslocado e o volume total da tubulação depois do bombeio do fluido deslocador. Assim:

$$
\beta_{\mathrm{t}}=\frac{\mathrm{V}_{\mathrm{f}_{2}}}{\mathrm{~V}}
$$

- Eficiência total: $\beta_{\mathrm{t}}$;

- Volume deslocado pelo fluido 2: $\mathrm{V}_{\mathrm{f}_{2}}$;

- Volume total da tubulação: V;

A eficiência na cavidade se define como a razão entre o volume ocupado pelo fluido 2 na área erodida e o volume da cavidade, assim temos:

$$
\beta_{\mathrm{c}}=\frac{\mathrm{V}_{\mathrm{f}_{2} \mathrm{c}}}{\mathrm{V}_{\mathrm{c}}}
$$

- Eficiência na cavidade: $\beta_{\mathrm{c}}$;

- Volume deslocado pelo fluido 2 na cavidade: $\mathrm{V}_{\mathrm{f}_{2} \mathrm{c}}$;

- Volume da cavidade: $\mathrm{V}_{\mathrm{c}}$;

A eficiência na área 1 da cavidade é definida como a razão entre o volume deslocado pelo fluido 2 na área 1 da região erodida e o volume na área 1 da cavidade, como mostra a seguinte equação:

$$
\beta_{\mathrm{c}_{1}}=\frac{\mathrm{V}_{\mathrm{f}_{2} \mathrm{c}_{1}}}{\mathrm{~V}_{\mathrm{c}_{1}}}
$$

- Eficiência na área 1 da cavidade: $\beta_{\mathrm{c}_{1}}$;

- Volume deslocado pelo fluido 2 na área 1 da cavidade: $\mathrm{V}_{\mathrm{f}_{2} \mathrm{c}_{1}}$;

- Volume da área 1 na cavidade: $\mathrm{V}_{\mathrm{c}_{1}}$; 
Da mesma forma, a eficiência na área 2 da cavidade é determinada pela razão entre o volume deslocado pelo fluido 2 na área 2 da cavidade e o volume na área 2 da cavidade, como vemos na equação abaixo:

$$
\beta_{\mathrm{c}_{2}}=\frac{\mathrm{V}_{\mathrm{f}_{2} \mathrm{c}_{2}}}{\mathrm{~V}_{\mathrm{c}_{2}}}
$$

- Eficiência na área 2 da cavidade: $\beta_{\mathrm{c}_{2}}$;

- Volume deslocado pelo fluido 2 na área 2 da cavidade: $\mathrm{V}_{\mathrm{f}_{2} \mathrm{c}_{2}}$;

- Volume da área 2 na cavidade: $\mathrm{V}_{\mathrm{c}_{1}}$; 


\section{3 \\ Método numérico}

A modelagem de um escoamento multifásico não é uma tarefa fácil, tanto desde o ponto de vista físico como numérico. A maior complexidade do fenômeno resulta da presença na superfície da interface em que as propriedades físicas se alteram de forma descontinua (por exemplo: densidade, viscosidade e pressão). Esta superfície pode ser considerada uma fronteira em movimento, em que devem ser impostas condições de contorno adequadas, e a evolução da mesma é parte da solução. No problema analisado os fluidos são imiscíveis, ou seja, não reagem entre eles, e portanto a interface se desloca com a velocidade do escoamento.

Para a análise numérica do escoamento muitos métodos podem ser encontrados na literatura. Os mais populares são: método das diferenças finitas (MDF), método dos volumes finitos (MVF) e método dos elementos finitos (MEF). Todos os tipos de métodos produzem resultado similares se a malha utilizada for suficientemente boa. No problema analisado a solução numérica do escoamento foi obtida através da técnica de volumes finitos, e para modelar o problema multifásico (dois fluidos) foi utilizado o método VOF (Volume of Fluid). A solução foi obtida usando o software comercial ANSYS Fluent.

\section{1}

\section{Método dos Volumes Finitos}

O método de volumes finitos emprega diretamente as equações de conservação na forma integral. Este método discretiza as equações em cada um dos poliedros do domínio, onde previamente é realizada uma discretização espacial. A integral da superfície que aparece no termo da direita da equação de Navier-Stokes completa (na forma integral) é aproximada pela soma dos escoamentos em cada uma das fases do poliedro. 
A principal vantagem do método de volumes finitos é que a discretização espacial é realizada diretamente no espaço físico do problema. Portanto, não há problemas com a transformação entre os sistemas de coordenadas, como no método das diferenças finitas.

Comparado com o método das diferenças finitas, este método é muito mais flexível (pode ser implementado em malhas estruturadas e não estruturadas); por essa razão, o método de volumes finitos é o mais utilizado para a resolução de escoamentos com geometrias complexas.

Assim, o método dos volumes finitos é baseado na discretização direta das equações de conservação de massa, momento e energia. Isso nos leva a outra característica importante deste método, que é a obtenção de soluções "simples" das equações.

O domínio de solução é discretizado sobre um conjunto finito de volume de controle (ou células), como mostrado na Figura 6. As equações gerais de conservação são resolvidas sobre esse conjunto de volumes de controle. As equações governantes como a equação de conservação de massa e a equação de quantidade de momento foram apresentadas no capítulo anterior, onde foi considerada a não dependência da temperatura, e portanto a equação de conservação de energia não é resolvida.

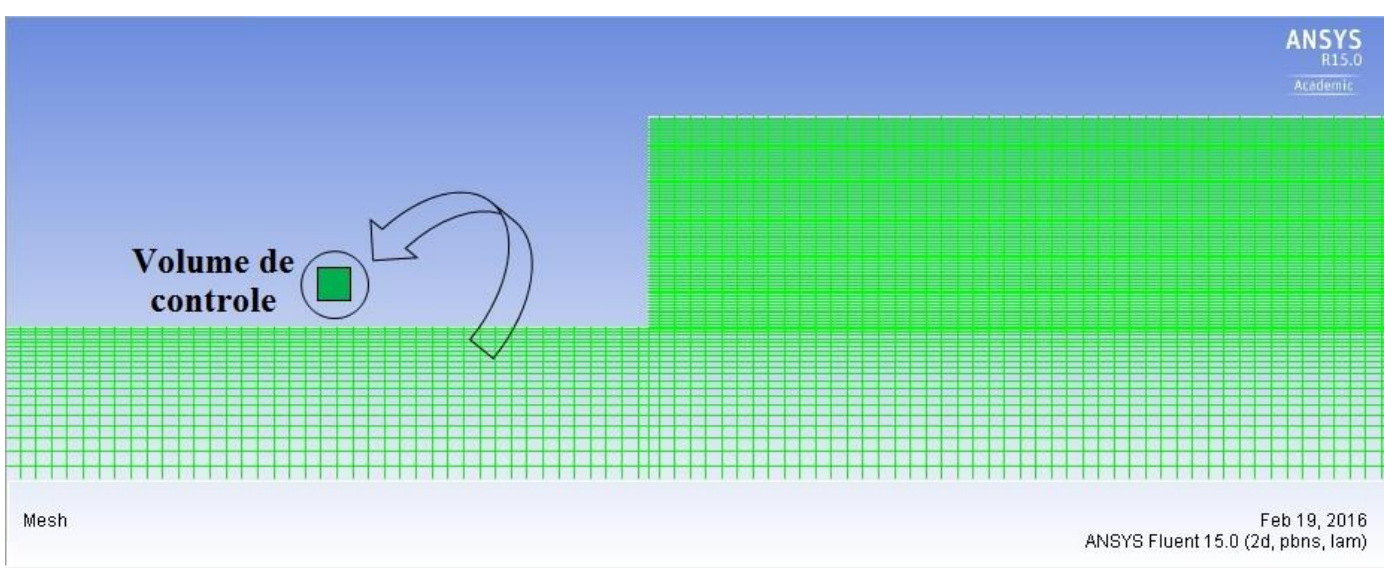

Figura 6 - Descrição da área erodida e seus limites.

\section{3}

\section{Método VOF (Volume of fluid)}

Como dito no capítulo anterior, o modelo VOF pode modelar dois ou mais fluidos imiscíveis, através da resolução de um único conjunto de equações de 
momento, e o acompanhamento da fração de volume de cada um dos fluidos durante todo o domínio. Hirt \& Nichols (1981) propuseram o método VOF, onde foi definida a fração de volume da fase na célula computacional $\alpha_{\mathrm{q}}$. Em cada volume de controle, as frações de volume de todas as fases somam a unidade. Os campos para todas as variáveis e propriedades estão compartilhados nas fases e representam valores baseados na média volumétrica, enquanto que a fração de volume de cada uma das fases é conhecida em cada posição.

Assim, células com valores de $\alpha_{\mathrm{q}}$ entre 0 e 1 contêm a interface. Logo,

- $\quad \alpha_{\mathrm{q}}=0$ : a célula está vazia (da $q$-ésima fase);

- $\alpha_{\mathrm{q}}=1$ : a célula está preenchida (da $q$-ésima fase);

- $0<\alpha_{\mathrm{q}}<1$ : a célula contém a interface entre as duas fases.

As seguintes restrições aplicam-se ao modelo VOF no Fluent:

- Deve usar-se o solver isolado. O modelo VOF não está disponível para solvers acoplados.

- Todos os volumes de controle devem ser preenchidos com uma única fase fluida ou uma combinação de fases. O modelo VOF não permite regiões vagas onde nenhuma das fases de fluido está presente.

\section{3 \\ Teste de malha}

O teste de malha se faz para verificar que a malha escolhida para as simulações seja a melhor, de modo que a sua qualidade seja alta e que o custo computacional seja o menor possível. Neste trabalho, definimos então três tipos de malhas: uma malha grosseira, uma intermediária e uma malha refinada, sabendo que a malha mais grosseira tem um número menor de nós e um custo computacional menor, enquanto que a refinada tem um número maior de elementos, tendo assim uma melhor qualidade e um custo computacional mais alto.

Todos os testes de malhas feitos nesta dissertação utilizaram como base a geometria 1, onde a relação entre o comprimento e o diâmetro da região erodida é igual a $0,5(\mathrm{~L} / \mathrm{D}=0,5)$.

Foram criadas quatro malhas diferentes usando o gerador de malha ICEM CFD de Ansys. O número de volumes de controle em cada fase do domínio de 
cálculo e as dimensões mínimas dos elementos de controle em cada direção cartesiana que definem o espaçamento entre os nós $(\Delta)$ e o nível de refinamento de cada malha, se encontram na Tabela 1. Para a análise foram usados x e y para a respectiva direção cartesiana.

$$
\Delta_{\mathrm{x}}=\frac{\mathrm{x}}{\mathrm{N}_{\mathrm{x}}}
$$

Onde,

- Espaçamentos dos nós: $\Delta_{\mathrm{x}}$;

- Comprimento em mm da malha na direção x: x;

- Número de nós na direção $\mathrm{x}: \mathrm{N}_{\mathrm{x}}$;

O mesmo acontece na direção y (radial), assim:

$$
\Delta_{\mathrm{y}}=\frac{\mathrm{y}}{\mathrm{N}_{\mathrm{y}}}
$$

Onde,

- Espaçamentos dos nós: $\Delta_{\mathrm{y}}$;

- Comprimento em mm da malha na direção y: y;

- Número de nós na direção y: $\mathrm{N}_{\mathrm{y}}$;

\begin{tabular}{|c|c|c|c|c|c|}
\hline $\begin{array}{c}\text { Espaçamento / } \\
\text { Malhas }\end{array}$ & $\begin{array}{c}\text { No. de nós } \\
\text { segundo } \mathbf{x}\end{array}$ & $\begin{array}{c}\text { No. de nós } \\
\text { segundo y }\end{array}$ & $\begin{array}{c}\text { No. de } \\
\text { pontos } \\
\text { nodais totais }\end{array}$ & $\Delta_{\mathbf{x}}$ & $\Delta_{\mathbf{y}}$ \\
\hline Malha 1 (M1) & 646 & 44 & 11546 & 0,36532 & 0,18181 \\
\hline Malha 2 (M2) & 710 & 55 & 15860 & 0,33239 & 0,14545 \\
\hline Malha 3 (M3) & 785 & 102 & 23755 & 0,30064 & 0,07843 \\
\hline Malha 4 (M4) & 865 & 141 & 33402 & 0,27283 & 0,05674 \\
\hline
\end{tabular}

Tabela 1 - Número de nós em cada direção da geometria e espaçamentos mínimos das malhas.

A Figura 7 apresenta a comparação entre os perfis calculados para o escoamento completamente desenvolvido de água com uma velocidade média de $0,001256011 \mathrm{~m} / \mathrm{s}$ na entrada, os perfis apresentados são tomados na metade da região erodida. Todos os perfis foram adimensionalizados, usando para tal a velocidade média e o raio entre a parede externa da região erodida e o casing. 


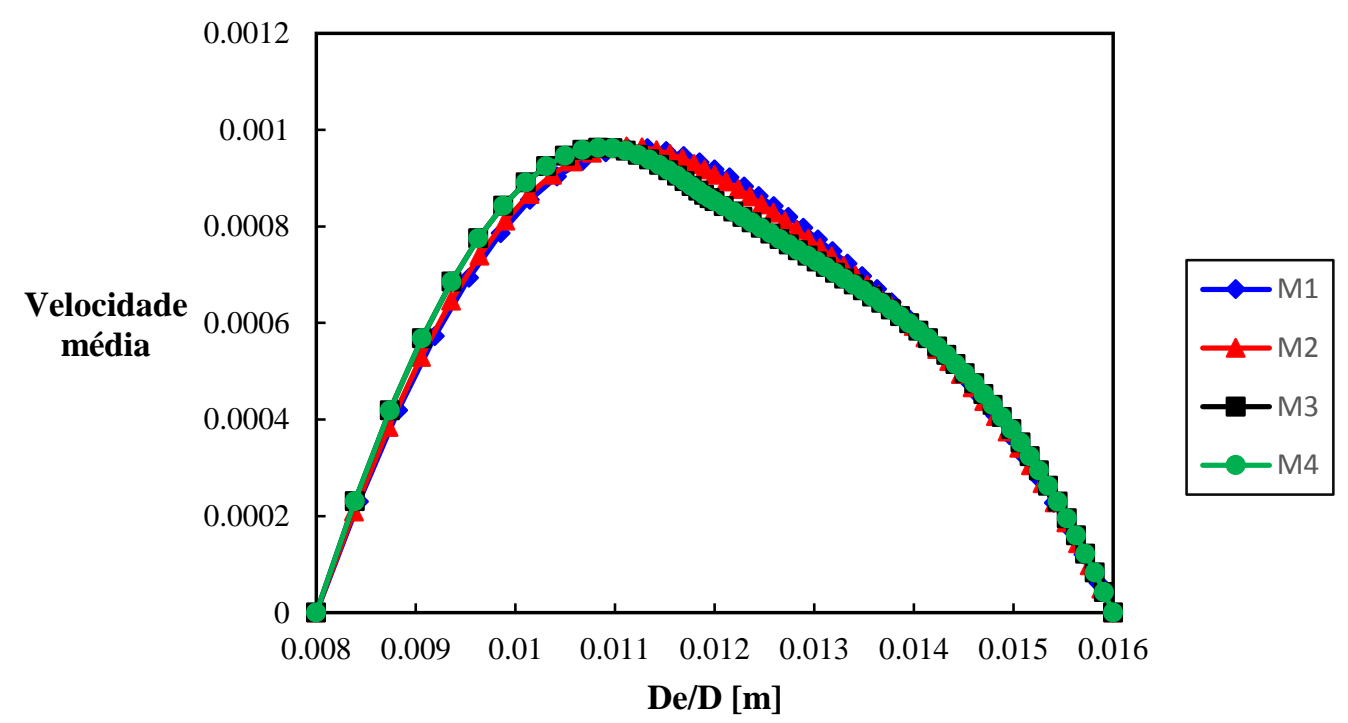

Figura 7 - Perfis de velocidade das malhas testadas para escoamento desenvolvido.

Para cada malha foi determinada a queda de pressão na região desenvolvida do anular. Essa queda de pressão é então usada para o cálculo do coeficiente de fricção $f$.

$$
\mathrm{f}=\mathrm{h}_{\mathrm{f}} \frac{\mathrm{D}_{\mathrm{h}}}{\mathrm{L}} \frac{2 \mathrm{~g}}{\overline{\mathrm{u}}^{2}}
$$

Onde,

- L é o comprimento da região;

- g é a gravidade;

- $\mathrm{D}_{\mathrm{h}}$ é o diâmetro hidráulico, e está dado neste caso por $\mathrm{D}_{\mathrm{h}}=\left(\mathrm{D}-\mathrm{D}_{e}\right)$;

- $\overline{\mathrm{u}}$ é a velocidade média;

e $\mathrm{h}_{\mathrm{f}}$ está dada pela seguinte equação:

$$
\mathrm{h}_{\mathrm{f}}=\frac{\Delta \mathrm{p}}{\rho \mathrm{g}}
$$

Onde,

- $\Delta \mathrm{p}$ é a queda de pressão da região desenvolvida;

- $\rho$ é a densidade.

Os valores obtidos e os erros relativos ao valor teórico mostram-se na Tabela 2. 


\begin{tabular}{|c|c|c|c|}
\hline & & \multicolumn{2}{|c|}{ Cálculo por $\Delta p=\frac{d p}{d x}$} \\
\hline Malhas & f teórico & $\mathbf{f}$ & $\begin{array}{c}\text { Erro relativo } \\
{[\%]}\end{array}$ \\
\hline Malha 1 (M1) & \multirow{4}{*}{95,15} & 95,13756 & 0,01307 \\
\hline Malha 2 (M2) & & 95,14475 & 0,00552 \\
\hline Malha 3 (M3) & & 95,14957 & 0,00045 \\
\hline Malha 4 (M4) & & 95,14985 & 0,00016 \\
\hline
\end{tabular}

Os resultados comprovam que a malha 3 (M3) apresenta bons resultados, em comparação com a malha mais refinada. Embora a malha 4 (M4) seja a mais refinada de todas, o erro relativo obtido na malha 3 é muito pequeno e quase imperceptível em comparação com a malha 4. Portanto, a malha 3 é a mais conveniente para usar nas simulações por seu menor custo computacional.

\section{4 \\ Malhas utilizadas}

Por causa da similaridade entre as geometrias 1, 2 e 3, nas malhas utilizadas neste trabalho, não houve a necessidade de refazer os testes de malhas para as duas outras geometrias, o número de elementos para cada malha foram calculados a partir da proporção entre a razão $\mathrm{L} / \mathrm{D}=0,5$ e o número de nós da mesma, calculando assim o número de elementos proporcional para a criação das outras duas geometrias com a razão $\mathrm{L} / \mathrm{D}=1 \mathrm{e} \mathrm{L} / \mathrm{D}=1,5$.

Como se mostra na Figura 8, a única medida que muda é o comprimento da área erodida, então é a única variação no número de nós, assim as três malhas possuem as mesmas características e se pode garantir a proximidade nos resultados dos testes de malha e com baixos erros das mesmas. 
Capítulo 3 - Método numérico
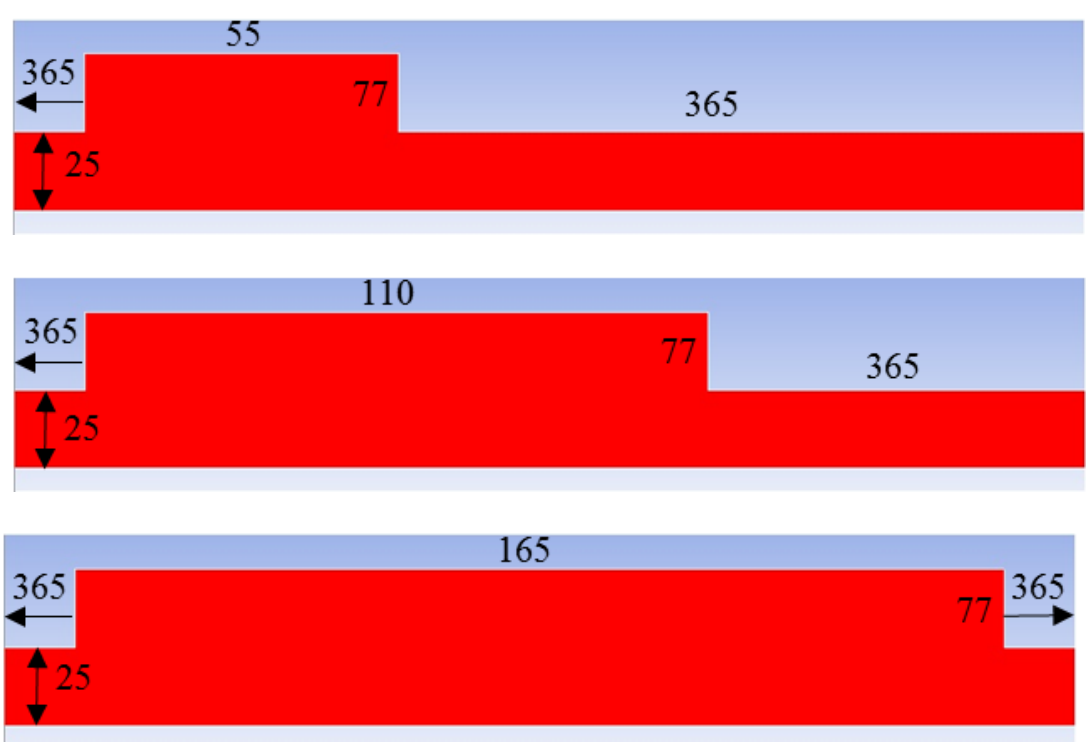

Figura 8 - Número de nós usados em cada coordenada para as três geometrias.

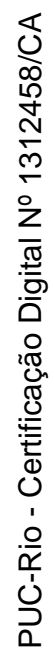




\section{Resultados}

Nos capítulos anteriores foi apresentado o modelo matemático e foi avaliada a malha fazendo várias simulações para comparar nossos resultados numéricos com outros resultados experimentais e da literatura. Neste capítulo vão ser apresentados e analisados resultados do padrão de escoamento e da eficiência de deslocamento. Foi feita uma análise paramétrica do problema, mostrando o efeito de alguns parâmetros do problema, tais como a geometria (L/D) da parcela erodida do poço, a relação entre as viscosidades e densidades dos fluidos deslocado e deslocador, e a reologia dos fluidos.

A tabela abaixo mostra os casos analisados no presente trabalho, que serão discutidos a seguir.

\begin{tabular}{|c|c|c|c|c|}
\hline \multirow{2}{*}{ Caso \# } & \multicolumn{2}{|c|}{ Fluidos } & \multirow{2}{*}{$\begin{array}{c}\text { Números Herschel-Bulkley } \\
\text { HB }\end{array}$} & \multirow{2}{*}{$\begin{array}{c}\text { Números de Reynolds } \\
\text { Re }\end{array}$} \\
\hline & Deslocador & Deslocado & & \\
\hline 1 & Carbopol & Água & $3,94-2,79-1,80-1,07-0,39$ & $0,001-0,01-0,1-1-50$ \\
\hline 2 & Carbopol & Água & $5,69-4,69-3,54-2,43-1,05$ & $0,001-0,01-0,1-1-50$ \\
\hline 3 & Carbopol & Água & $6,32-5,48-4,43-3,28-1,58$ & $0,001-0,01-0,1-1-50$ \\
\hline 4 & Carbopol & Água & $6,59-5,86-4,89-3,76-1,93$ & $0,001-0,01-0,1-1-50$ \\
\hline 5 & Glicerina & Carbopol & 0,91353 & $0,001-0,1-25$ \\
\hline 6 & Glicerina & Carbopol & 1,52255 & $0,001-0,1-25$ \\
\hline 7 & Glicerina & Carbopol & 2 & $0,001-0,1-25$ \\
\hline 8 & Cimento & $\begin{array}{l}\text { Fluido de } \\
\text { perfuração }\end{array}$ & $\tau_{\mathbf{y c}}=12$ e $\tau_{\mathbf{y f}}=0,80 ; \tau_{\mathbf{y}}^{*}=15$ & $0,001-0,1-50$ \\
\hline 9 & Cimento & $\begin{array}{l}\text { Fluido de } \\
\text { perfuração }\end{array}$ & $\tau_{\mathbf{y c}}=24$ e $\tau_{\mathbf{y f}}=0,80 ; \boldsymbol{\tau}_{\mathbf{y}}^{*}=30$ & $0,001-0,1-50$ \\
\hline 10 & Cimento & $\begin{array}{l}\text { Fluido de } \\
\text { perfuração }\end{array}$ & $\tau_{\mathbf{y c}}=24$ e $\tau_{\mathbf{y f}}=0,40 ; \tau_{\mathbf{y}}^{*}=60$ & $0,001-0,1-50$ \\
\hline
\end{tabular}

Tabela 3 - Listado de casos testados neste trabalho. 
Os resultados das simulações estão focados na área erodida do poço ou cavidade, onde o fluido deslocado de cor vermelha (também chamado de fluido 1) é empurrado em todos os casos pelo fluido deslocador de cor amarela (ou fluido 2), dando como resultado uma porção maior ou menor do fluido deslocado na região de estudo, reduzindo ou aumentado a eficiência do deslocamento. Todas as simulações foram feitas com um sentido de fluxo da esquerda para direita.

\section{1}

\section{Carbopol deslocando Água}

Este primeiro caso descreve o deslocamento da água, que se comporta como um fluido Newtoniano, pelo Carbopol, que consideraremos como um fluido não Newtoniano de comportamento viscoplástico. A densidade e os parâmetros reológicos destes dois fluidos são:

- Água: densidade $\rho=998,2 \mathrm{~kg} / \mathrm{m}^{3}$ e viscosidade $\mu=0,001003$ Pa.s.

- Carbopol 0,1\%: densidade $\rho=1000 \mathrm{~kg} / \mathrm{m}^{3}$. O Carbopol é modelado pela equação de Herschel-Bulkley, com os seguintes parâmetros: a tensão limite de escoamento $\tau_{\mathrm{y}}=0,30451 \mathrm{~Pa}$, o índice de consistência $\mathrm{k}=0,55653$ Pa.s ${ }^{\mathrm{n}}$ e o índice Power-Law n =0,44633.

Foram feitas simulações para diferentes valores de Reynolds e tensões limites de escoamento do Carbopol, a fim de avaliar os efeitos causados por estas duas propriedades na eficiência de deslocamento.

As tensões limites de escoamento utilizadas nas simulações foram: $\tau_{\mathrm{y}}=$ $0,30451 \mathrm{~Pa} ; \tau_{\mathrm{y}}=0,91353 \mathrm{~Pa} ; \tau_{\mathrm{y}}=1,52255 \mathrm{~Pa}$ e $\tau_{\mathrm{y}}=2 \mathrm{~Pa}$ e os valores de Reynolds utilizados foram: $\operatorname{Re}=0,001 ; \operatorname{Re}=0,01 ; \operatorname{Re}=0,1 ; \operatorname{Re}=1$ e $\operatorname{Re}=50$.

A partir dos dados anteriores se calculam os números Herschel-Bulkley HB 1, HB 2, HB 3 e HB 4 com quatro valores diferentes de tensões limites de escoamento e cinco valores distintos do número de Reynolds como se mostra na Tabela 4 abaixo. 


\begin{tabular}{|c|c|c|c|c|}
\hline \multicolumn{5}{|c|}{ Número Herschel Bulkley $H B=\frac{\tau_{y} D_{h}}{\mu_{2} \bar{u}}$} \\
\hline $\begin{array}{c}\text { Tensão } \\
\text { Limite de } \\
\text { Escoamento } \\
\text { / Reynolds }\end{array}$ & $\begin{array}{c}\text { HB 1 } \\
\boldsymbol{\tau}_{\mathbf{y}}=0,30451 \mathrm{~Pa}\end{array}$ & $\begin{array}{c}\text { HB 2 } \\
\boldsymbol{\tau}_{\mathbf{y}}=0,91353 \mathrm{~Pa}\end{array}$ & $\begin{array}{c}\text { HB 3 } \\
\boldsymbol{\tau}_{\mathbf{y}}=1,52255 \mathrm{~Pa}\end{array}$ & $\begin{array}{c}\text { HB } 4 \\
\tau_{\mathbf{y}}=2 \mathrm{~Pa}\end{array}$ \\
\hline $\operatorname{Re}=0,001$ & 3,94 & 5,69 & 6,32 & 6,59 \\
\hline $\operatorname{Re}=0,01$ & 2,79 & 4,69 & 5,48 & 5,86 \\
\hline $\operatorname{Re}=0,1$ & 1,80 & 3,54 & 4,43 & 4,89 \\
\hline $\operatorname{Re}=1$ & 1,07 & 2,43 & 3,28 & 3,76 \\
\hline $\mathbf{R e}=\mathbf{5 0}$ & 0,39 & 1,05 & 1,58 & 1,93 \\
\hline
\end{tabular}

Tabela 4 - Números Herschel-Bulkley para o caso entre a Água e o Carbopol.

A densidade da água vale $\rho=998,2 \mathrm{~kg} / \mathrm{m}^{3}$, enquanto que o Carbopol tem densidade $\rho=1000 \mathrm{~kg} / \mathrm{m}^{3}$. Assim neste primeiro caso particular temos a seguinte razão de densidades:

$$
\rho^{*}=\frac{\rho_{2}}{\rho_{1}} \rightarrow \rho^{*}=\frac{1000 \mathrm{~kg} / \mathrm{m}^{3}}{998,2 \mathrm{~kg} / \mathrm{m}^{3}} \rightarrow \rho^{*}=1,002
$$

Como se observa o resultado da razão de densidade é aproximadamente igual a 1, logo ela não deve afetar o processo de deslocamento.

\begin{tabular}{|c|c|c|c|c|}
\hline \multicolumn{5}{|c|}{ Razões de viscosidades $\left(\boldsymbol{\mu}^{*}=\boldsymbol{\eta}_{\mathbf{c}} / \boldsymbol{\mu}\right)$} \\
\hline $\begin{array}{c}\text { Número } \\
\text { Herschel- } \\
\text { Bulkley / } \\
\text { Reynolds }\end{array}$ & HB 1 & HB 2 & HB 3 & HB 4 \\
\hline $\mathbf{R e}=\mathbf{0 , 0 0 1}$ & 2218,36 & 3194,71 & 3915,11 & 4392,62 \\
\hline $\mathbf{R e}=\mathbf{0 , 0 1}$ & 832,65 & 1113,59 & 1329,15 & 1473,95 \\
\hline $\mathbf{R e}=\mathbf{0 , 1}$ & 327,67 & 405,03 & 467,46 & 510,26 \\
\hline $\mathbf{R e}=\mathbf{1}$ & 134,26 & 154,53 & 171,84 & 184,03 \\
\hline $\mathbf{R e}=\mathbf{5 0}$ & 31,35 & 33,23 & 34,98 & 36,27 \\
\hline
\end{tabular}

Tabela 5 - Razões de viscosidades entre a Água e o Carbopol.

$\mathrm{Na}$ Tabela 5 acima se apresentam as razões de viscosidades para todos os casos estudados do Carbopol empurrando água. Observa-se que o aumento do 
Reynolds leva a menores valores da razão de viscosidades, devido ao aumento nas taxas de deformação que levam a redução dos valores de viscosidade do fluido não Newtoniano. Além disso, as razões de viscosidade aumentam à medida que a tensão limite de escoamento aumenta.

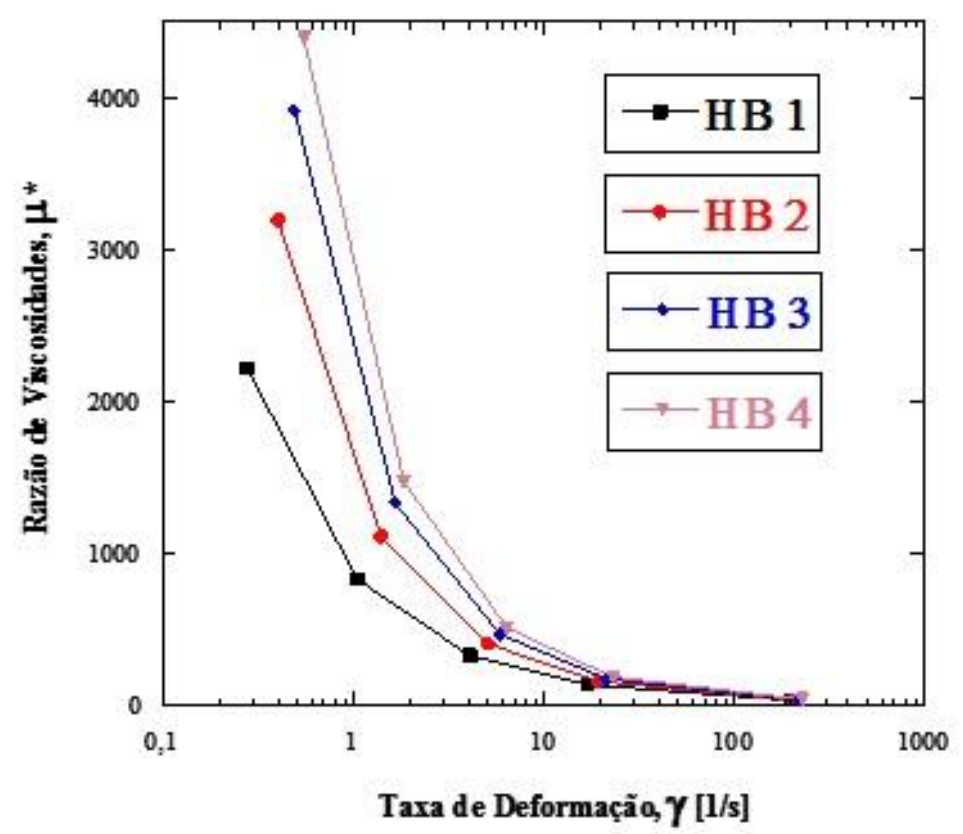

Figura 9 - Razões de viscosidades entre a Água e o Carbopol para os números Herschel-Bulkley HB 1, HB 2, HB 3 e HB 4.

A Figura 9 ajuda a visualizar o comportamento das razões de viscosidades entre a água e o Carbopol em função da taxa de deformação, e claramente mostram o aumento da razão de viscosidade em função do número HerschelBulkley, o que significa o aumento nas tensões limites de escoamento. Além disso, a forma das quatro curvas mostra que não há diferença no comportamento pseudoplástico entre os dois fluidos.

\subsection{1}

\section{Carbopol deslocando Água - geometria 1 (L/D=0,5)}

As Figuras 10 e 11 mostram as duas fases, o Carbopol (de cor amarela) deslocando a água (de cor vermelha) na geometria 1, para diferentes valores de Reynolds e números Herschel-Bulkley. O sentido do movimento dos fluidos é indicado pela seta preta, sempre da esquerda para a direita, neste e nos outros casos. 


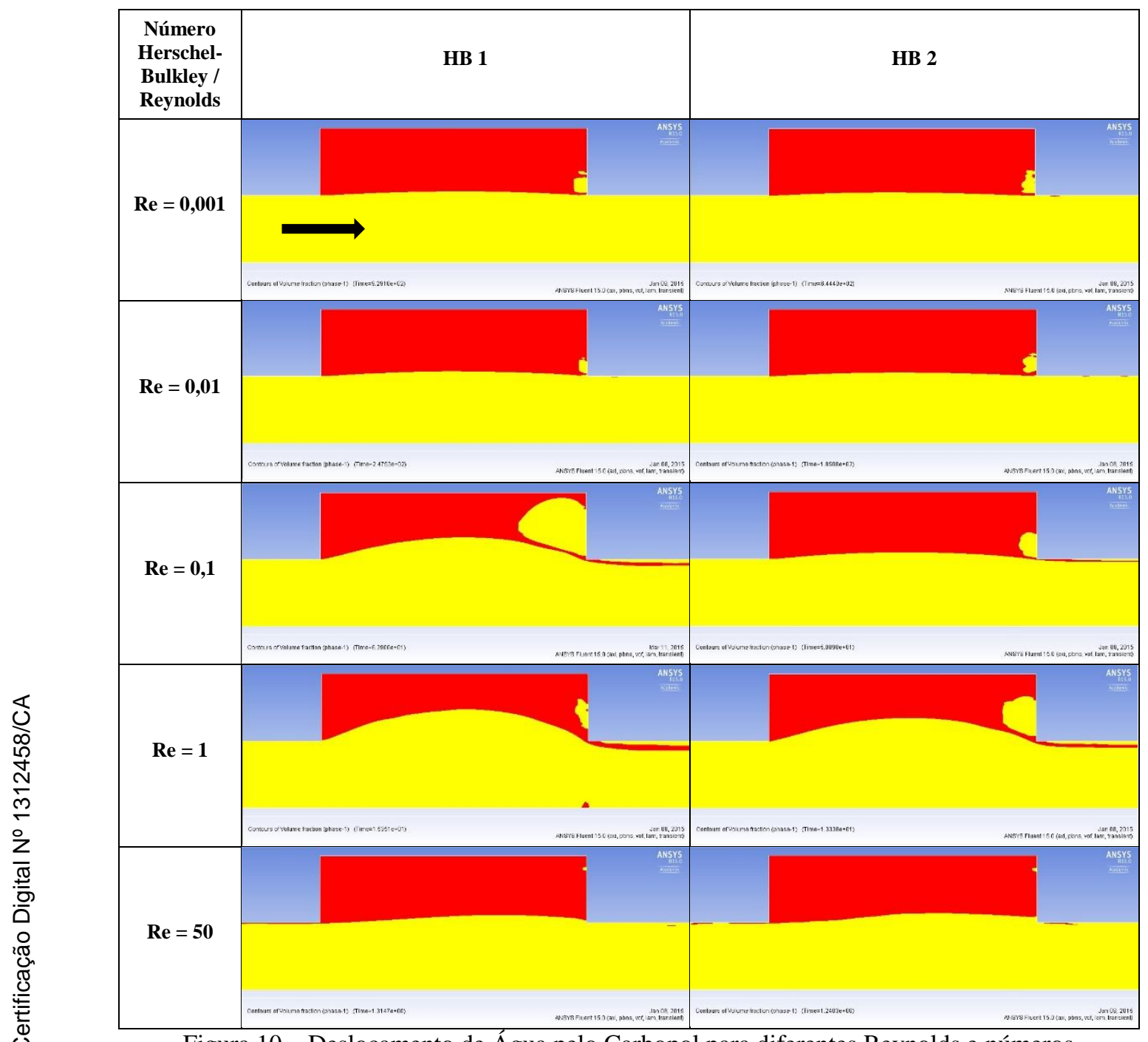

Figura 10 - Deslocamento de Água pelo Carbopol para diferentes Reynolds e números HerschelBulkley na geometria 1 .

Na Figura 11 mostra-se a mesma geometria 1 mas com outros valores do número Herschel-Bulkley (HB 3 e HB 4).

\begin{tabular}{|c|c|c|}
\hline $\begin{array}{l}\text { Número } \\
\text { Herschel- } \\
\text { Bulkley / } \\
\text { Reynolds }\end{array}$ & HB 3 & HB 4 \\
\hline \multicolumn{3}{|l|}{$\operatorname{Re}=0,001$} \\
\hline & 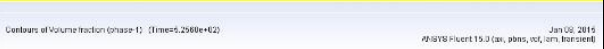 & 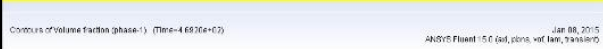 \\
\hline
\end{tabular}




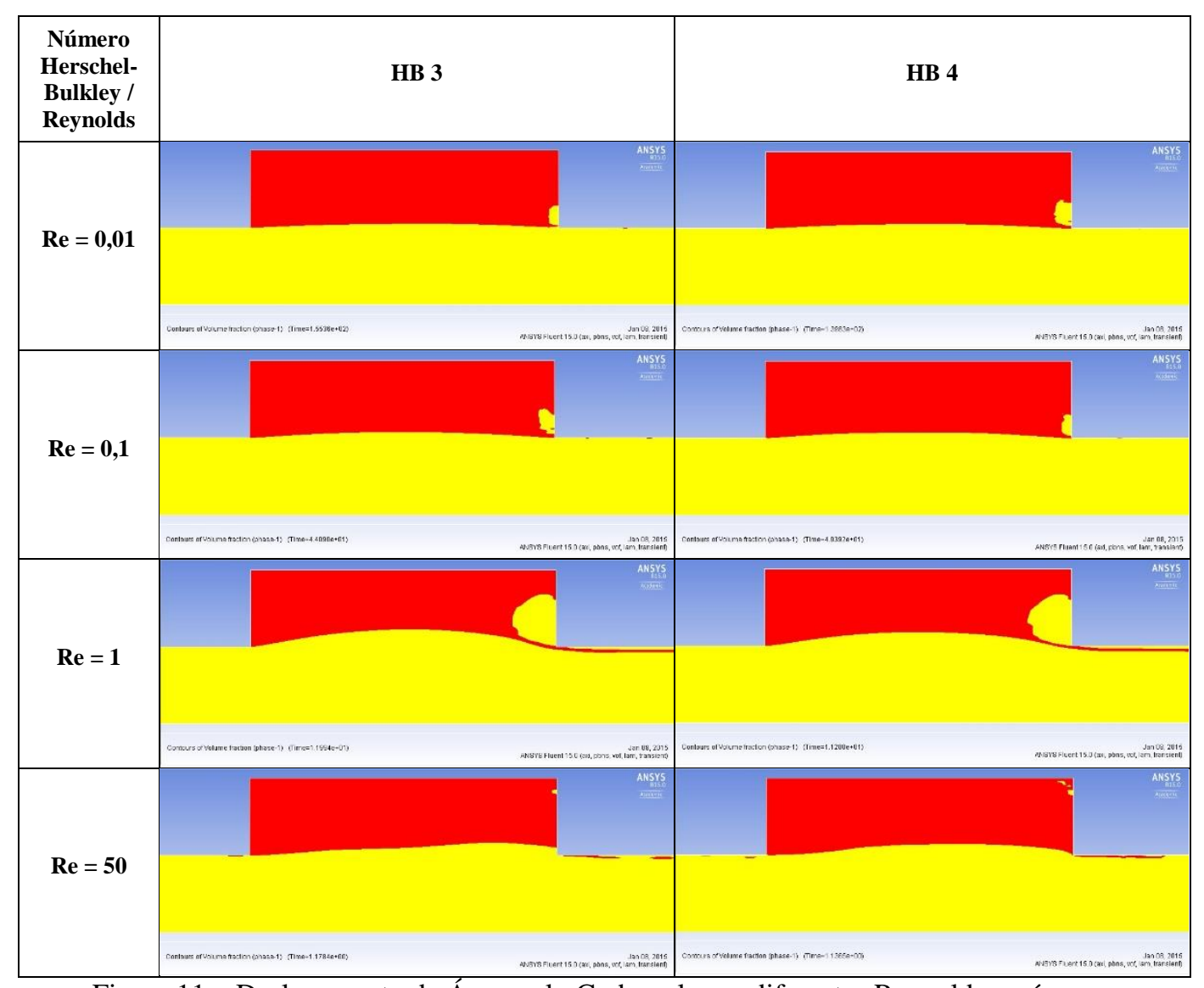

Figura 11 - Deslocamento de Água pelo Carbopol para diferentes Reynolds e números HerschelBulkley na geometria 1.

Observa-se que para Reynolds muito baixos $(\operatorname{Re}=0,001$ e $\operatorname{Re}=0,01)$ o volume deslocado na cavidade é quase nulo sem importar o número HerschelBulkley. As baixas tensões envolvidas nos baixos números Herschel-Bulkley fazem com que o Carbopol não entre na cavidade, e a água fica retida nesta região.

Para Reynolds intermediários $(\operatorname{Re}=0,1$ e $\operatorname{Re}=1)$ nota se um pequeno volume deslocado na cavidade devido ao aumento das tensões no escoamento, e o surgimento de uma quantidade pequena de Carbopol estagnado, próximo da saída da zona erodida.

No caso especifico de Reynolds igual a 1, observa-se que o volume deslocado é maior. Para números de Reynolds mais elevados, a inércia faz com que o Carbopol escoe sem entrar na cavidade.

Seguem abaixo as Figuras 12 e 13, onde mostra-se para a geometria 1 as linhas de corrente para os mesmos valores de Reynolds e números HerschelBulkley. Advertindo que as linhas de corrente de cor vermelha mostram a velocidade máxima em cada caso e as linhas de corrente de cor azul são valores da 
velocidade muito pequenos, perto de cero, que é o que indicam as legendas em cada caso.

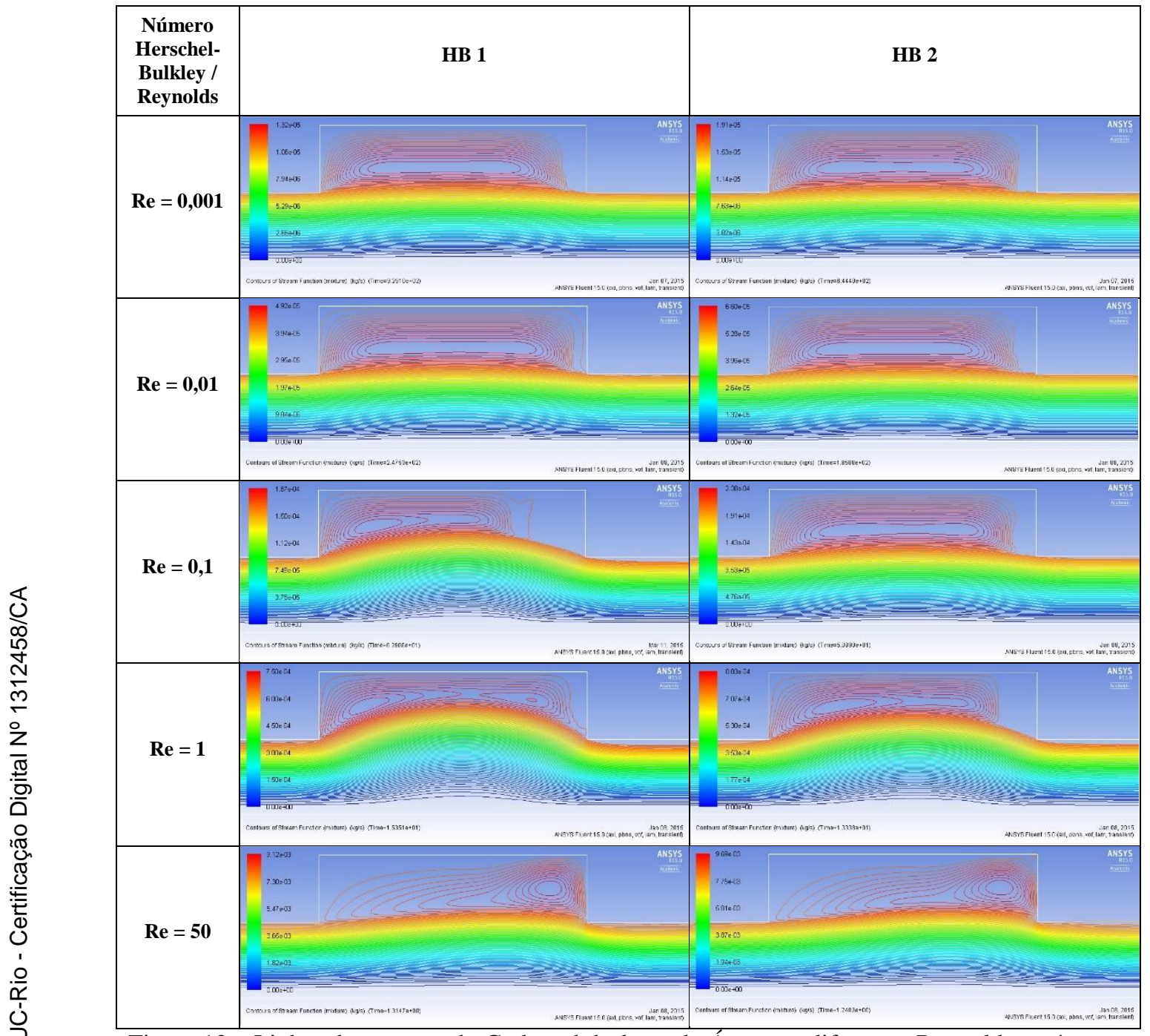

Figura 12 - Linhas de corrente do Carbopol deslocando Água em diferentes Reynolds e números Herschel-Bulkley na geometria 1.

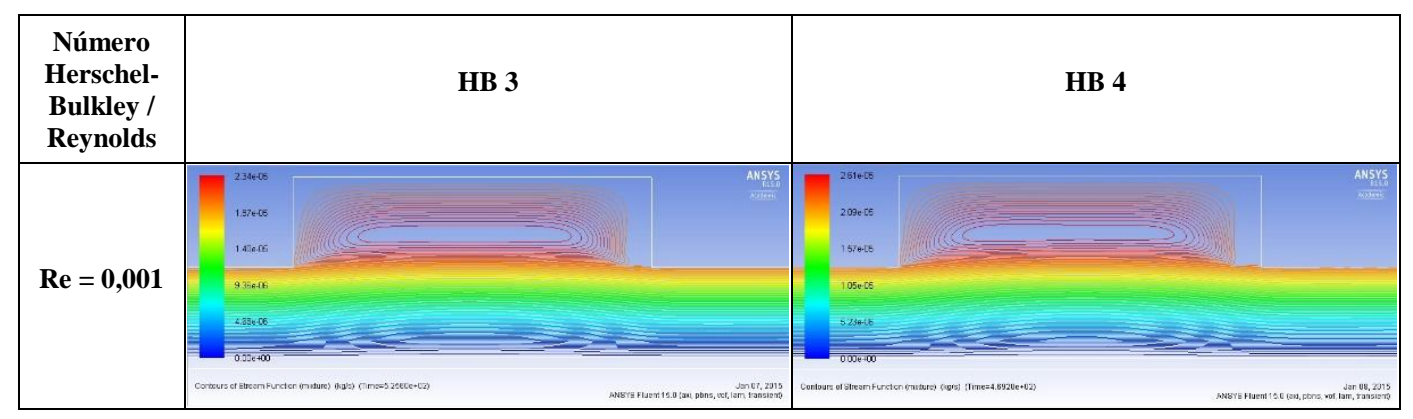




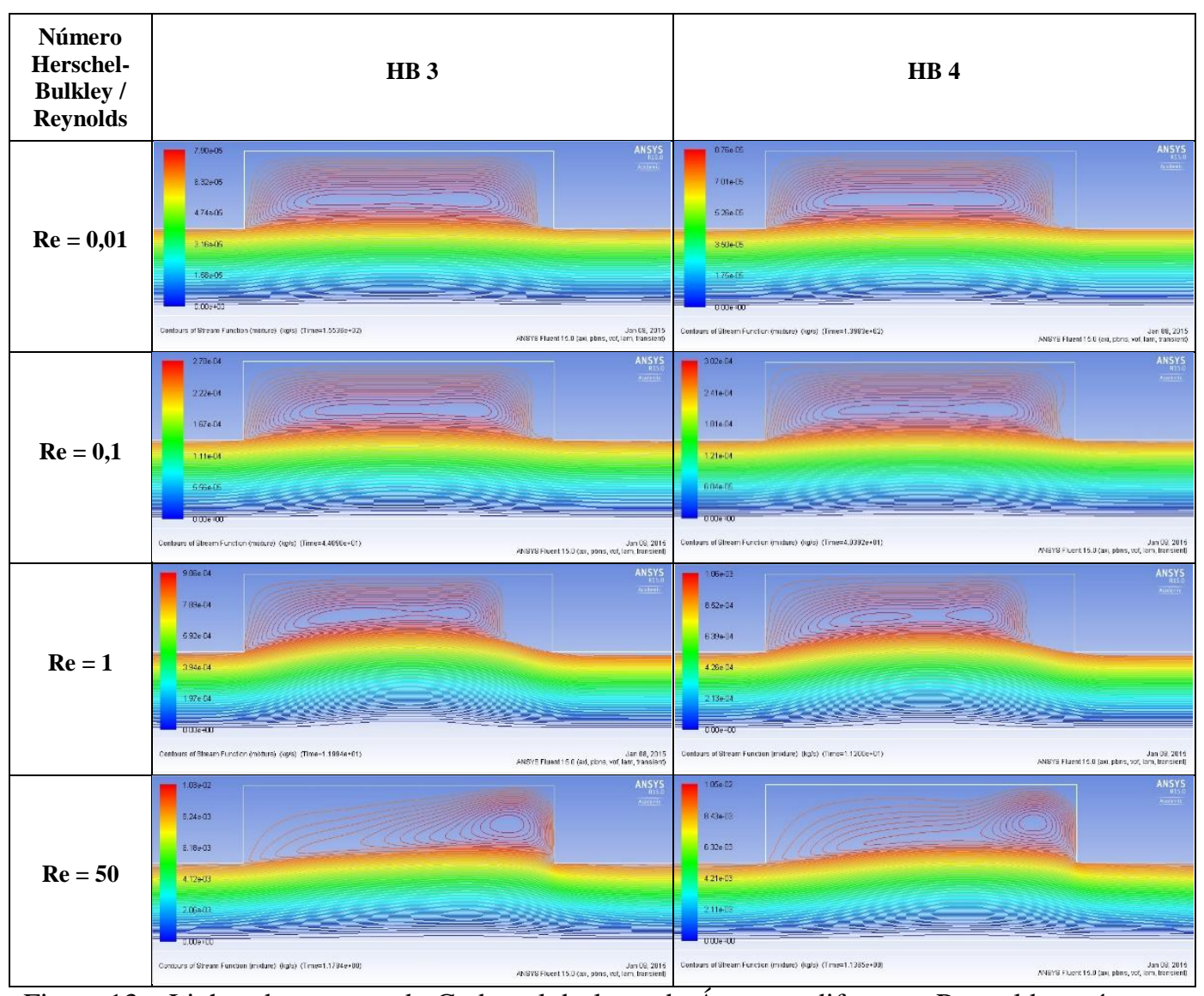

Figura 13 - Linhas de corrente do Carbopol deslocando Água em diferentes Reynolds e números Herschel-Bulkley na geometria 1.

Observa-se que para baixos valores de Reynolds o escoamento na cavidade é quase simétrico em relação ao eixo central (esquerda/direita), pois a inércia é desprezível nestes casos.

As linhas de corrente mostram que a água recircula no interior da cavidade, e evidenciam uma pequena quantidade do Carbopol estagnado para os Reynolds intermediários $(\operatorname{Re}=0,1$ e $\operatorname{Re}=1)$, além de mostrarem claramente o efeito da inércia para Reynolds alto $(\operatorname{Re}=50)$, com a advecção do escoamento na direção da parede próxima a saída da região erodida.

Os resultados que mostram os valores de eficiência serão apresentados mais tarde.

\subsection{2 \\ Carbopol deslocando Água - geometria $2(\mathrm{~L} / \mathrm{D}=1,0)$}

Nas Figuras 14 e 15 mostram-se de novo as duas fases, o Carbopol (cor amarela) empurrando a água (cor vermelha), na geometria 2, para diferentes valores de Reynolds e números Herschel-Bulkley. 


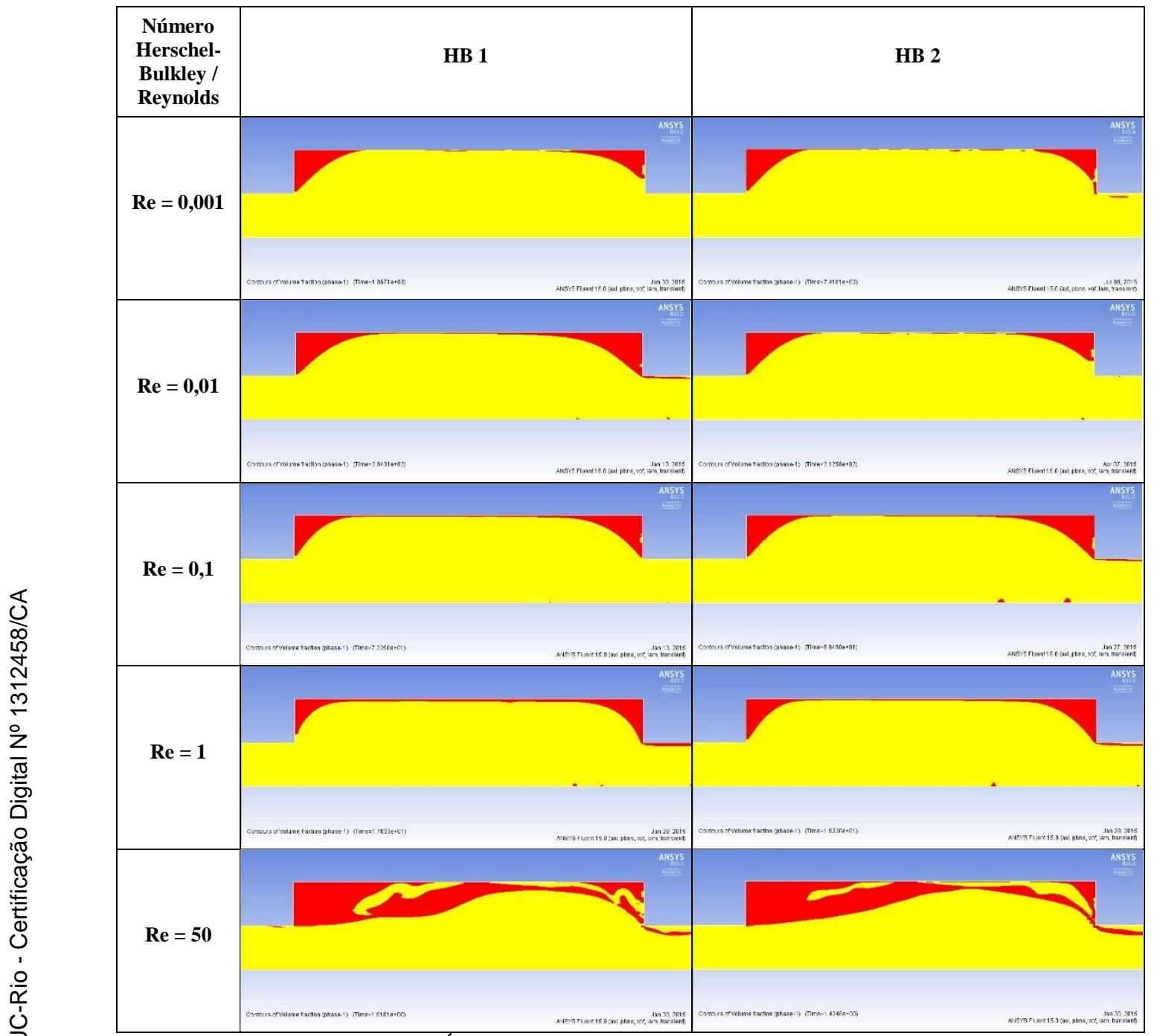

Figura 14 - Deslocamento de Água pelo Carbopol para diferentes Reynolds e números HerschelBulkley na geometria 2.

Mostra-se na Figura 15 a mesma geometria 2, mas com outros valores do número Herschel-Bulkley (HB 3 e HB 4).

\begin{tabular}{|c|c|c|}
\hline $\begin{array}{l}\text { Número } \\
\text { Herschel- } \\
\text { Bulkley / } \\
\text { Reynolds }\end{array}$ & HB 3 & HB 4 \\
\hline $\operatorname{Re}=0,001$ & & \\
\hline & 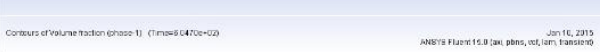 & 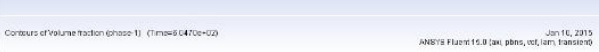 \\
\hline
\end{tabular}




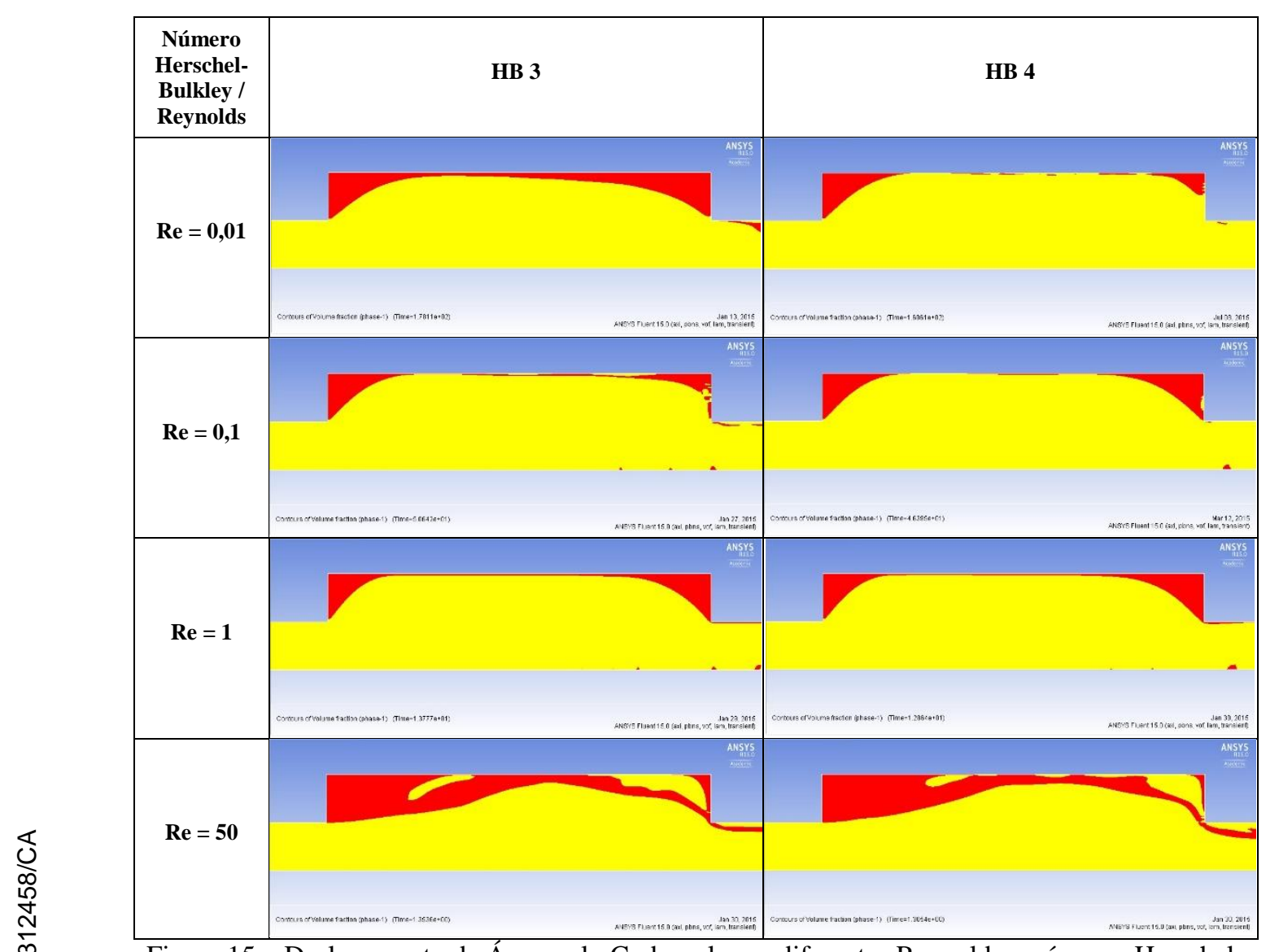

Figura 15 - Deslocamento de Água pelo Carbopol para diferentes Reynolds e números HerschelBulkley na geometria 2.

As Figuras 16 e 17 mostram as linhas de corrente para os mesmos valores de Reynolds e números Herschel-Bulkley.

Em contraste com o observado na geometria 1, nestes novos casos da geometria 2 se observa que o volume deslocado é muito maior, exceto no caso do Reynolds igual a 50, onde se observa que ocorre uma recirculação causada pela ação da inércia.

\begin{tabular}{|c|c|c|c|}
\hline $\begin{array}{c}\text { Número } \\
\text { Herschel- } \\
\text { Bulkley / } \\
\text { Reynolds }\end{array}$ & HB 1 & & HB 2 \\
\hline & & & \\
$\mathbf{R e}=\mathbf{0 , 0 0 1}$ & & & \\
& & & \\
& &
\end{tabular}




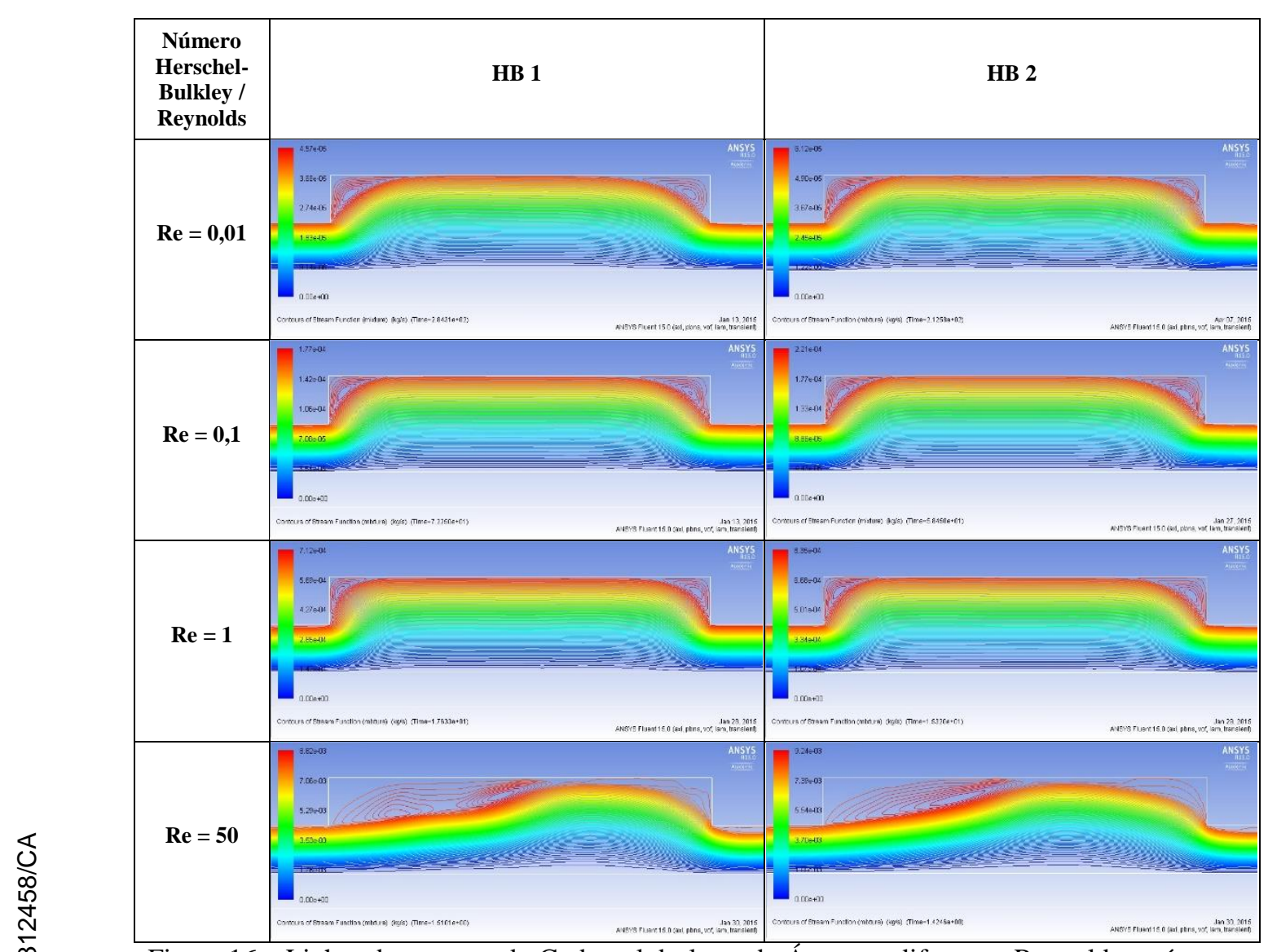

Figura 16 - Linhas de corrente do Carbopol deslocando Água em diferentes Reynolds e números Herschel-Bulkley na geometria 2.

Observa-se que no caso de Reynolds muito baixo $(\operatorname{Re}=0,001)$ o volume deslocado diminui significativamente para valores mais altos do número HerschelBulkley (HB 3 e HB 4). Novamente, em todos os casos observa-se que a água retida na cavidade recircula, e a inércia quebra a simetria do escoamento, fazendo com que as linhas de corrente se desloquem na direção da parede de saída da cavidade.

\begin{tabular}{|c|c|c|}
\hline $\begin{array}{l}\text { Número } \\
\text { Herschel- } \\
\text { Bulkley / } \\
\text { Reynolds }\end{array}$ & HB 3 & HB 4 \\
\hline $\operatorname{Re}=0,001$ & $=$ & 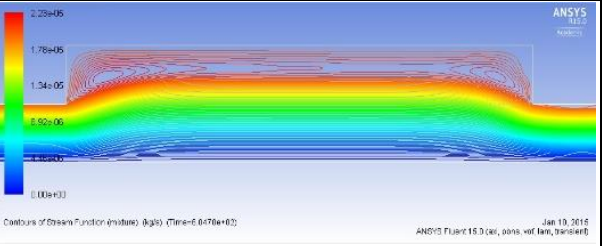 \\
\hline $\operatorname{Re}=0,01$ & $=0$ & 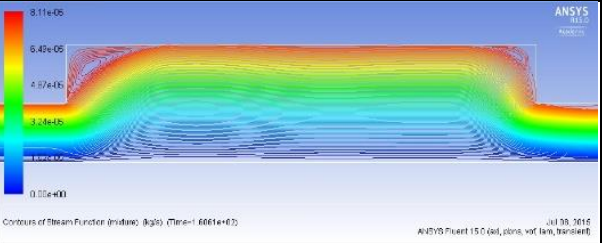 \\
\hline
\end{tabular}




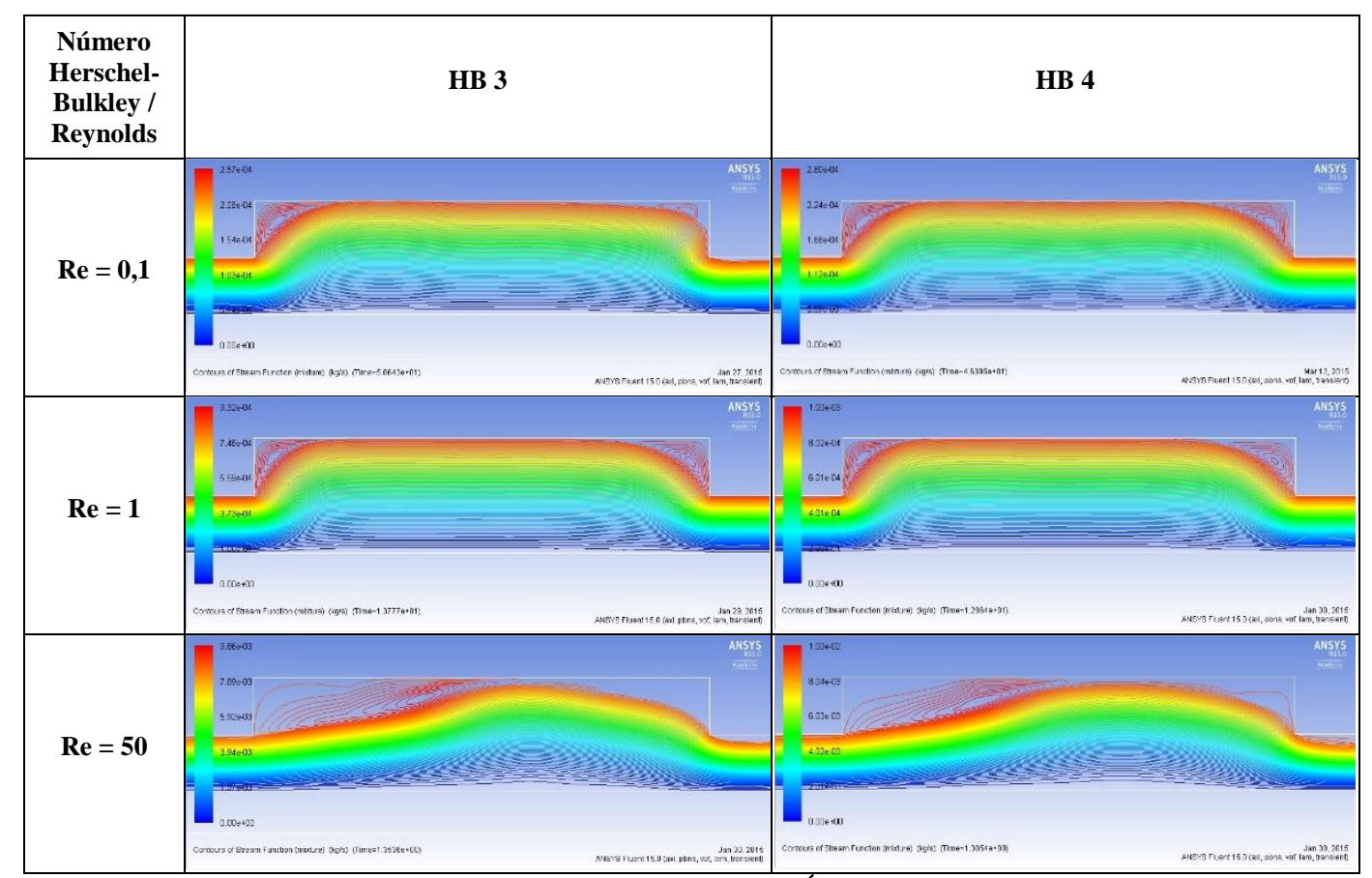

Figura 17 - Linhas de corrente do Carbopol deslocando Água em diferentes Reynolds e números Herschel-Bulkley na geometria 2.

\subsection{3 \\ Carbopol deslocando Água - geometria $3(\mathrm{~L} / \mathrm{D}=1,5)$}

Esta seção mostra nas Figuras 18 e 19 o Carbopol empurrando a água na geometria 3, com diferentes valores de Reynolds e distintas configurações nos números Herschel-Bulkley. As Figuras 20 e 21 mostram as linhas de corrente para os mesmos casos.

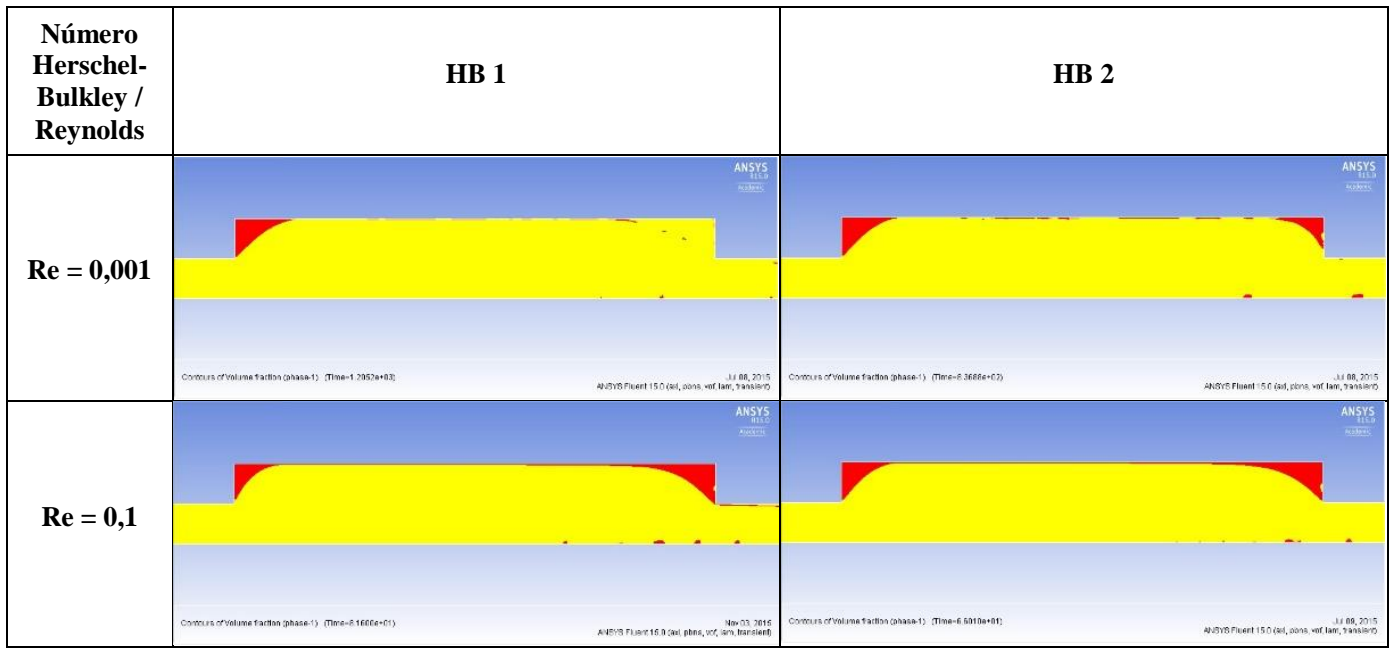




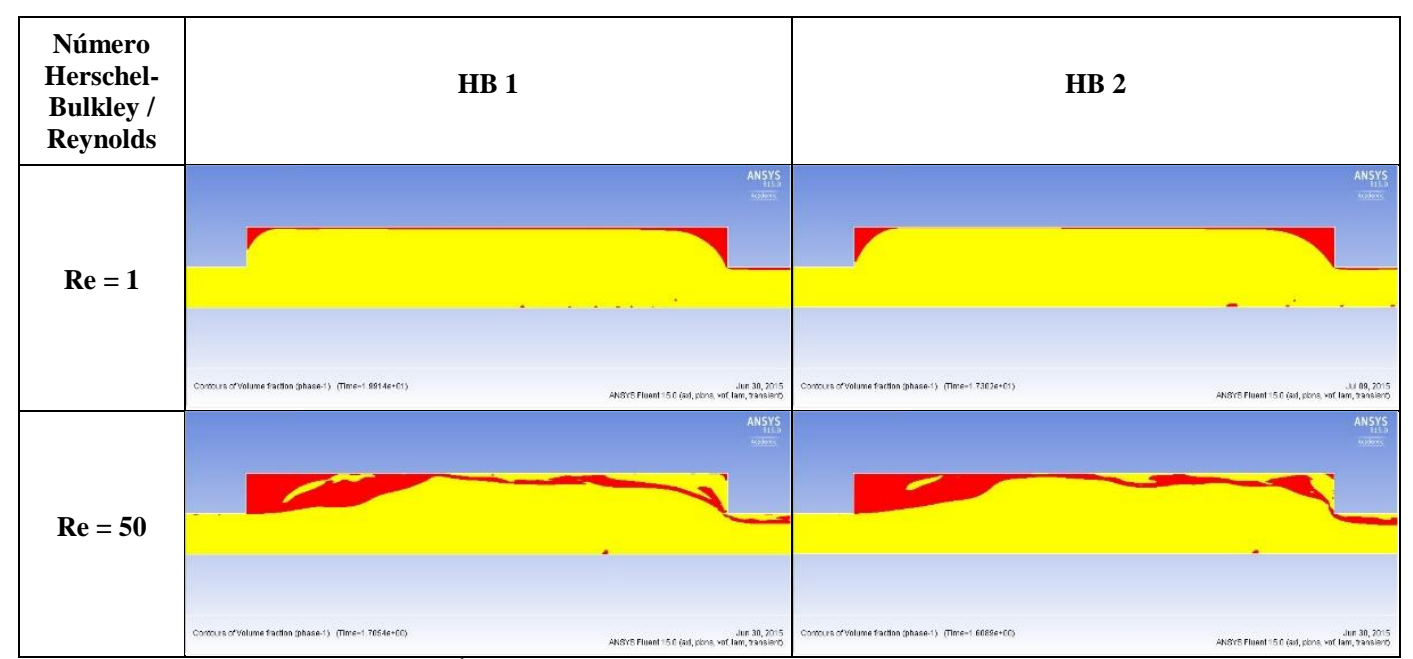

Figura 18 - Deslocamento de Água pelo Carbopol para diferentes e números Herschel-Bulkley na geometria 3.

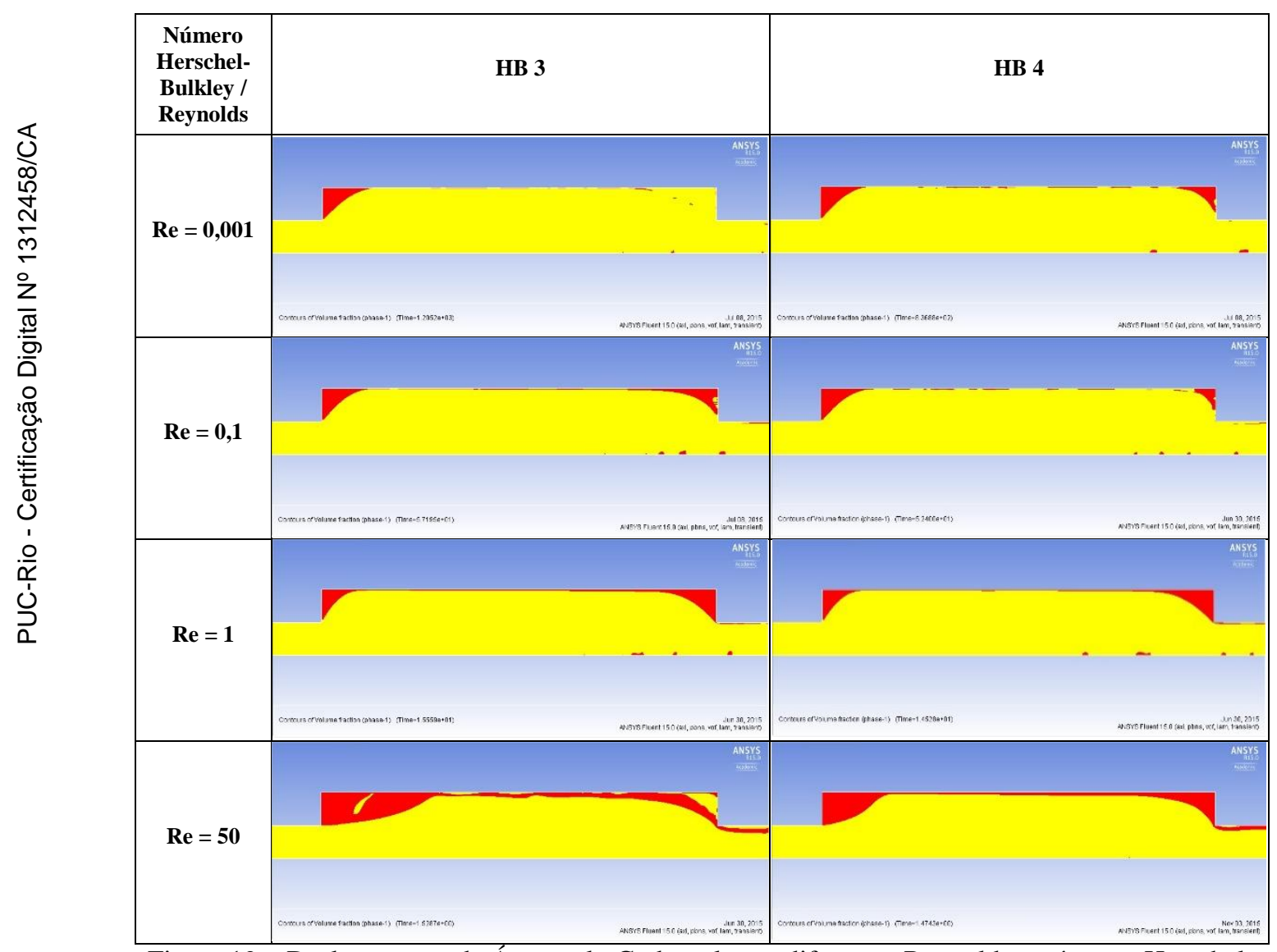

Figura 19 - Deslocamento de Água pelo Carbopol para diferentes Reynolds e números HerschelBulkley na geometria 3.

Observa-se o mesmo comportamento qualitativo dos casos anteriores, i.e., não se nota uma influência muito grande do número Herschel-Bulkley na faixa investigada, observa-se uma quase simetria em relação ao eixo central para os casos de Reynolds mais baixos, e o efeito da inércia para Reynolds mais elevado. 
Capítulo 4 - Resultados

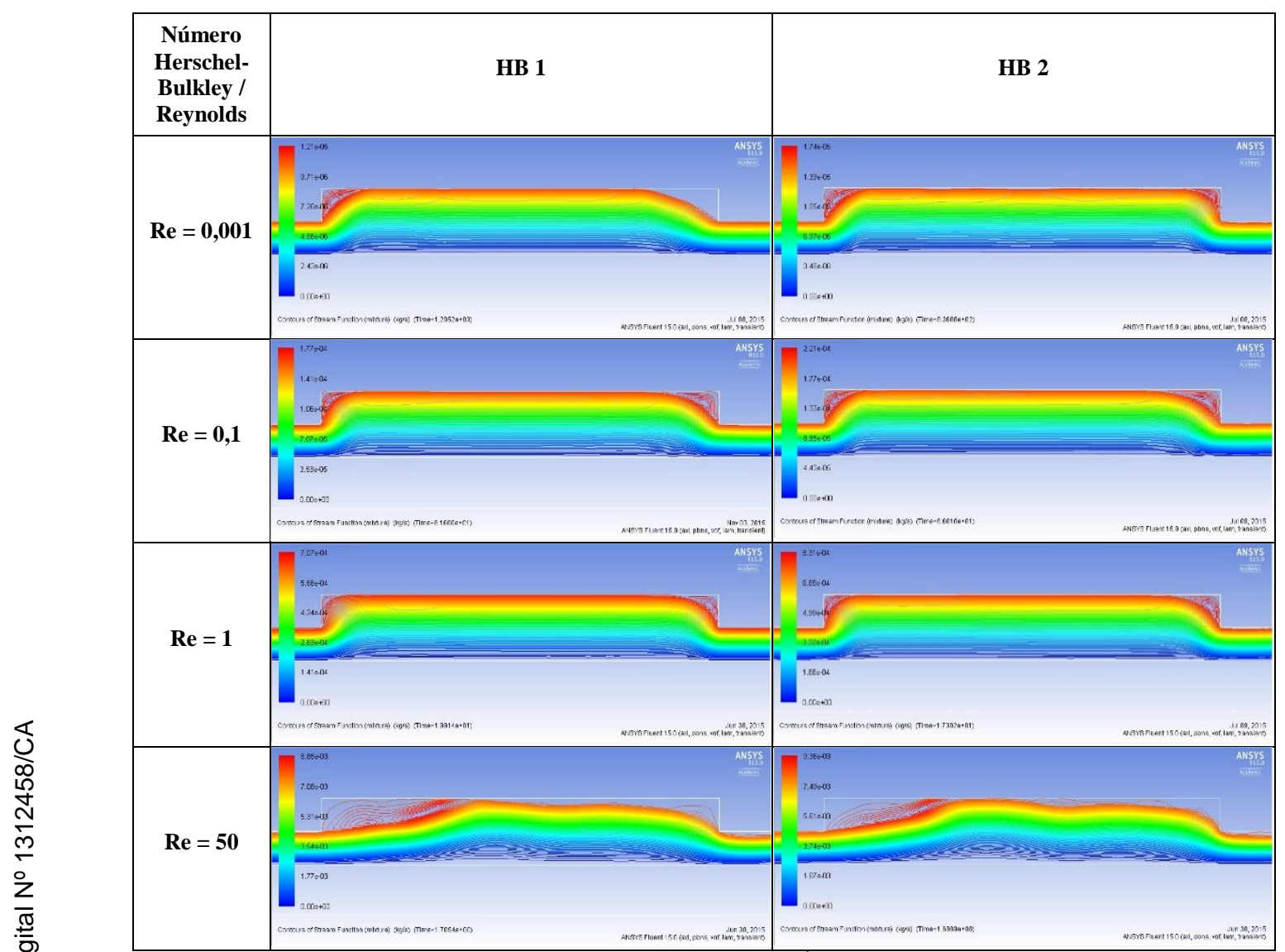

Figura 20 - Linhas de corrente do Carbopol deslocando Água em diferentes Reynolds e números Herschel-Bulkley na geometria 3

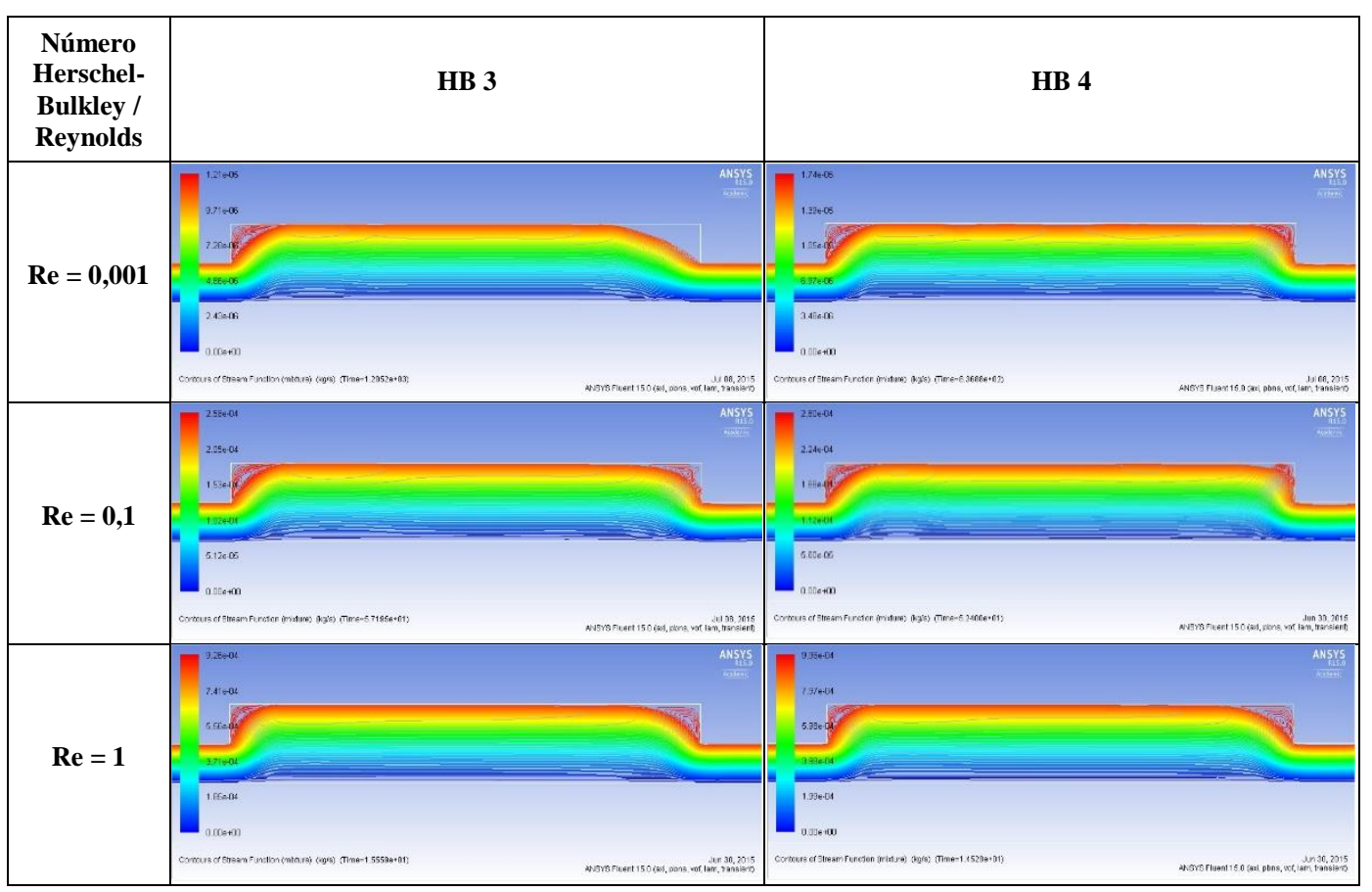




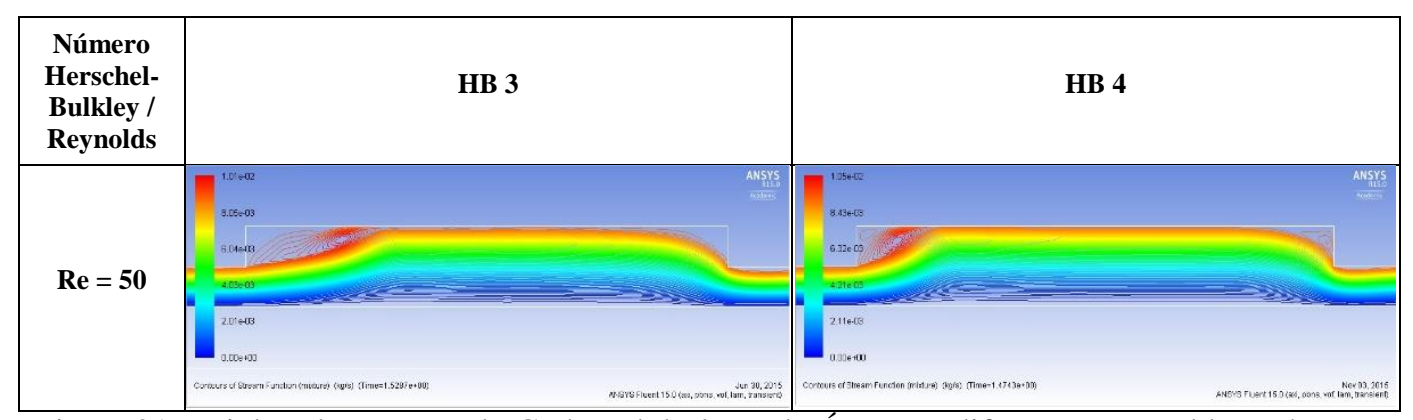

Figura 21 - Linhas de corrente do Carbopol deslocando Água em diferentes Reynolds e números Herschel-Bulkley na geometria 3.

\subsection{4 \\ Eficiências do caso Carbopol deslocando Água}

Após a análise qualitativa feita dos resultados obtidos nas simulações em todos os casos do Carbopol deslocando água, ainda fica difícil perceber os efeitos da geometria, da tensão limite de escoamento e do número de Reynolds sobre a eficiência do processo de deslocamento.

Para proceder a uma análise mais quantitativa do processo vamos analisar a eficiência do deslocamento, conforme definido nas equações (28) e (29) do capitulo 2.

Nas figuras seguintes, são apresentados de forma quantitativa os resultados de todas essas simulações, lembrando que para um deslocamento totalmente eficiente o valor da eficiência é igual a 1.

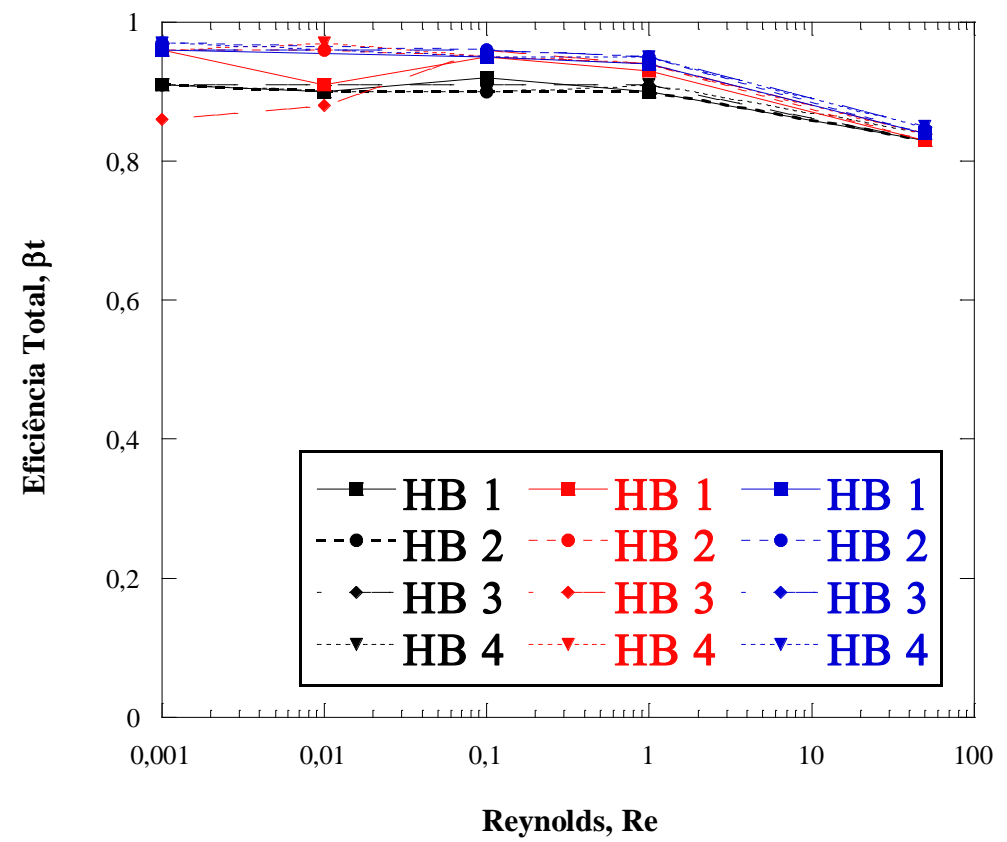

Figura 22 - Eficiência total nas três geometrias (preto: geometria 1; vermelho: geometria 2; azul: geometria 3) para diferentes Reynolds e números Herschel-Bulkley. 
A Figura 22 mostra a eficiência em toda a tubulação e a Figura 23 mostra a eficiência na região erodida, nas três geometrias testadas. As curvas de cor azul representam a eficiência na geometria três $(L / D=1,5)$, as curvas de cor vermelha representam os resultados da eficiência na geometria dois $(\mathrm{L} / \mathrm{D}=1)$, e as pretas representam a geometria um $(\mathrm{L} / \mathrm{D}=0,5)$.

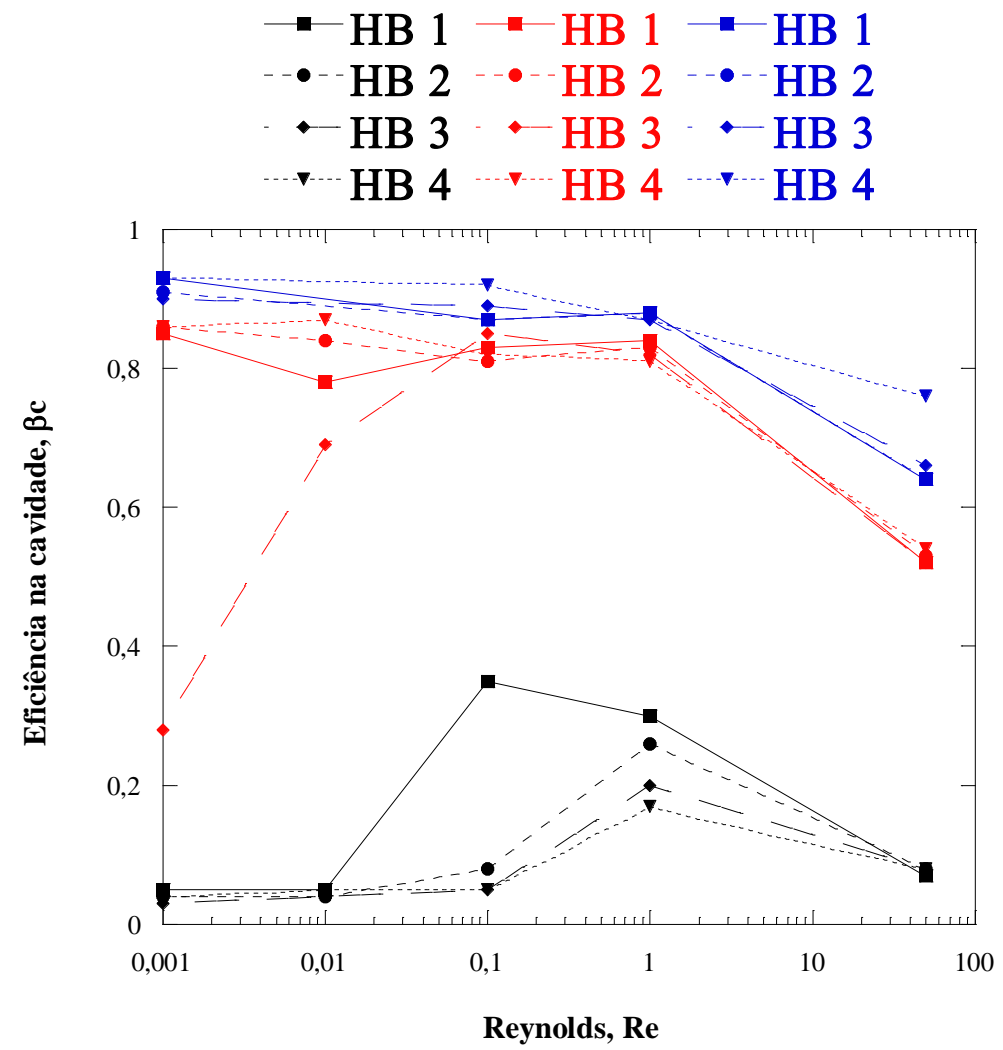

Figura 23 - Eficiência na cavidade nas três geometrias para diferentes Reynolds.

Tanto na Figura 22 como na Figura 23 mostra-se que a eficiência de deslocamento é maior na geometria três que nas outras duas geometrias. Além disso, na Figura 23 observa-se que a eficiência na cavidade da geometria um é muito menor em comparação com as outras duas geometrias. Pode-se notar também que a eficiência varia pouco nos casos de números de Reynolds mais baixos, aumenta quando Reynolds é próximo de um e em seguida há uma queda para valores mais elevados de Reynolds. Esta variação está associada ao efeito da inércia, que empurra o fluido deslocador para a região próxima a parede, deixando uma parte do fluido a ser deslocado estagnado. À medida que a inércia predomina, o fluido deslocador começa a entrar na cavidade em posições mais a jusante, 
fazendo com que a eficiência volte a cair. Nota-se que a variação da eficiência é mais acentuada na região erodida, que é a zona de maior interesse deste trabalho.

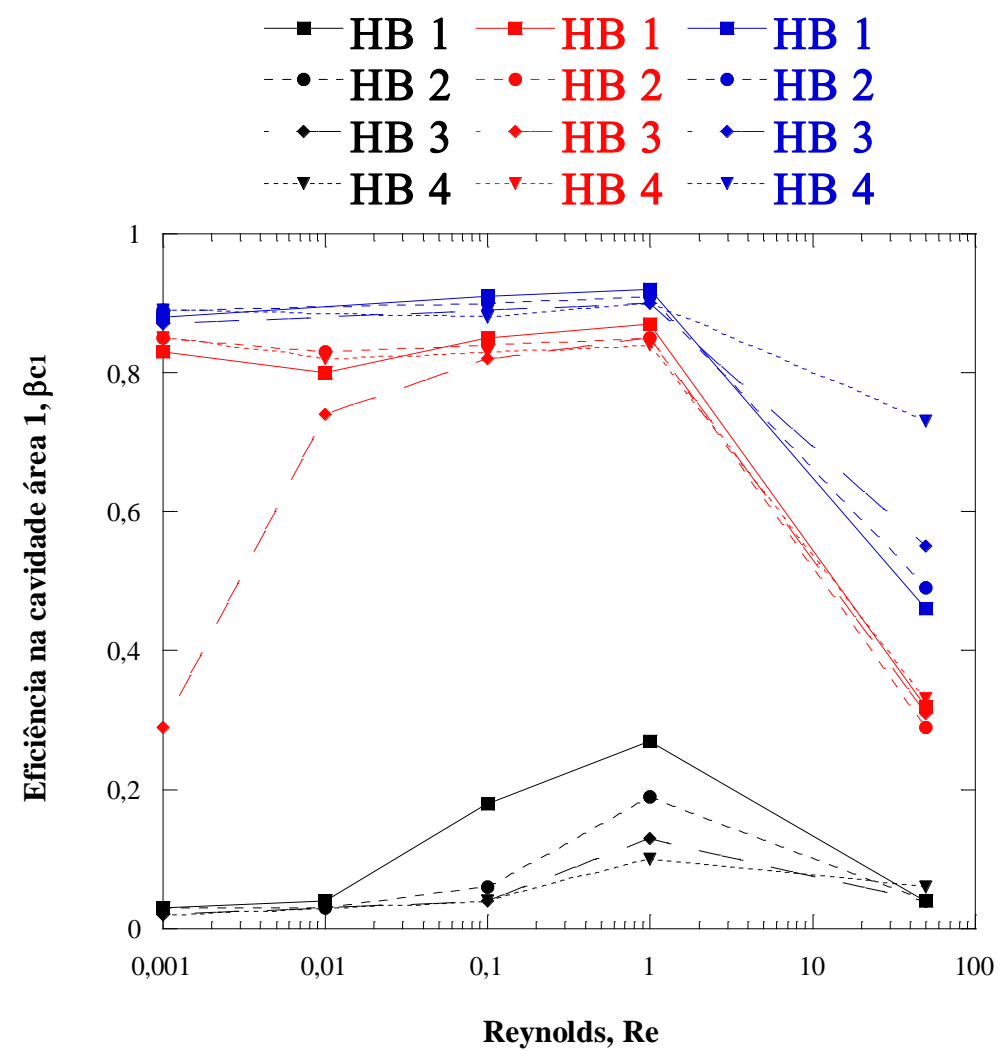

Figura 24 - Eficiência na cavidade da área 1 nas três geometrias para diferentes Reynolds.

As Figuras 24 e 25 nos permitem observar a eficiência nas áreas 1 (a esquerda da cavidade) e 2 (a direita da cavidade), mostrando de forma geral o mesmo comportamento na cavidade e na tubulação. Mas estes resultados permitem avaliar a simetria com relação ao eixo central. Pode-se observar que para Reynolds muito alto $(\operatorname{Re}=50)$ e maiores $L / D$, a eficiência na área 1 da cavidade (esquerda) é menor do que a eficiência para a área 2, que permanece praticamente constante. 


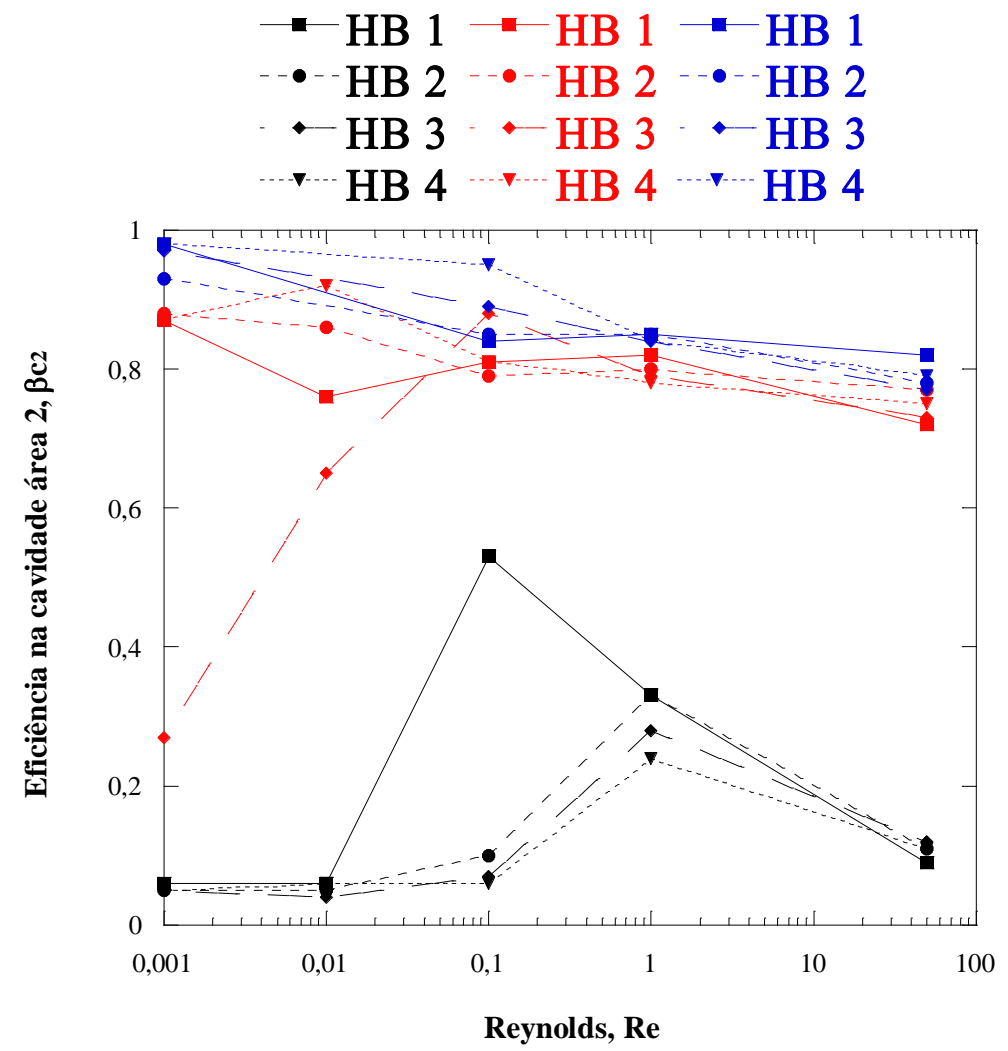

Figura 25 - Eficiência na cavidade da área 2 nas três geometrias para diferentes Reynolds.

As figuras seguintes mostram a eficiência na cavidade em função da geometria. A Figura 26 apresenta o comportamento da eficiência para o valor do Reynolds baixo $(\operatorname{Re}=0,001)$.

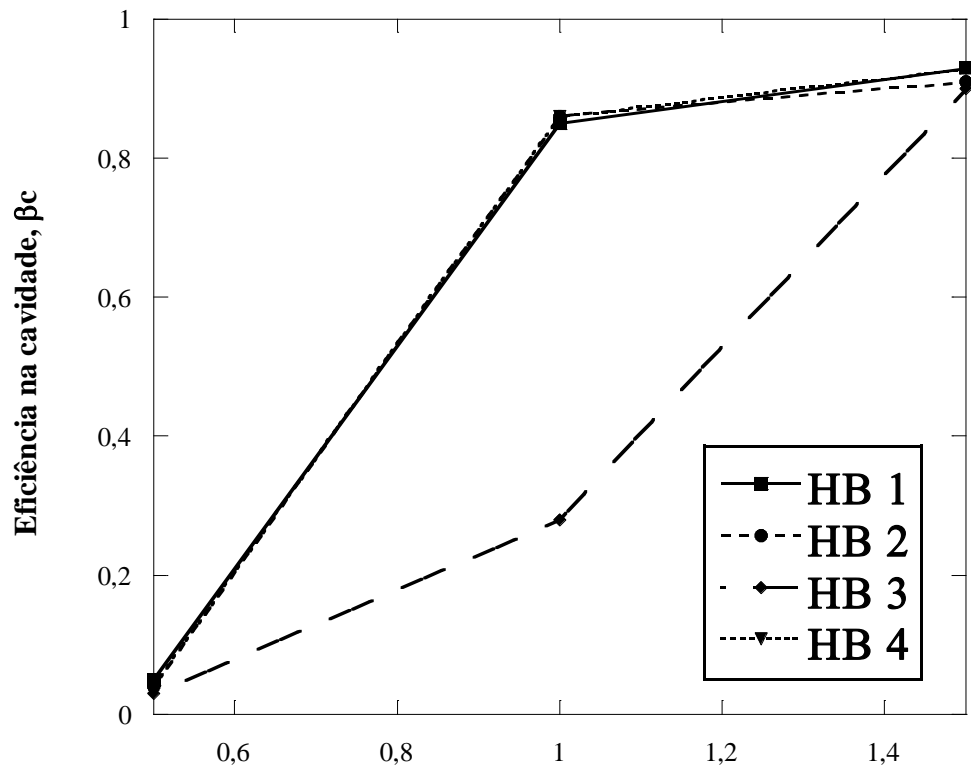

Relação comprimento e diâmetro, (L/D)

Figura 26 - Eficiência na cavidade com relação ao comprimento e diâmetro para Reynolds muito baixos $(\operatorname{Re}=0,001)$. 
Na figura anterior se pode ver que a eficiência cresce à medida que a relação do comprimento e diâmetro também aumenta.

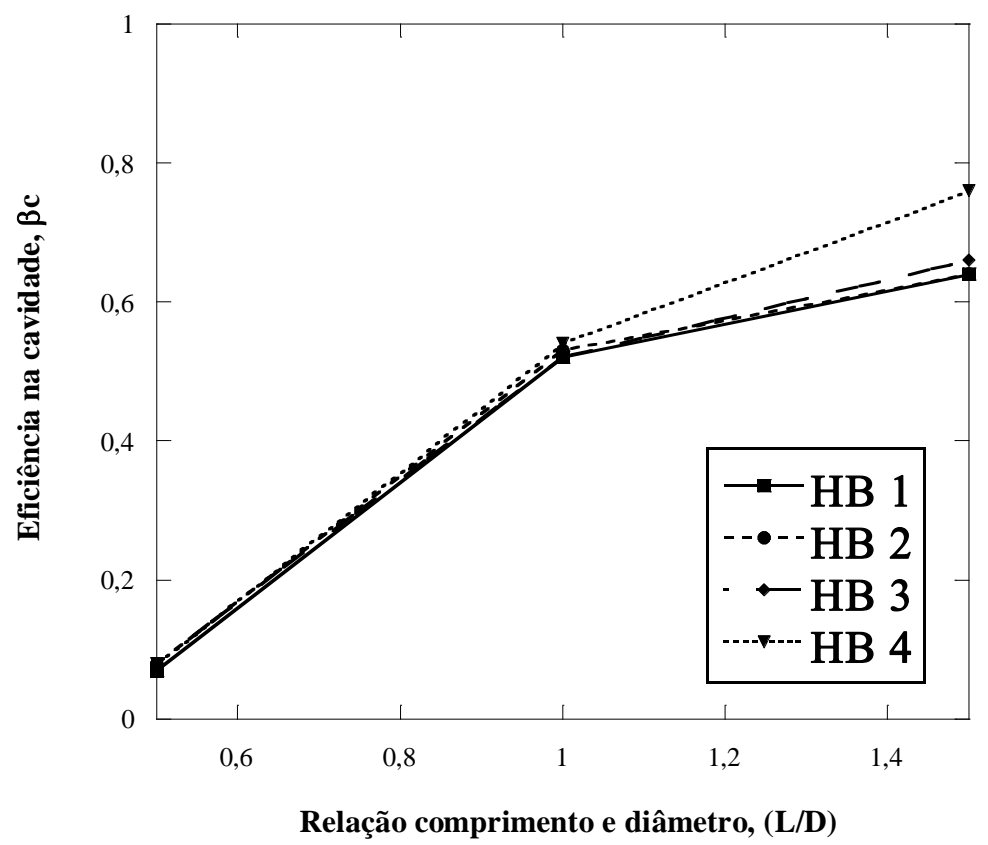

Figura 27 - Eficiência na cavidade com relação ao comprimento e diâmetro para Reynolds alto $(\mathrm{Re}=50)$.

A eficiência na cavidade em função de $\mathrm{L} / \mathrm{D}$ para $\mathrm{Re}=50$ é mostrada na Figura 27. Observa-se mais claramente o aumento da eficiência com L/D, e o pouco efeito da tensão limite de escoamento.

\section{2}

\section{Glicerina deslocando Carbopol}

O segundo caso estudado teve como fluido deslocador a Glicerina e como fluido deslocado o Carbopol. A Glicerina tem um comportamento Newtoniano e tem alta viscosidade, mas o Carbopol, como no primeiro caso, tem um comportamento não Newtoniano viscoplástico. A densidade e os parâmetros reológicos destes dois fluidos utilizados são:

- Glicerina: a densidade $\rho=1259,9 \mathrm{~kg} / \mathrm{m}^{3}$ e a viscosidade $\mu=0,799$ Pa.s. 
- Carbopol 0,1\%: a densidade $\rho=1000 \mathrm{~kg} / \mathrm{m}^{3}$, a tensão limite de escoamento $\tau_{\mathrm{y}}=0,30451 \mathrm{~Pa}$, o índice de consistência $\mathrm{k}=0,55653$ Pa.s ${ }^{\mathrm{n}}$ e o índice Power-Law $\mathrm{n}=0,44633$.

As simulações feitas neste caso foram para três números distintos de Reynolds e três valores diferentes de tensões limites de escoamento do Carbopol a fim de achar os efeitos causados por estas duas propriedades no processo de deslocamento. As tensões limites de escoamento utilizadas nas simulações foram: $\tau_{\mathrm{y}}=0,91353 \mathrm{~Pa} ; \tau_{\mathrm{y}}=1,52255 \mathrm{~Pa}$ e $\tau_{\mathrm{y}}=2 \mathrm{~Pa}$ e os números de Reynolds foram: $\mathrm{Re}$ $=0,001 ; \operatorname{Re}=0,1 ; \mathrm{e} \operatorname{Re}=25$.

A partir dos dados anteriores se calculam os números Herschel-Bulkley HB 1, HB 2 e HB 3 com três valores diferentes de tensões limites de escoamento e três valores distintos do número de Reynolds como se mostra na Tabela 6 abaixo.

\begin{tabular}{|c|c|c|c|}
\hline \multicolumn{4}{|c|}{ Número Herschel Bulkley HB $=\frac{\boldsymbol{\tau}_{\mathbf{y}} \mathbf{D}_{\mathbf{h}}}{\boldsymbol{\mu}_{\mathbf{2}} \overline{\mathbf{u}}}$} \\
\hline $\begin{array}{c}\text { Tensão } \\
\text { Limite de } \\
\text { Escoamento } \\
/ \text { Reynolds }\end{array}$ & HB 1 & HB 2 & HB 3 \\
$\mathbf{R e}=\mathbf{0 , 0 0 1}$ & 8,58 & 5,55 & $\begin{array}{c}\text { HB } \\
\boldsymbol{\tau}_{\mathbf{y}}=2 \mathrm{~Pa}\end{array}$ \\
\hline $\mathbf{R e}=\mathbf{0 , 1}$ & 3,84 & 3,08 & 4,35 \\
\hline $\mathbf{R e}=\mathbf{2 5}$ & 0,49 & 0,48 & 2,67 \\
\hline
\end{tabular}

Tabela 6 - Números Herschel-Bulkley para o caso entre o Carbopol e a Glicerina.

A densidade da Glicerina é $\rho=1259,9 \mathrm{~kg} / \mathrm{m}^{3}$, e a do Carbopol é $\rho=1000$ $\mathrm{kg} / \mathrm{m}^{3}$, então para este segundo caso temos como razão de densidade o seguinte:

$$
\rho^{*}=\frac{\rho_{2}}{\rho_{1}} \rightarrow \rho^{*}=\frac{1259,9 \mathrm{~kg} / \mathrm{m}^{3}}{1000 \mathrm{~kg} / \mathrm{m}^{3}} \rightarrow \rho^{*}=1,2599
$$

A razão de densidade é maior a 1 , razões de densidade maiores que implicariam interfaces plug mais acentuadas. 


\begin{tabular}{|c|c|c|c|}
\hline \multicolumn{4}{|c|}{ Razões de viscosidades $\left(\boldsymbol{\mu}^{*}=\boldsymbol{\mu}_{/} \boldsymbol{\eta}_{\mathbf{c}}\right)$} \\
\hline $\begin{array}{c}\text { Número } \\
\text { Herschel- } \\
\text { Bulkley / } \\
\text { Reynolds }\end{array}$ & HB 1 & HB 2 & HB 3 \\
\hline $\mathbf{R e}=\mathbf{0 , 0 0 1}$ & 0,07435 & 0,04810 & 0,03768 \\
\hline $\mathbf{R e}=\mathbf{0 , 1}$ & 3,32545 & 2,67306 & 2,31674 \\
\hline $\mathbf{R e}=\mathbf{2 5}$ & 106,3327 & 103,1139 & 100,7236 \\
\hline
\end{tabular}

Tabela 7 - Razões de viscosidades entre o Carbopol e a Glicerina.

Observando a Tabela 7 acima, é possível visualizar que à medida que se aumenta o número Herschel-Bulkley o que significa, também o aumento da tensão limite de escoamento, a razão de viscosidade diminui. Porém, número de Reynolds maiores levam ao aumento na razão de viscosidades. A Figura 28 mostra a variação da razão de viscosidades com a taxa de deformação. Observa-se que para altas taxas de deformação (altas vazões) a razão de viscosidade cresce exponencialmente.

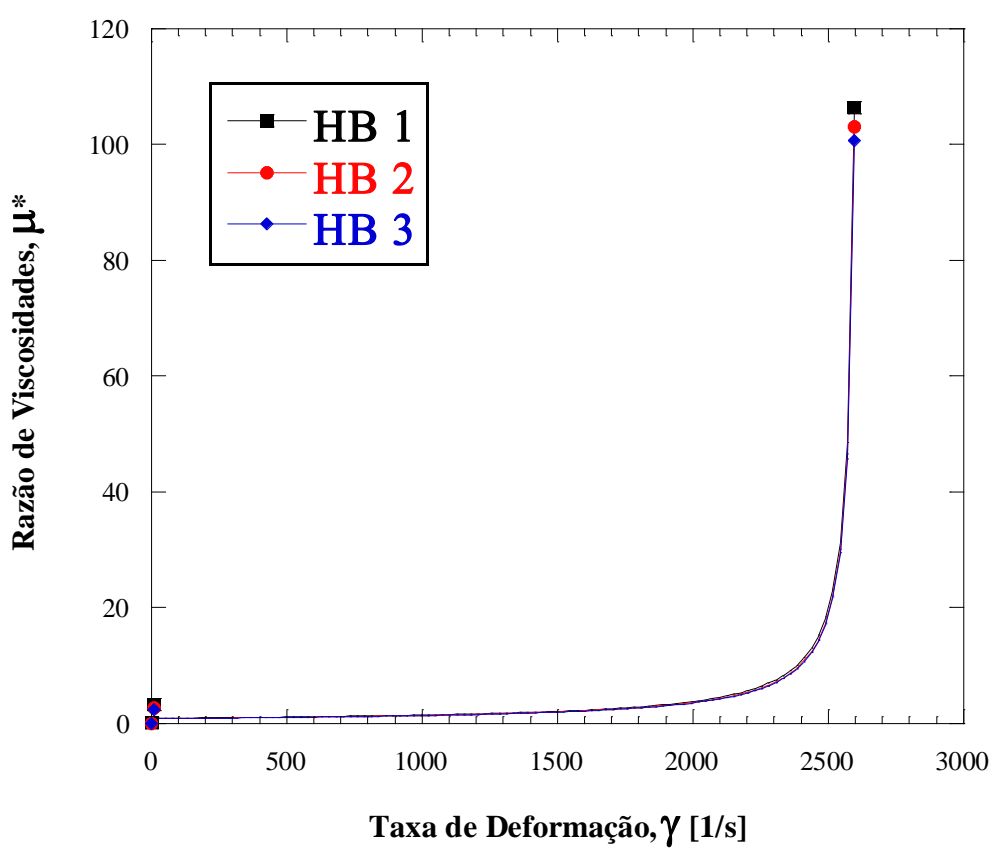

Figura 28 - Razões de viscosidades entre o Carbopol e a Glicerina para números Herschel-Bulkley HB 1, HB 2 e HB 3. 


\subsection{1 \\ Glicerina deslocando Carbopol - geometria $1(L / D=0,5)$}

Similar ao estudo feito no caso anterior, serão apresentadas as imagens das frações mássicas das fases e as linhas de corrente dos testes feitos para as três distintas geometrias. As Figuras 29 e 30 mostram as frações mássicas da Glicerina (cor amarela) empurrando o Carbopol (cor vermelha) na geometria 1 para três valores do número Herschel-Bulkley e três valores de números de Reynolds.

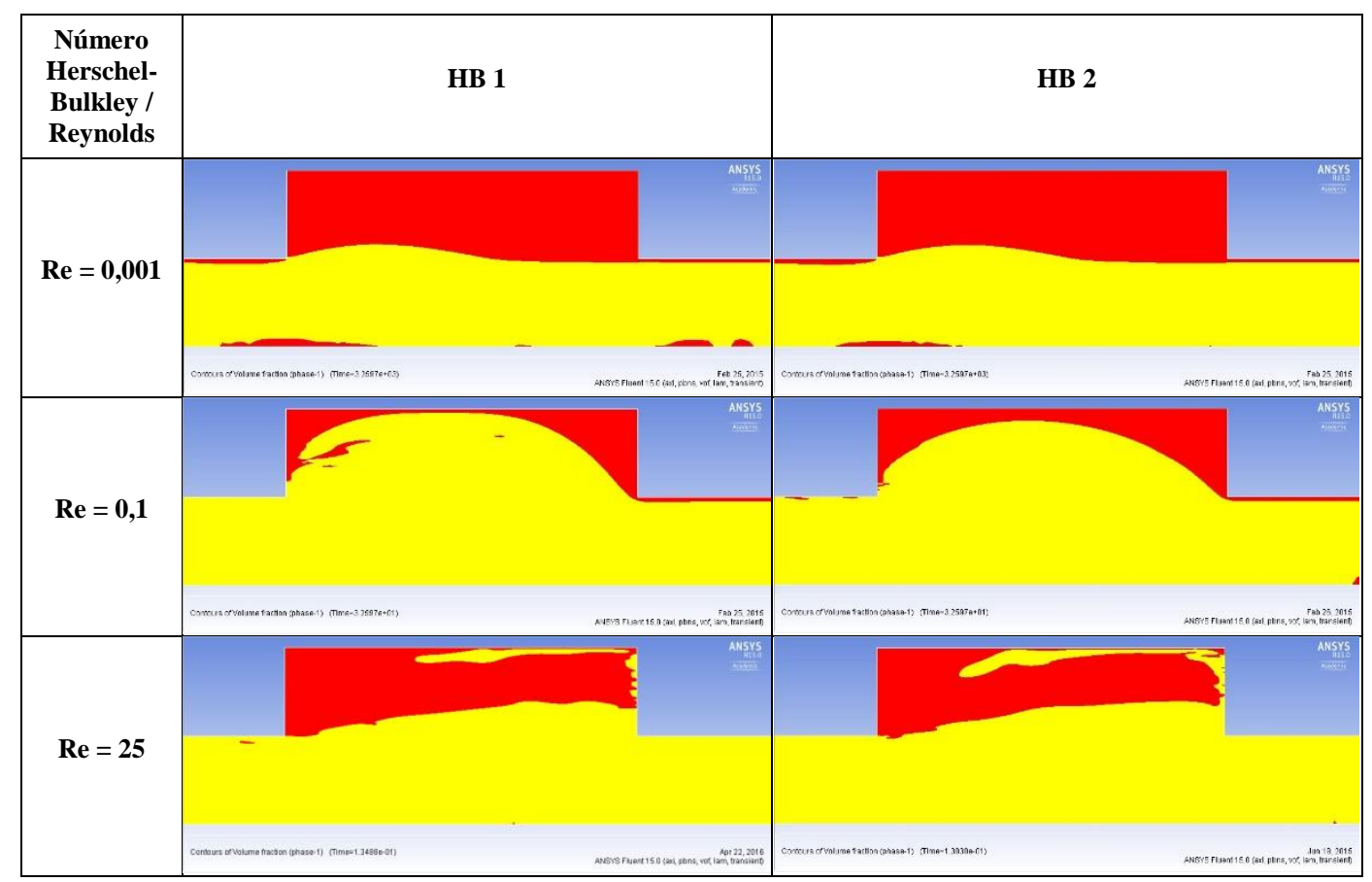

Figura 29 - Deslocamento do Carbopol pela Glicerina para diferentes Reynolds e números Herschel-Bulkley na geometria 1.

As Figuras 29 e 30 mostram claramente que para Reynolds $(\operatorname{Re}=0,1)$ o deslocamento na cavidade é muito melhor do que nos casos de $\operatorname{Re}=0,001$ e $\operatorname{Re}=$ 25. Para os casos de Reynolds muito baixos, as tensões são baixas, e portanto insuficiente para deslocar o Carbopol da cavidade. À medida que as vazões aumentam, as tensões crescem e ultrapassam a tensão limite de escoamento na cavidade, deslocando o Carbopol nesta região. No caso do Reynolds alto $(\operatorname{Re}=$ 25) observa-se o efeito da inércia, que tende a empurrar o fluido deslocador para jusante. Porém, como as tensões são elevadas, a inércia gera a recirculação do Carbopol no interior da cavidade, e o deslocamento é menos eficiente do que no caso de $\operatorname{Re}=0,01$. Esta recirculação pode ser observada com a ajuda das Figuras 31 e 32, que mostram as linhas de corrente para os mesmos casos. Observa-se 
também que o Carbopol fica estagnado na cavidade para números de Reynolds mais baixos, pois as tensões nestas regiões são inferiores às tensões limite de escoamento.

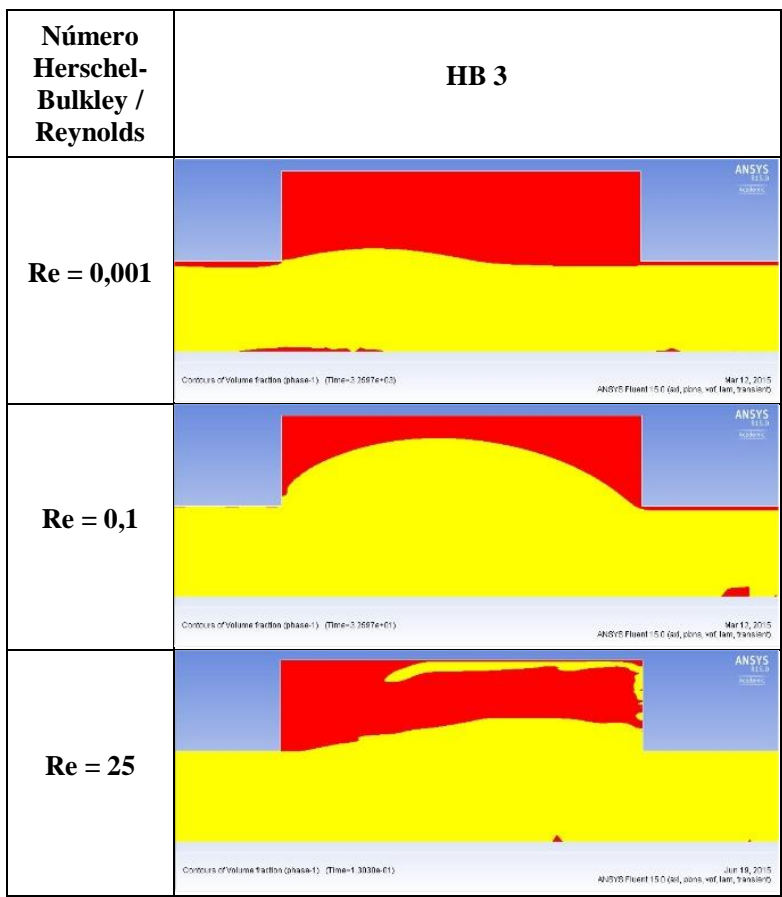

Figura 30 - Deslocamento do Carbopol pela Glicerina para diferentes Reynolds e números Herschel-Bulkley na geometria 1.

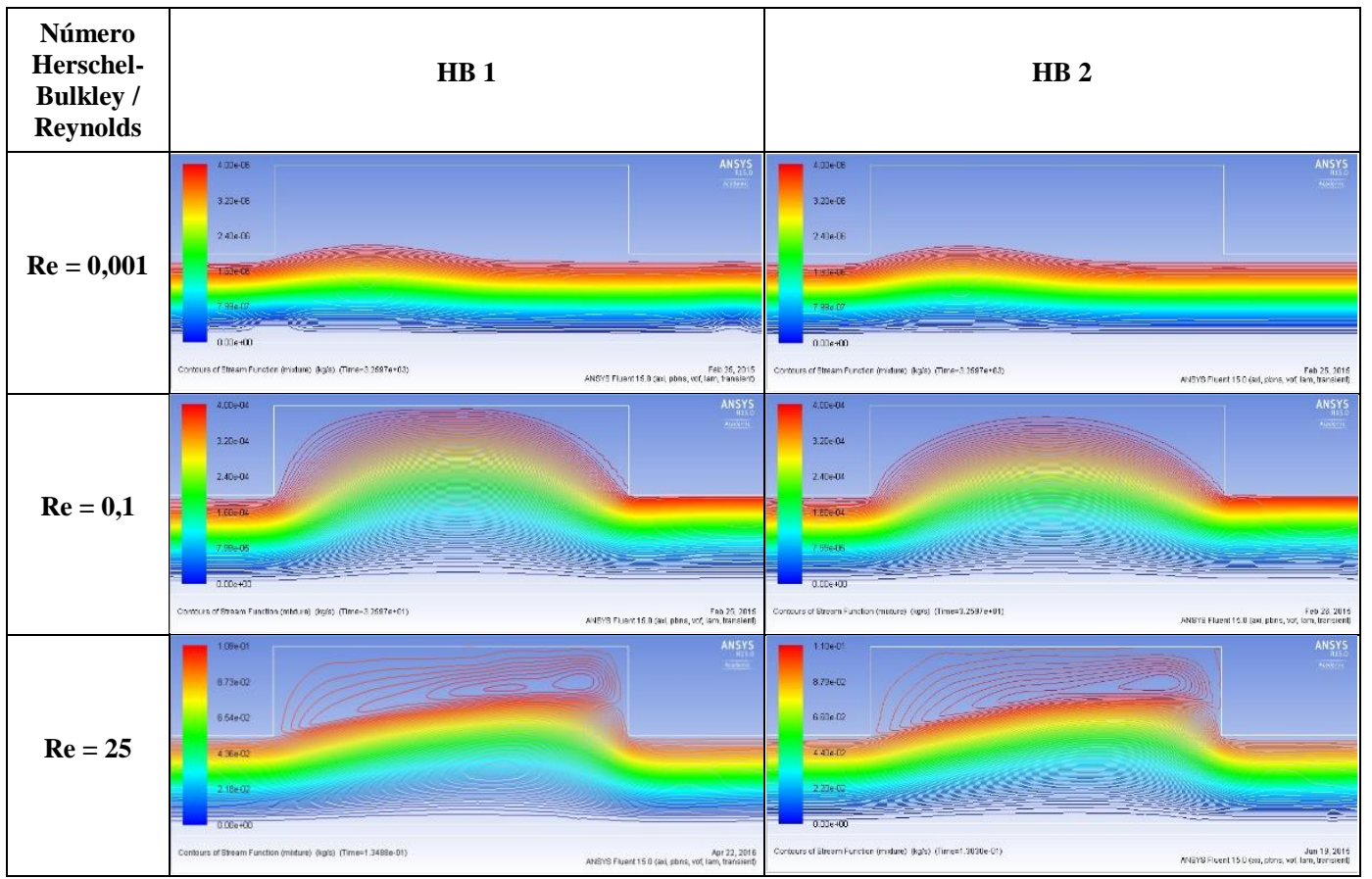

Figura 31 - Linhas de corrente da Glicerina deslocando Carbopol em diferentes Reynolds e números Herschel-Bulkley na geometria 1. 
Capítulo 4 - Resultados

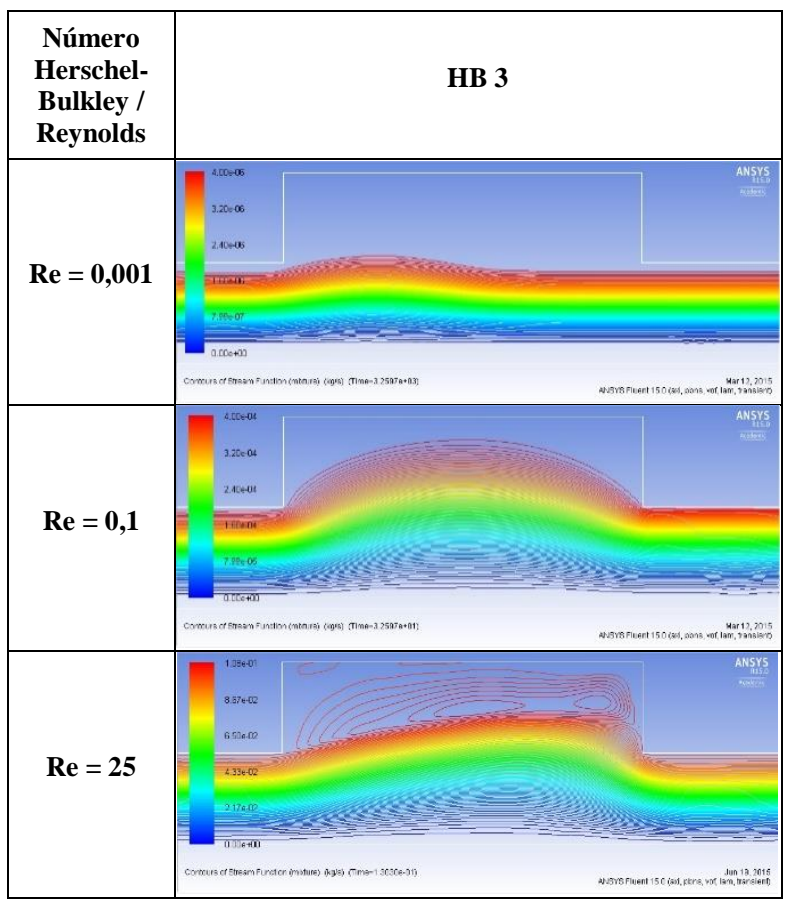

Figura 32 - Linhas de corrente da Glicerina deslocando Carbopol em diferentes Reynolds e números Herschel-Bulkley na geometria 1.

\subsection{2}

Glicerina deslocando Carbopol - geometria $2(L / D=1,0)$

O processo de deslocamento do Carbopol pela Glicerina na geometria 2 é apresentado nas Figuras 33 e 34.

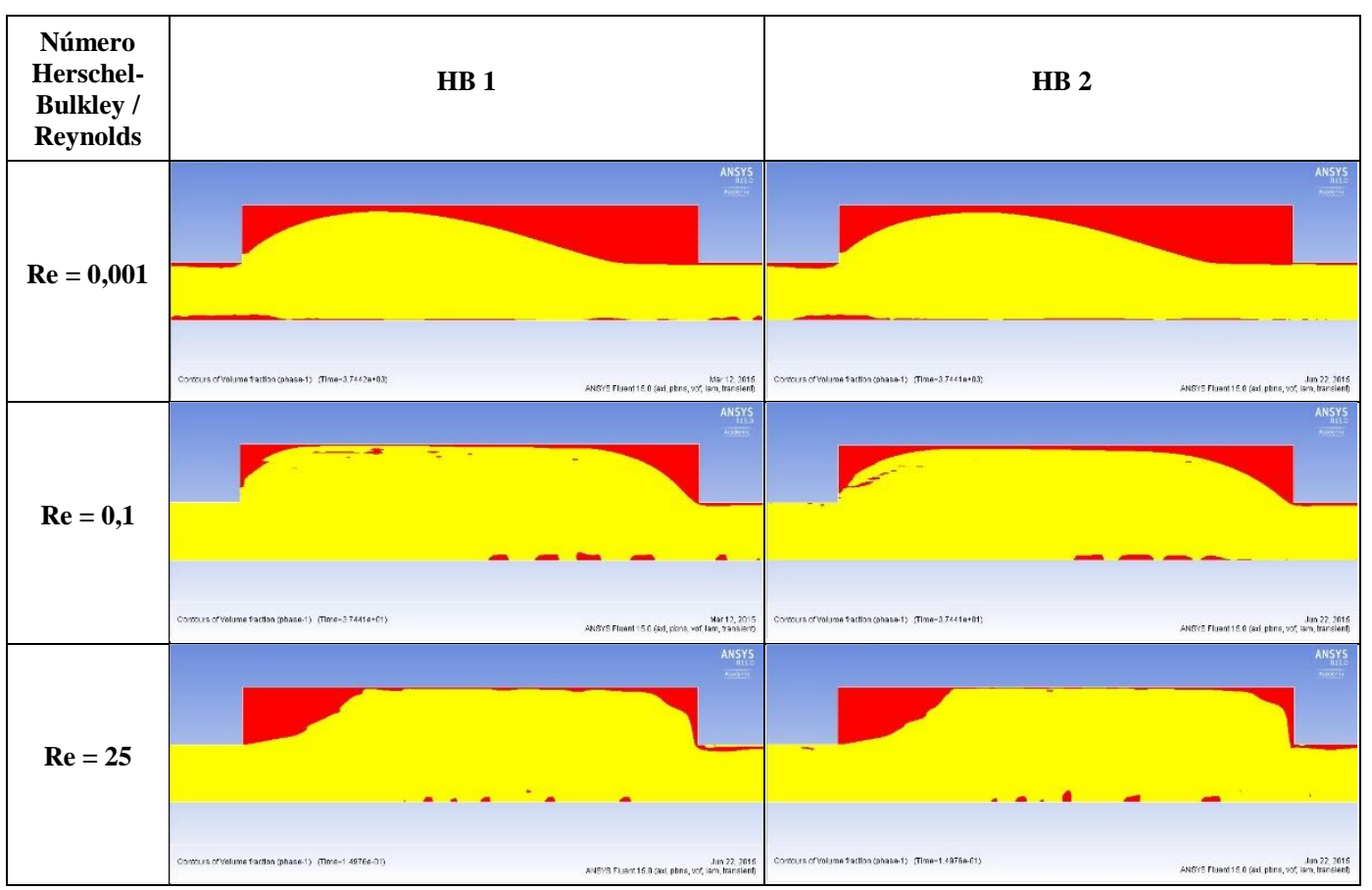

Figura 33 - Deslocamento do Carbopol pela Glicerina para diferentes Reynolds e números Herschel-Bulkley na geometria 2. 


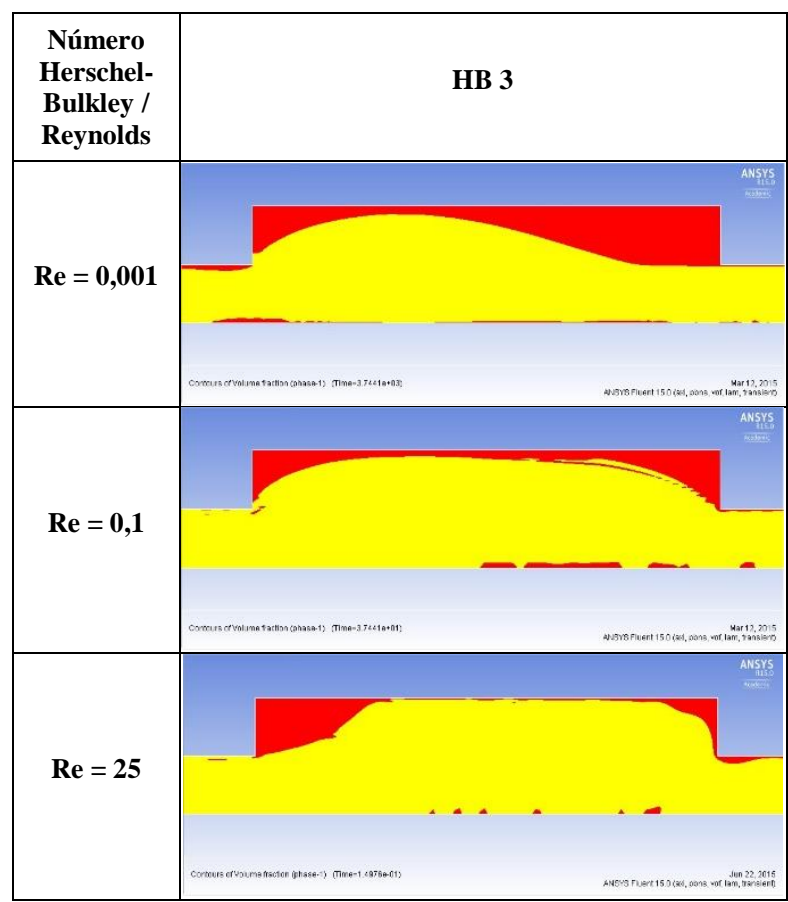

Figura 34 - Deslocamento do Carbopol pela Glicerina para diferentes Reynolds e números Herschel-Bulkley na geometria 2.

Os resultados mostrados nas imagens anteriores mostram que novamente não há alteração significativa no deslocamento com os números de HerschelBulkley na faixa investigada. No entanto, observa-se que para baixos valores de Reynolds a frente de Carbopol é deslocada a esquerda, e à medida que a inércia aumenta, a mesma vai se deslocando na direção da saída da zona erodida. Nota-se também que o processo de deslocamento é mais eficiente do que no caso anterior, $\mathrm{L} / \mathrm{D}=0,5$. A seguir se apresentam as linhas de corrente para a mesma relação $\mathrm{L} / \mathrm{D}$ $=1$.

\begin{tabular}{|c|c|c|c|}
\hline $\begin{array}{c}\text { Número } \\
\text { Herschel- } \\
\text { Bulkley / } \\
\text { Reynolds }\end{array}$ & & HB 1 & \\
\hline \\
$\mathbf{R e}=\mathbf{0 , 0 0 1}$
\end{tabular}




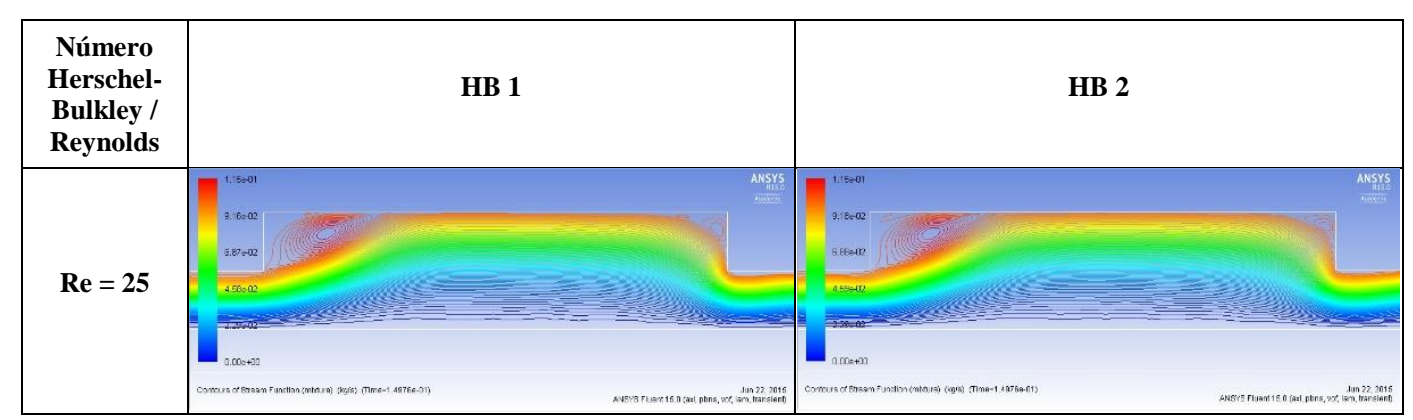

Figura 35 - Linhas de corrente da Glicerina deslocando Carbopol em diferentes Reynolds e números Herschel-Bulkley na geometria 2.

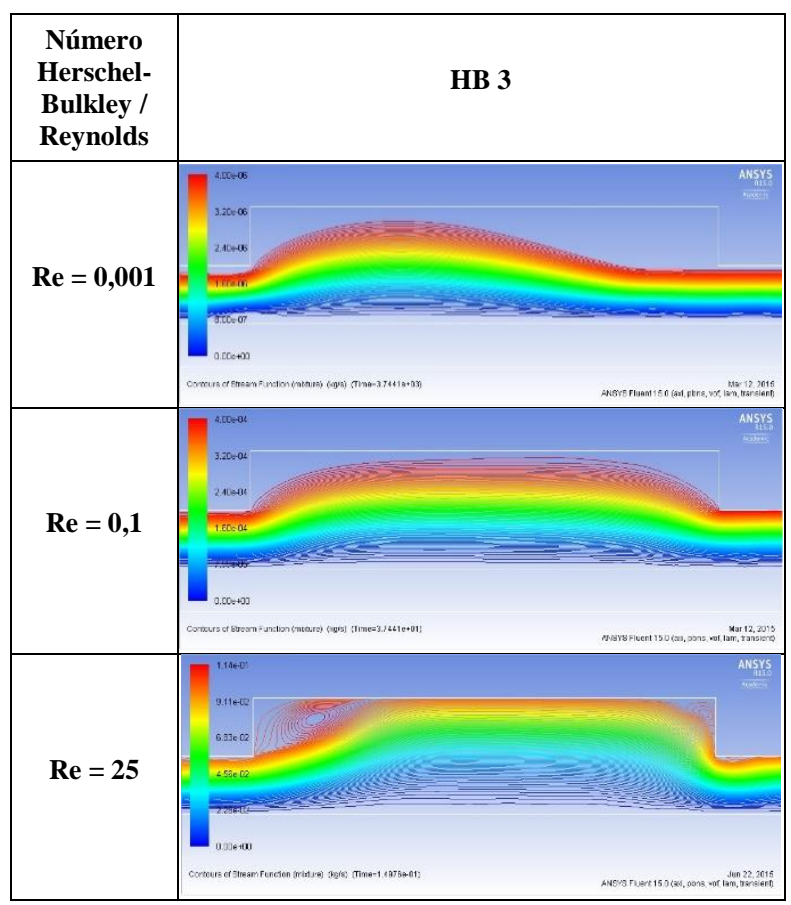

Figura 36 - Linhas de corrente da Glicerina deslocando Carbopol em diferentes Reynolds e números Herschel-Bulkley na geometria 2.

Como foi comentado acima, as linhas de corrente apresentadas nas Figuras 35 e 36 mostram um melhor deslocamento na área 1 da cavidade (a esquerda) que na área 2 (a direita) para o Reynolds baixo $(\operatorname{Re}=0,001)$. À medida que o número de Reynolds cresce, a inércia vai começando a ter influência, e desloca a onda de fluido para jusante. Assim, o caso de $\operatorname{Re}=0,1$ é praticamente simétrico em relação ao eixo central. No caso do Reynolds alto $(\operatorname{Re}=25)$ a inércia tem efeito mais acentuado, e faz com que o deslocamento seja melhor na área 2 da cavidade. Observando-se novamente que para Reynolds baixos as zonas de Carbopol não deslocado estão estagnadas pois as tensões nas regiões não deslocadas são inferiores a tensão limite de escoamento, mas no caso de Reynolds alto, a tensão limite de escoamento é vencida e o fluido, embora preso na cavidade, recircula dentro dela. 


\subsection{3}

\section{Glicerina deslocando Carbopol - geometria $3(L / D=1,5)$}

Nas Figuras 37 e 38 são apresentados os campos de fração mássica da Glicerina deslocando o Carbopol na geometria $3(\mathrm{~L} / \mathrm{D}=1,5)$.

Observa-se novamente que o efeito do número Herschel-Bulkley é muito pequeno, e a inércia tende a empurrar o fluido para a direita, similar ao que ocorre nos casos anteriores.

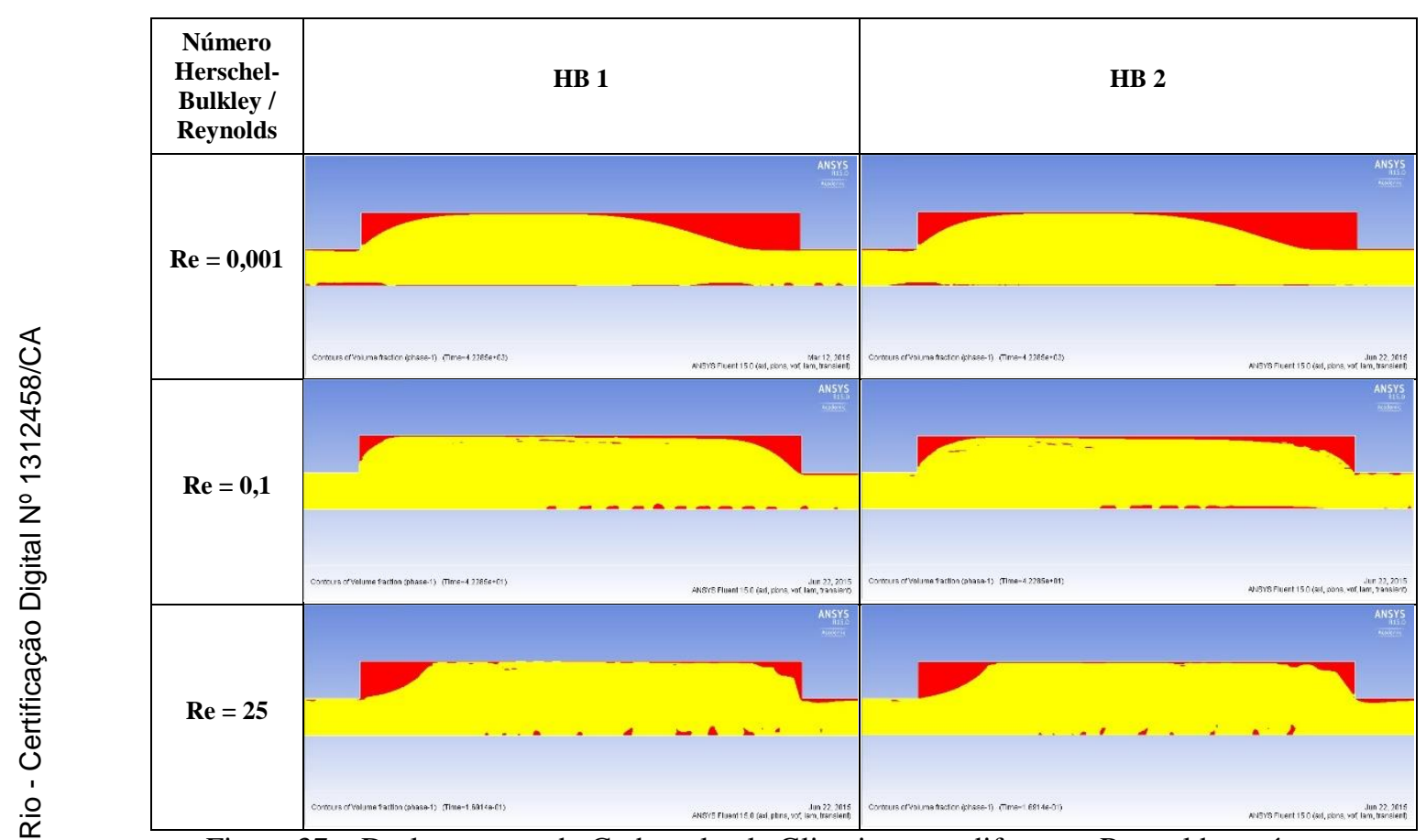

Figura 37 - Deslocamento do Carbopol pela Glicerina para diferentes Reynolds e números Herschel-Bulkley na geometria 3.

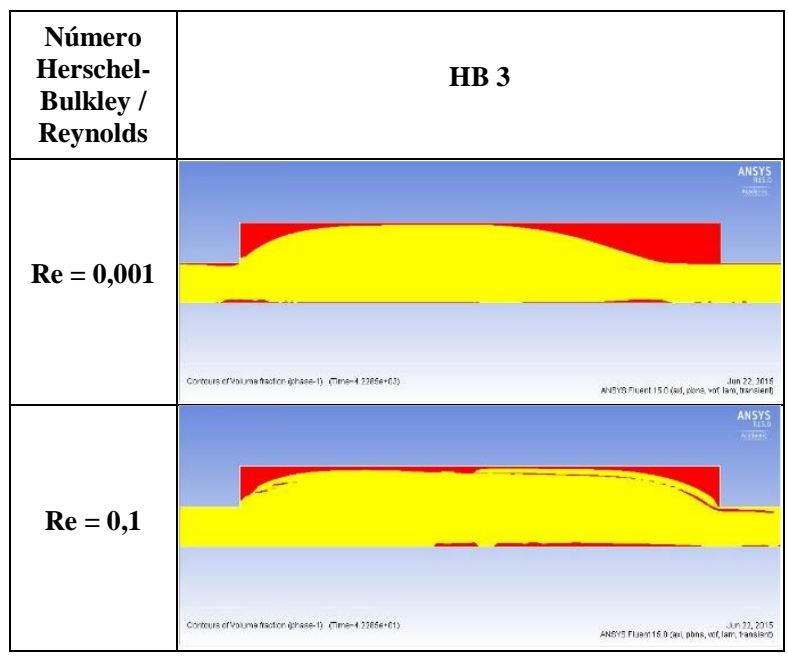




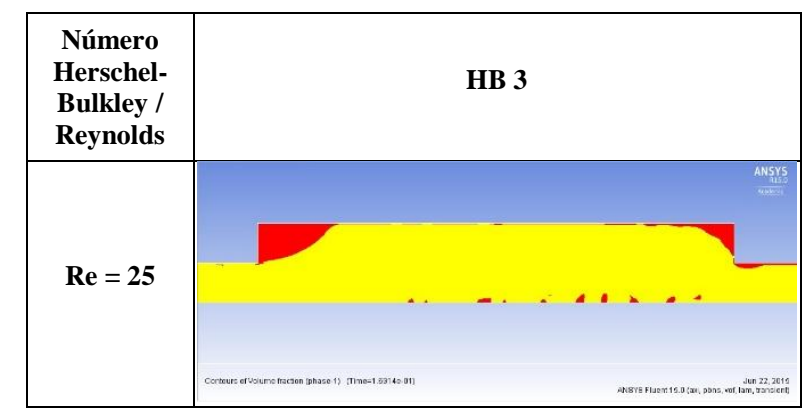

Figura 38 - Deslocamento do Carbopol pela Glicerina para diferentes Reynolds e números Herschel-Bulkley na geometria 3.

As linhas de corrente são mostradas nas Figuras 39 e 40. Mais uma vez, o Carbopol fica estagnado na cavidade nos casos onde Reynolds é mais baixo, e recircula nas zonas não deslocadas para o caso em que $\operatorname{Re}=25$.

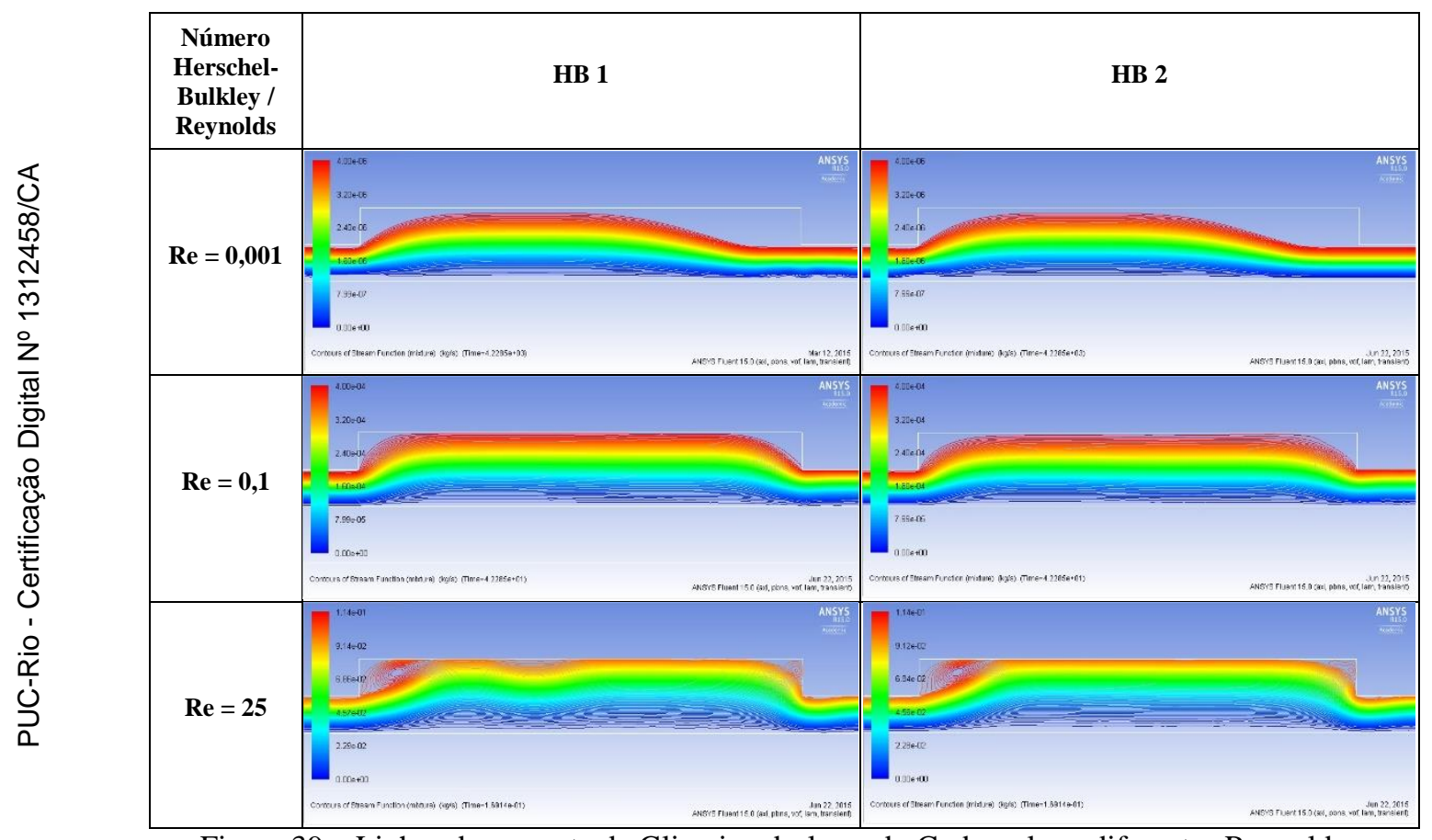

Figura 39 - Linhas de corrente da Glicerina deslocando Carbopol em diferentes Reynolds e números Herschel-Bulkley na geometria 3.

\begin{tabular}{|c|c|}
\hline $\begin{array}{l}\text { Número } \\
\text { Herschel- } \\
\text { Bulkley / } \\
\text { Reynolds }\end{array}$ & HB 3 \\
\hline & 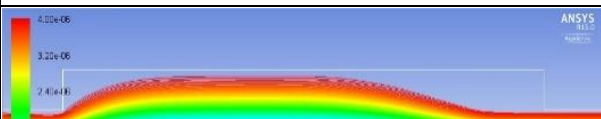 \\
\hline $\operatorname{Re}=0,001$ & 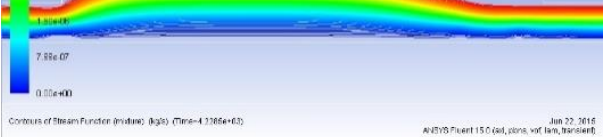 \\
\hline
\end{tabular}




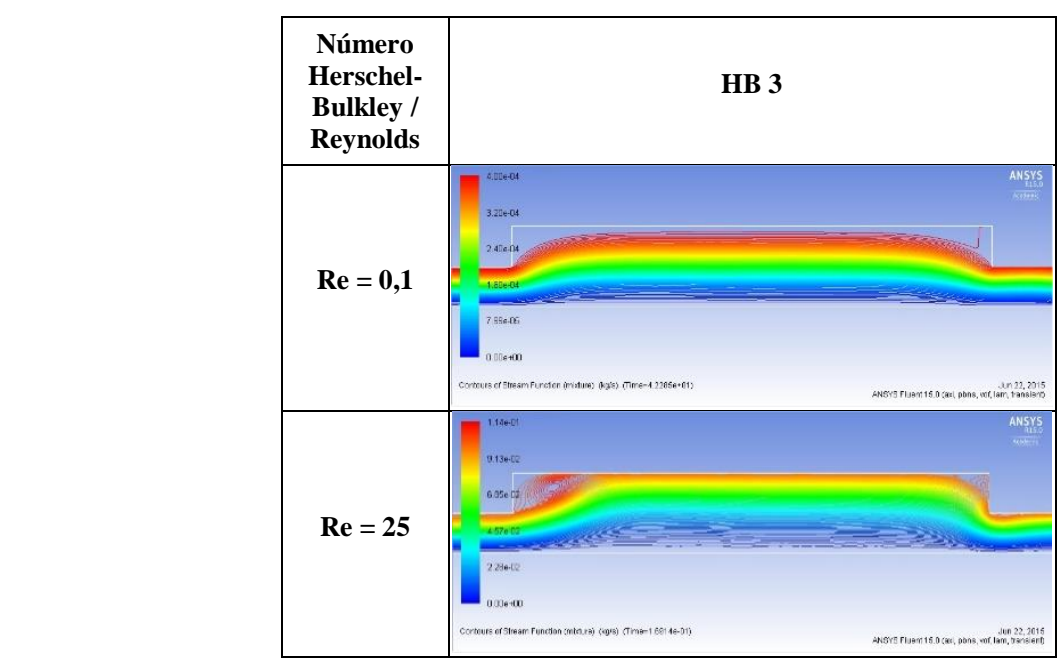

Figura 40 - Linhas de corrente da Glicerina deslocando Carbopol em diferentes Reynolds e números Herschel-Bulkley na geometria 3.

\subsection{4 \\ Eficiências do caso Glicerina deslocando Carbopol}

Apresenta-se agora os resultados da eficiência de deslocamento para os casos analisados de Glicerina deslocando Carbopol, a fim de avaliar os efeitos causados pela geometria, pelo número de Reynolds e pelo número HerschelBulkley.

Similar ao caso anterior do Carbopol empurrando água, a eficiência igual a 1 representa um processo ótimo de deslocamento, e zero significa deslocamento nulo do fluido na cavidade.

Assim, nas figuras a seguir poderemos observar a pouca influência da tensão limite de escoamento contida no número de Herschel-Bulkley na eficiência de deslocamento. Observa-se também que o efeito da geometria é similar aos casos anteriores, i.e., maiores eficiências na cavidade quando as regiões erodidas são mais longas (maiores L/D). Novamente, a eficiência total (cavidade + tubo) varia muito pouco na faixa de parâmetros analisados. Há apenas um pequeno aumento com L/D. A eficiência aumenta um pouco com o número de Reynolds e depois apresenta uma tendência de estabilização e posterior queda, devido ao efeito da inércia. Na região erodida, está variação é mais sentida. Nota-se um aumento até um ponto de máxima eficiência e posterior queda, numa clara competição entre os efeitos da tensão limite e da inércia. 


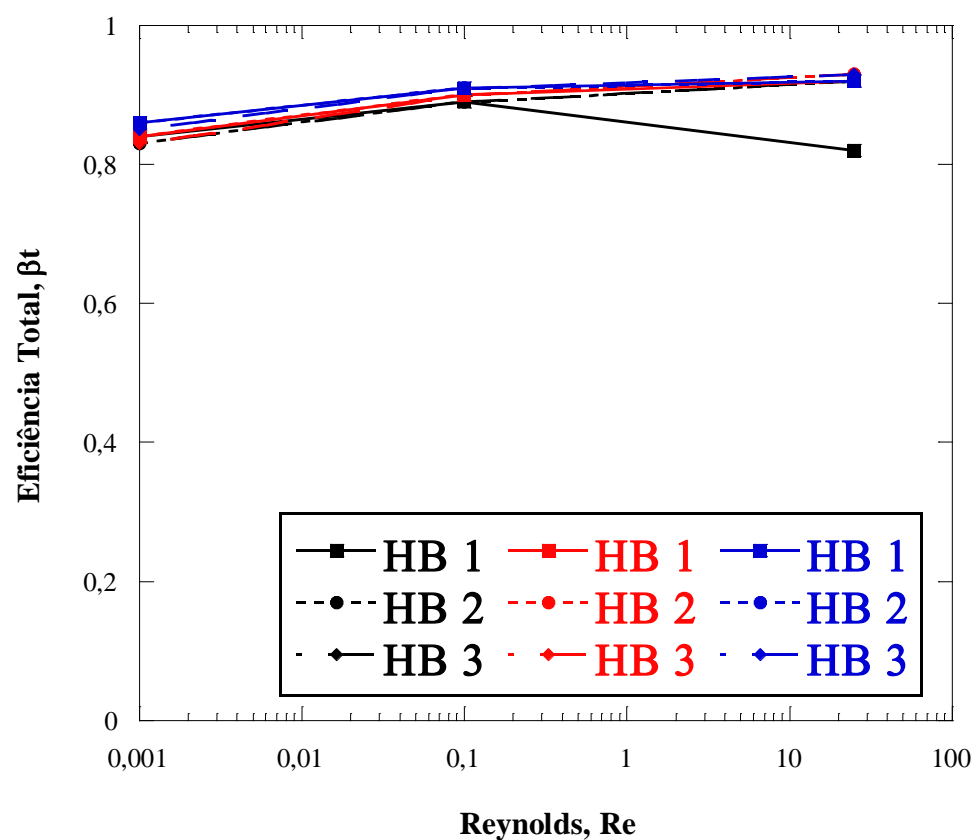

Figura 41 - Eficiência total nas três geometrias para diferentes Reynolds.

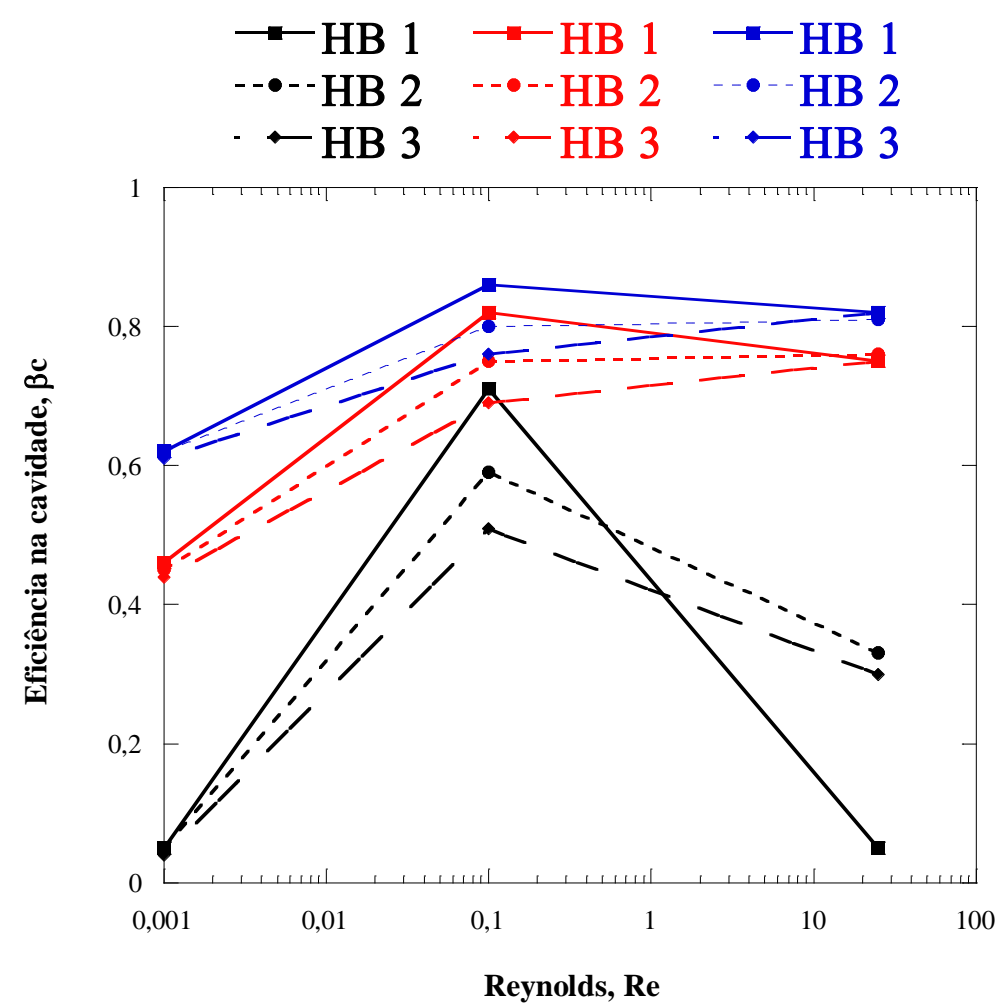

Figura 42 - Eficiência na cavidade nas três geometrias para diferentes Reynolds.

Nas Figuras 43 e 44 se apresentam os resultados da eficiência para as áreas 1 e 2 da cavidade, onde se pode ver, que a eficiência a montante é maior do que a eficiência a jusante nas regiões de Reynolds mais baixo e menor nas regiões de números de Reynolds mais elevados. 


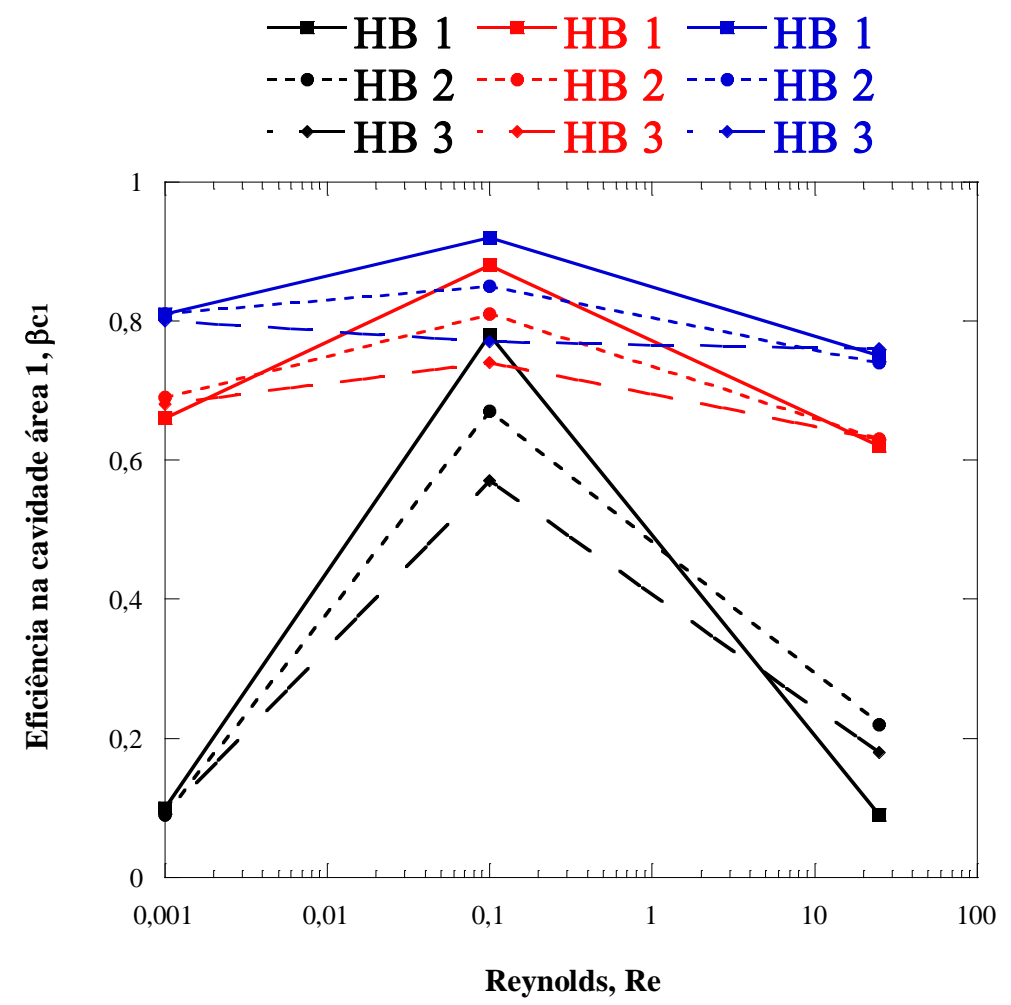

Figura 43 - Eficiência na cavidade da área 1 nas três geometrias para diferentes Reynolds.

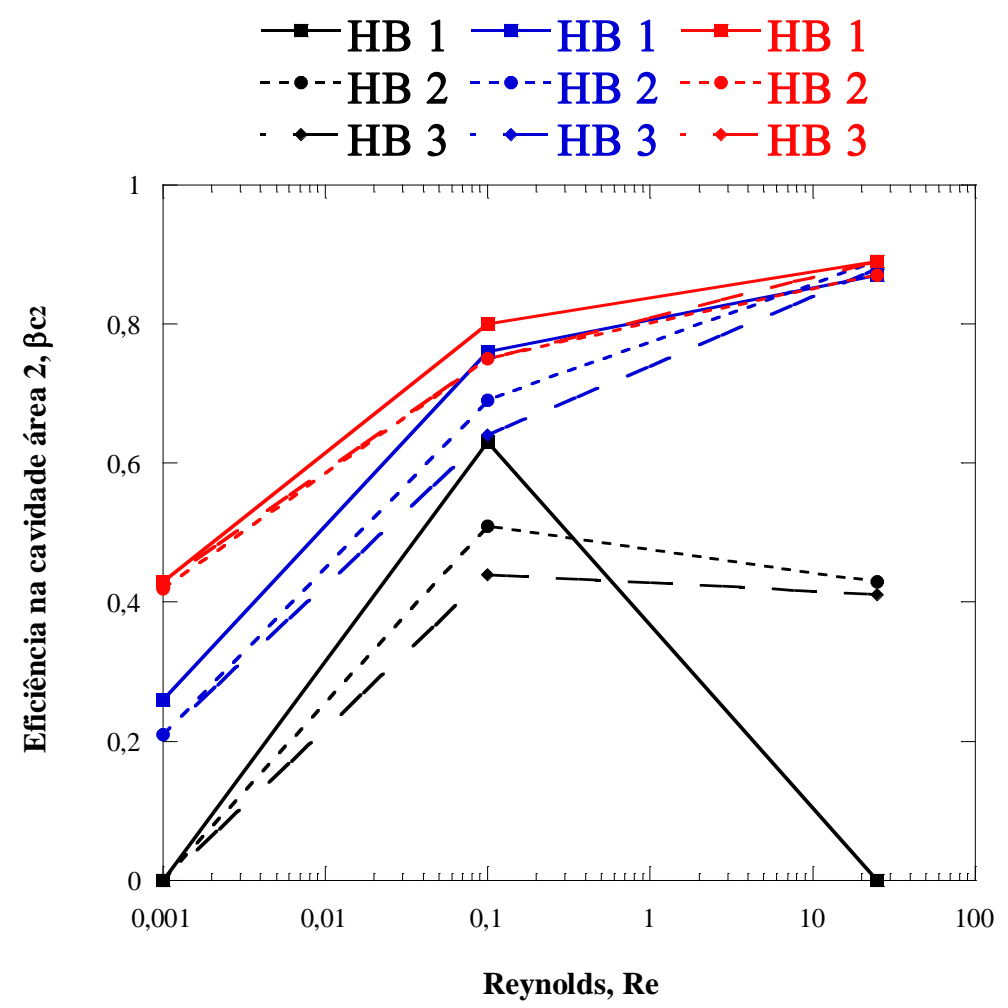

Figura 44 - Eficiência na cavidade da área 2 nas três geometrias para diferentes Reynolds. 


\section{3 \\ Cimento deslocando Fluido de perfuração}

O terceiro caso analisado descreve o deslocamento de um fluido de perfuração, o qual se comporta como um fluido não Newtoniano com comportamento viscoplástico, pelo cimento que também consideraremos como um fluido viscoplástico. Este caso representa mais efetivamente o processo que ocorre no caso real. A densidade e os parâmetros reológicos destes dois fluidos são:

- Cimento: a densidade $\rho=1980 \mathrm{~kg} / \mathrm{m}^{3}$, a tensão limite de escoamento $\tau_{\mathrm{y}}=24 \mathrm{~Pa}$, o índice de consistência $\mathrm{k}=1,062$ Pa. $\mathrm{s}^{\mathrm{n}}$ e o índice PowerLaw $\mathrm{n}=0,605$.

- Fluido de perfuração: a densidade $\rho=1529,7 \mathrm{~kg} / \mathrm{m}^{3}$, a tensão limite de escoamento $\tau_{\mathrm{y}}=0,8 \mathrm{~Pa}$, o índice de consistência $\mathrm{k}=0,365 \mathrm{~Pa} \cdot \mathrm{s}^{\mathrm{n}}$ e o índice Power-Law $n=0,657$.

Neste caso foi definido um outro parâmetro adimensional para o problema, a relação entre a tensão limite de escoamento do cimento e a tensão limite de escoamento do fluido de perfuração, como se mostra na equação (27):

$$
\tau_{\mathrm{y}}^{*}=\frac{\tau_{\mathrm{yc}}}{\tau_{\mathrm{yfp}}}
$$

Onde,

- Razão entre tensões limite de escoamento: $\tau_{\mathrm{y}}^{*}$;

- Tensão limite de escoamento do cimento: $\tau_{\mathrm{yc}}$;

- Tensão limite de escoamento do fluido de perfuração: $\tau_{\mathrm{yfp}}$;

Os valores da tensão limite de escoamento para o cimento e o fluido de perfuração foram obtidos de ensaios experimentais em fluidos reais, e são dados por: $\tau_{\mathrm{yc}}=24 \mathrm{~Pa}$ e $\tau_{\mathrm{yfp}}=0,8 \mathrm{~Pa}$, respectivamente. Desta forma, foram escolhidos três diferentes valores da razão de tensão limite de escoamento, a fim de analisar a influência deste parâmetro no escoamento:

$$
\begin{aligned}
\tau_{\mathrm{y}}^{*} & =15, \\
\tau_{\mathrm{y}}^{*} & =30,
\end{aligned}
$$




$$
\text { e } \tau_{\mathrm{y}}^{*}=60 \text {. }
$$

Para este último caso de estudo foram feitas simulações para diferentes valores de Reynolds e razões de tensões limites de escoamento, a fim de avaliar os efeitos causados por estas duas propriedades no processo de deslocamento. As tensões limites de escoamento característico utilizadas nas simulações foram: $\tau_{\mathrm{y}}^{*}=$ $15 \mathrm{~Pa} ; \tau_{\mathrm{y}}^{*}=30 \mathrm{~Pa}$ e $\tau_{\mathrm{y}}^{*}=60 \mathrm{~Pa}$ e os valores de Reynolds foram: $\operatorname{Re}=0,001 ; \operatorname{Re}=$ 0,1 e $\operatorname{Re}=50$.

Assim, lembrando que a densidade do fluido de perfuração é $\rho=1529,7$ $\mathrm{kg} / \mathrm{m}^{3}$, e a do cimento é $\rho=1980 \mathrm{~kg} / \mathrm{m}^{3}$, então neste último caso temos a seguinte razão de densidade:

$$
\rho^{*}=\frac{\rho_{2}}{\rho_{1}} \rightarrow \rho^{*}=\frac{1980 \mathrm{~kg} / \mathrm{m}^{3}}{1529,7 \mathrm{~kg} / \mathrm{m}^{3}} \rightarrow \rho^{*}=1,2944
$$

A razão de densidade é maior a 1, o que significa que o fluido deslocador tem maior densidade do que o deslocado, o que tende a gerar interfaces plug mais acentuadas.

Na Tabela 8 mostram-se os resultados das razões de viscosidades para os três casos de tensões limite de escoamento característico e para os três diferentes números de Reynolds. Pode-se notar que na medida que a razão entre as tensões limite de escoamento característico aumenta, a razão de viscosidade aumenta, enquanto que quando o número de Reynolds aumenta, a razão de viscosidade também diminui.

\begin{tabular}{|c|c|c|c|}
\hline \multicolumn{4}{|c|}{ Razões de viscosidades $\left(\boldsymbol{\mu}^{*}=\boldsymbol{\eta}_{\mathbf{c}} / \boldsymbol{\eta}_{\mathbf{f}}\right)$} \\
\hline $\begin{array}{c}\text { Tensão Limite de } \\
\text { Escoamento } \\
\text { Característico } / \\
\text { Reynolds }\end{array}$ & $\boldsymbol{\tau}_{\mathbf{y c}}=12$ e $\boldsymbol{\tau}_{\mathbf{y f}}=0,80$ & $\boldsymbol{\tau}_{\mathbf{y c}}=24$ e $\boldsymbol{\tau}_{\mathbf{y f}}=0,80$ & $\boldsymbol{\tau}_{\mathbf{y c}}^{*}=24$ e $\boldsymbol{\tau}_{\mathbf{y f}}=0,40$ \\
\hline $\mathbf{R e}=\mathbf{0 , 0 0 1}$ & 10,99644 & 19,83102 & 29,28611 \\
\hline $\mathbf{R e}=\mathbf{0 , 1}$ & 6,34393 & 9,87309 & 11,45667 \\
\hline $\mathbf{R e}=\mathbf{5 0}$ & 2,58287 & 3,05780 & 3,11379 \\
\hline
\end{tabular}

Tabela 8 - Razões de viscosidades entre o Fluido de perfuração e o Cimento. 
A Figura 45 confirma o comportamento exposto no parágrafo anterior e ainda exibe o comportamento decrescente da razão de viscosidade à medida que a taxa de deformação aumenta.

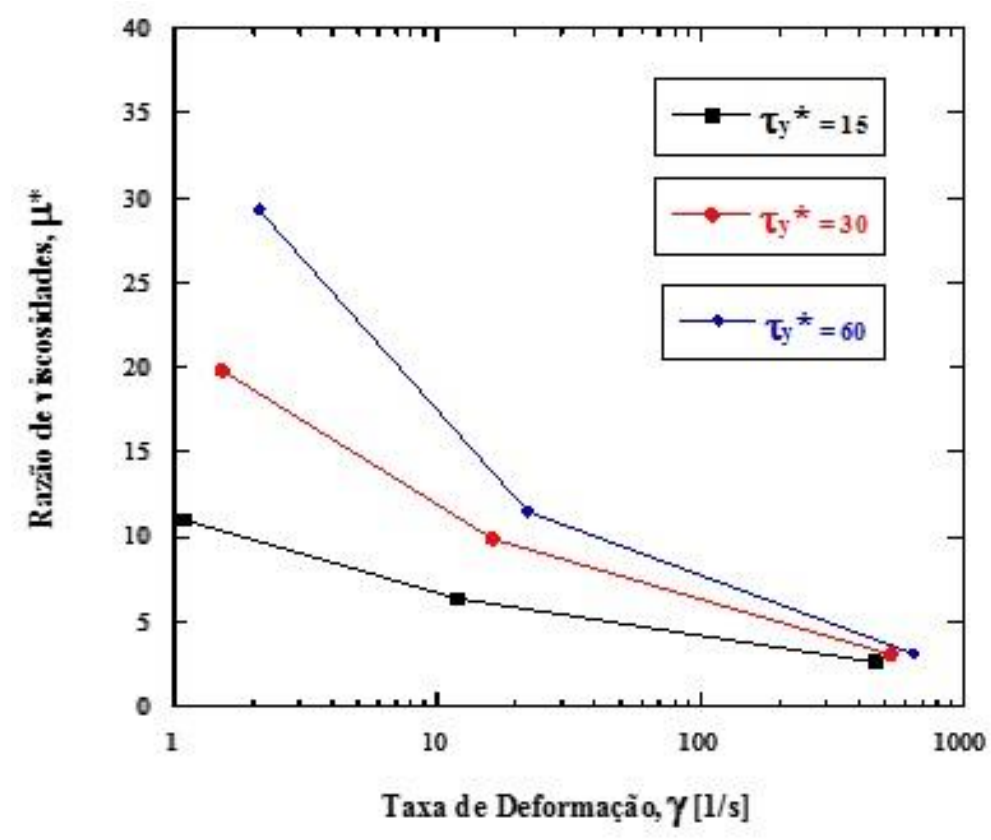

Figura 45 - Razões de viscosidades entre o Fluido de perfuração e o Cimento para tensões limite de escoamento característico $\tau_{\mathrm{y}}^{*}=15 \mathrm{~Pa}, \tau_{\mathrm{y}}^{*}=30 \mathrm{~Pa}$ e $\tau_{\mathrm{y}}^{*}=60 \mathrm{~Pa}$.

É interessante observar que neste caso, como as razões de densidade e de viscosidade são maiores do que um, espera-se uma interface mais aguda entre os fluidos.

\subsection{1}

Cimento deslocando Fluido de perfuração - geometria $1(L / D=0,5)$

As Figuras 46 e 47 mostram as frações volumétricas das duas fases, o cimento (amarela) deslocando o fluido de perfuração (vermelha) na geometria 1, para diferentes valores de Reynolds e razões de tensões limites de escoamento. 


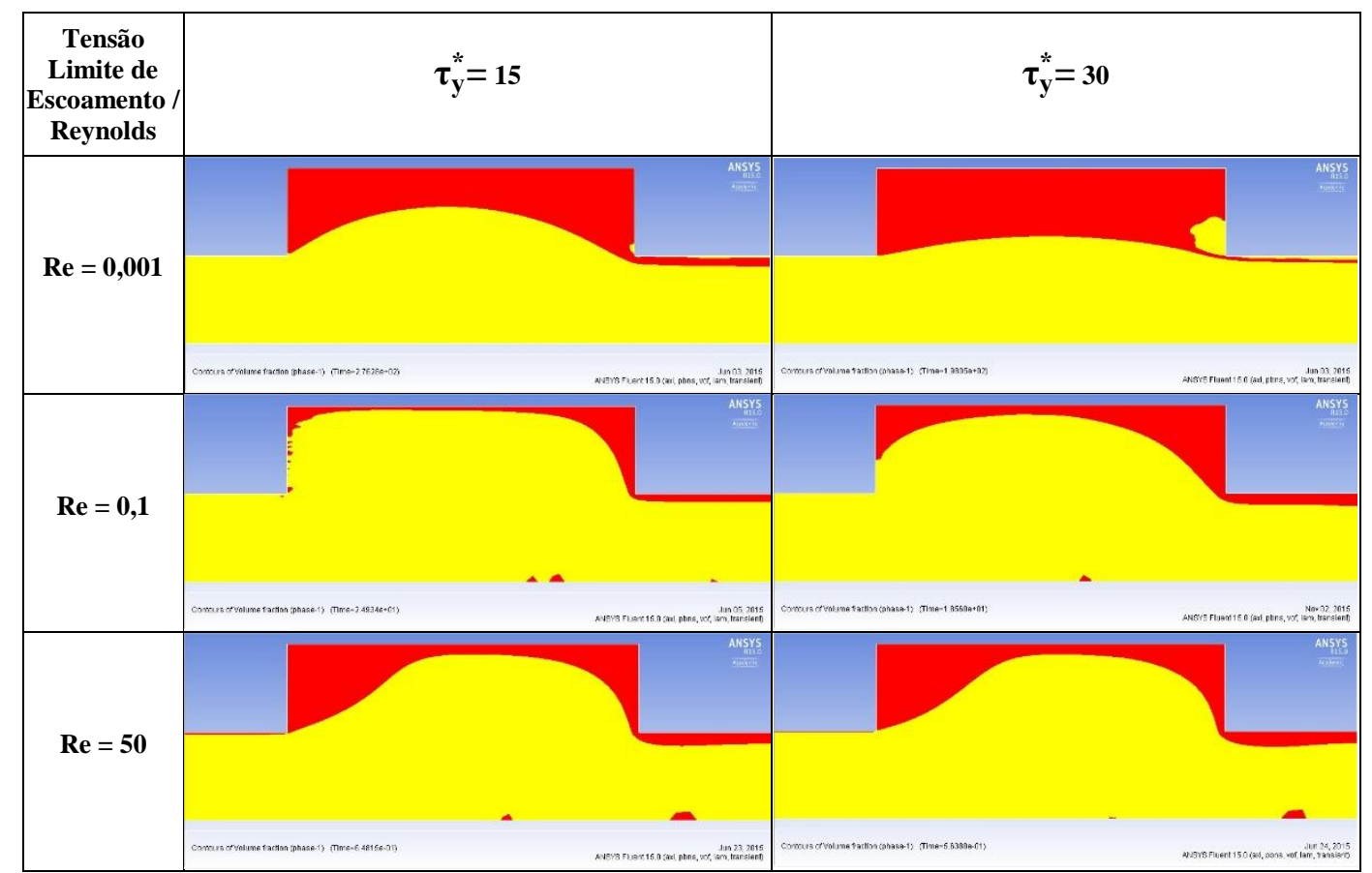

Figura 46 - Deslocamento do Fluido de perfuração pelo Cimento para diferentes Reynolds e tensões limites de escoamento característico na geometria 1.

A análise visual das Figuras 46 e 47 mostra que quanto maior é a razão entre as tensões limite de escoamento, a quantidade de fluido de perfuração deslocado é menor.

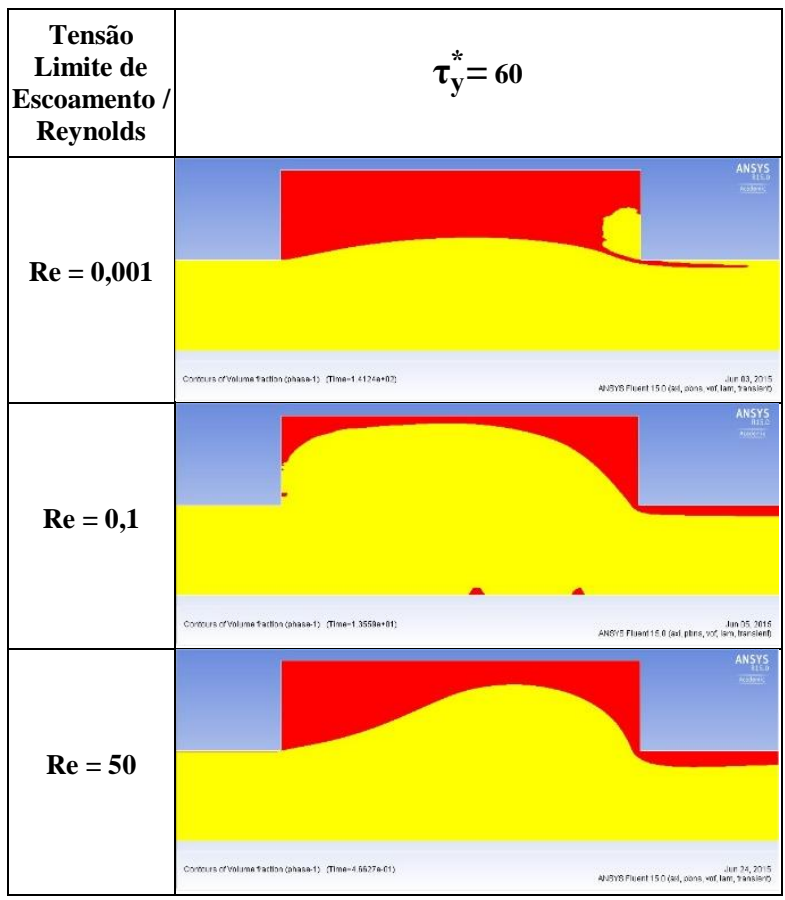

Figura 47 - Deslocamento do Fluido de perfuração pelo Cimento para diferentes Reynolds e tensões limites de escoamento característico na geometria 1. 
As linhas de corrente desta primeira geometria são apresentadas nas Figuras 48 e 49 e confirmam o comportamento no Reynolds alto $(\operatorname{Re}=50)$, onde a inércia faz que o cimento se desloque mais para à saída da região erodida, levando a um aumento da eficiência na área 2 da cavidade, em comparação com a área 1.

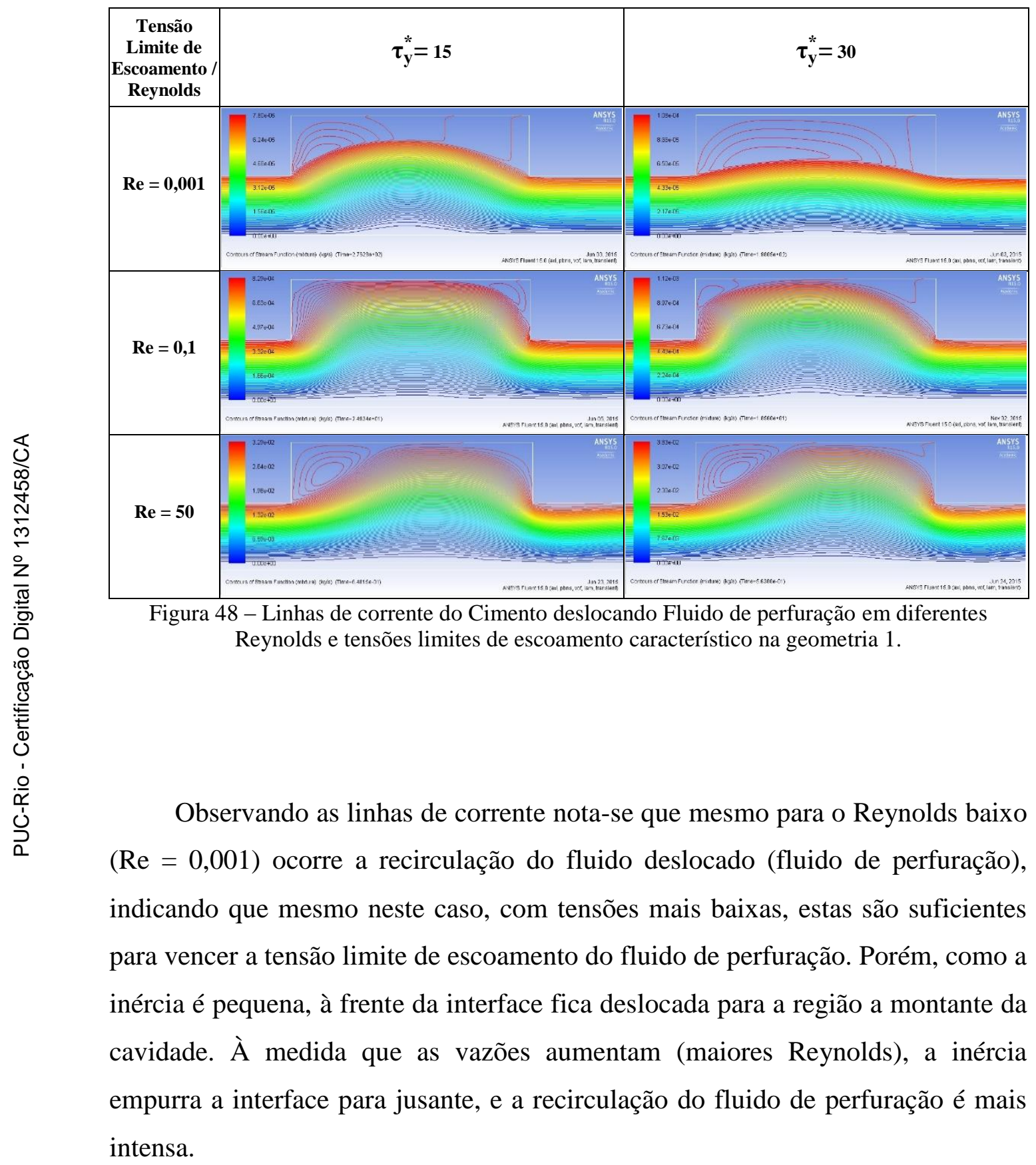




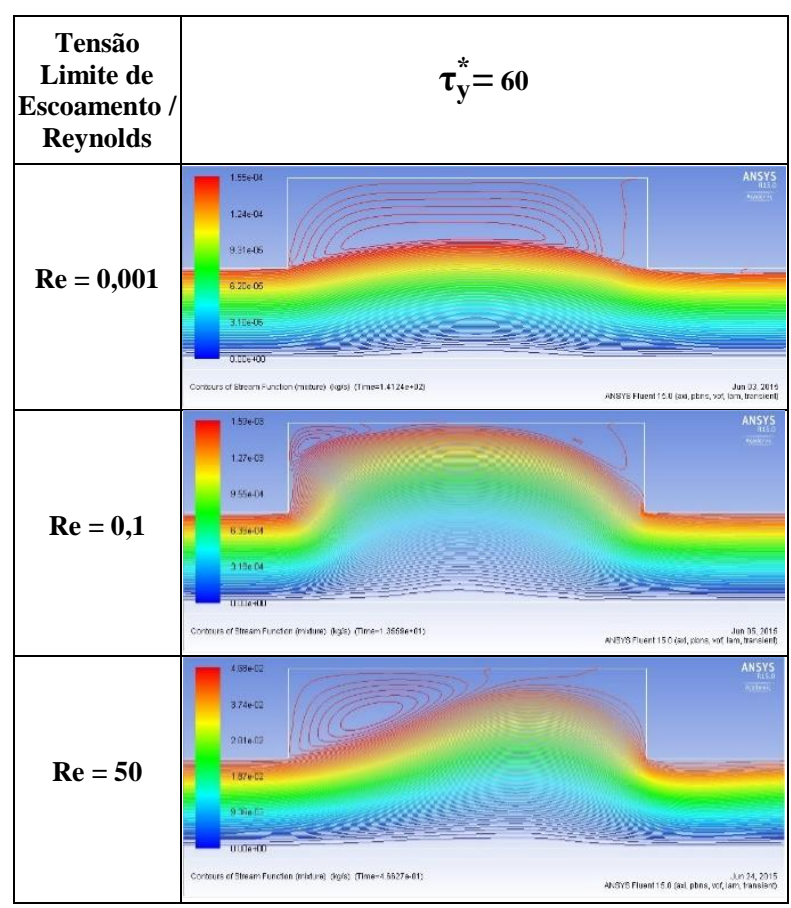

Figura 49 - Linhas de corrente do Cimento deslocando Fluido de perfuração em diferentes Reynolds e tensões limites de escoamento característico na geometria 1.

\subsection{2}

Cimento deslocando Fluido de perfuração - geometria $2(L / D=1,0)$

Nas Figuras 50 e 51 mostram-se também as duas fases, o cimento empurrando fluido de perfuração na geometria 2, com as mesmas configurações de Reynolds e das razões de tensões limites de escoamento.

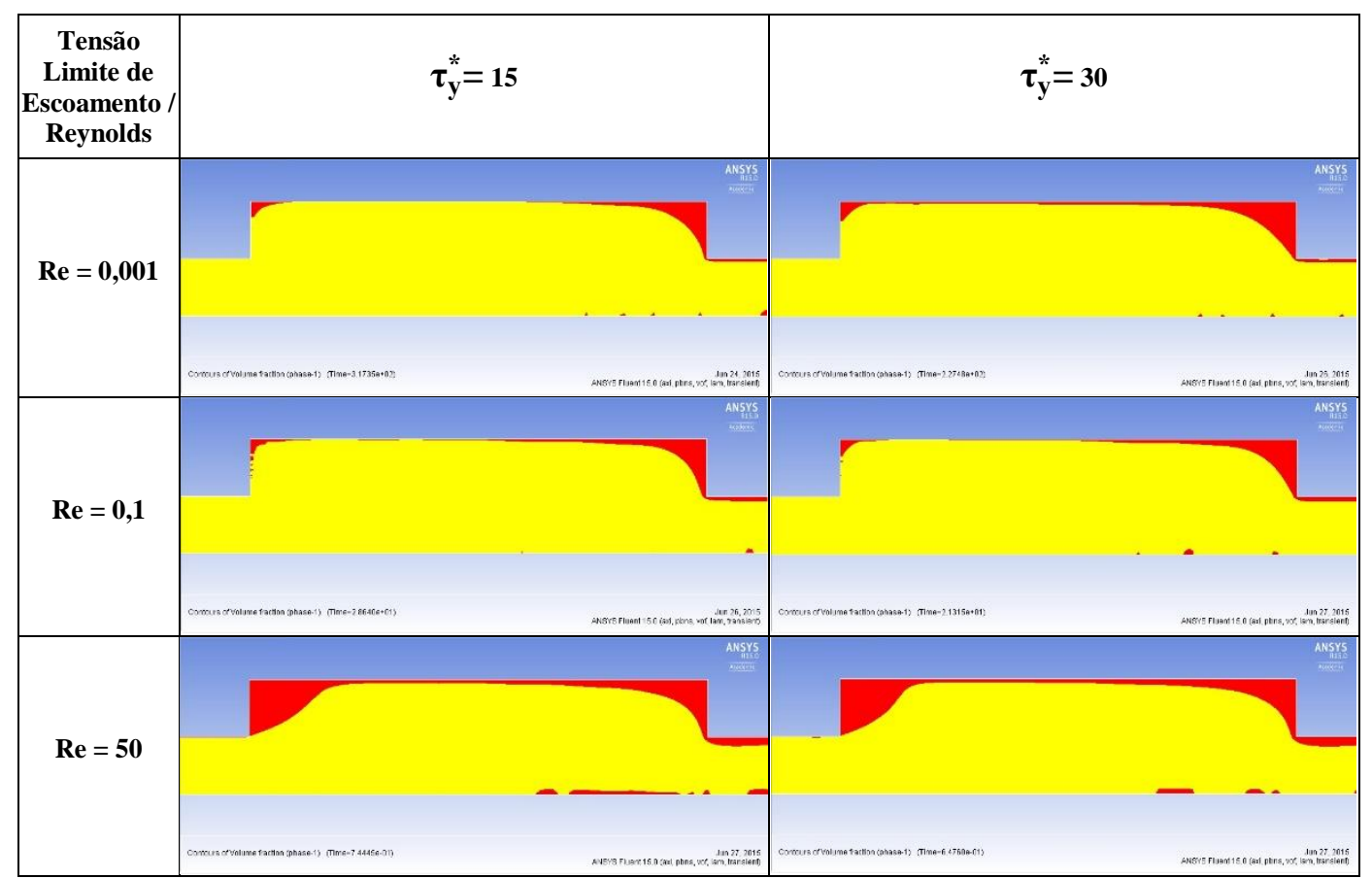


Figura 50 - Deslocamento do Fluido de perfuração pelo Cimento para diferentes Reynolds e tensões limites de escoamento característico na geometria 2.

Novamente, o comportamento qualitativo é similar ao caso anterior, mas o processo de deslocamento é mais efetivo.

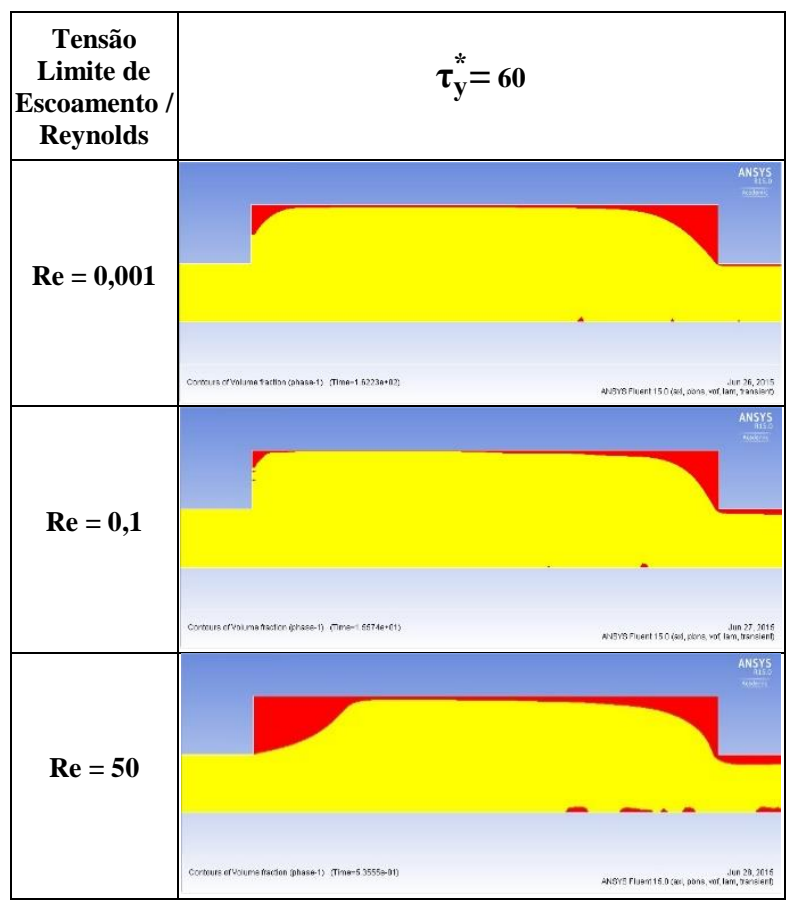

Figura 51 - Deslocamento do Fluido de perfuração pelo Cimento para diferentes Reynolds e tensões limites de escoamento característico na geometria 2.

As Figuras 52 e 53 mostram as linhas de corrente, onde observa-se que as zonas não deslocadas do fluido de perfuração recirculam, mesmo nos casos de baixos números de Reynolds, com exceção das regiões a esquerda, muito pequenas, quando o fluido não se movimenta.

\begin{tabular}{|c|c|c|}
\hline \begin{tabular}{|c|} 
Tensão \\
Limite de \\
Escoamento / \\
Reynolds
\end{tabular} & $\tau_{y}^{*}=15$ & $\tau_{\mathbf{y}}^{*}=30$ \\
\hline $\operatorname{Re}=0,001$ & 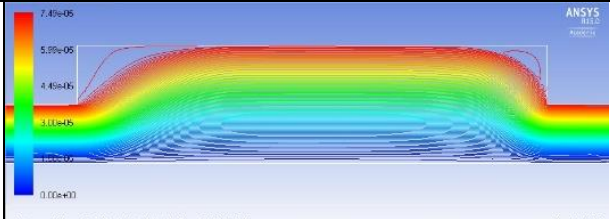 & 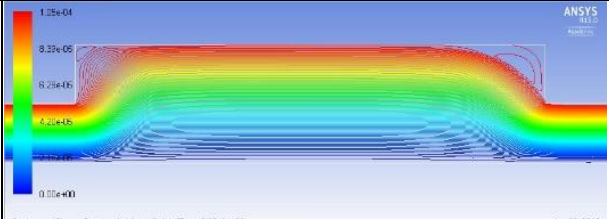 \\
\hline
\end{tabular}




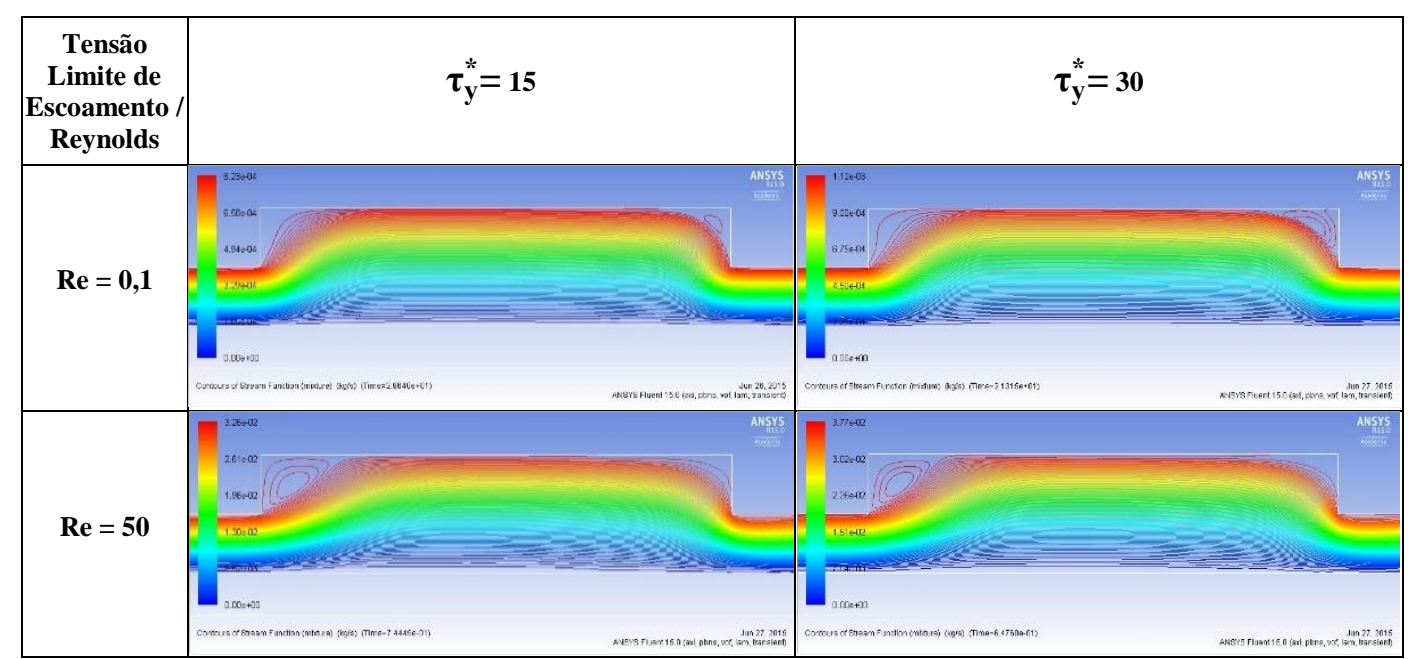

Figura 52 - Linhas de corrente do Cimento deslocando Fluido de perfuração em diferentes Reynolds e tensões limites de escoamento característico na geometria 2.

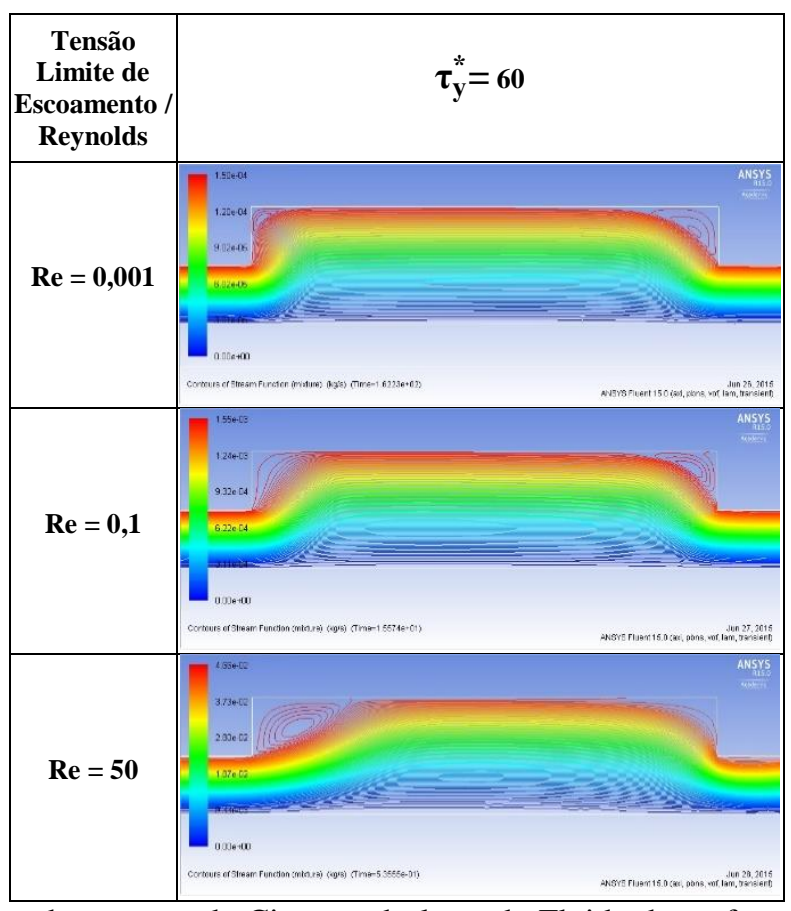

Figura 53 - Linhas de corrente do Cimento deslocando Fluido de perfuração em diferentes Reynolds e tensões limites de escoamento característico na geometria 2.

\subsection{3}

\section{Cimento deslocando Fluido de perfuração - geometria $3(L / D=1,5)$}

Por último, para a análise da geometria $3(\mathrm{~L} / \mathrm{D}=1,5)$ se exibem o campo de fração volumétrica das fases e as linhas de corrente, do cimento deslocando o fluido de perfuração mas com a relação, para três valores de Reynolds e as três razões de tensões limites de escoamento. 


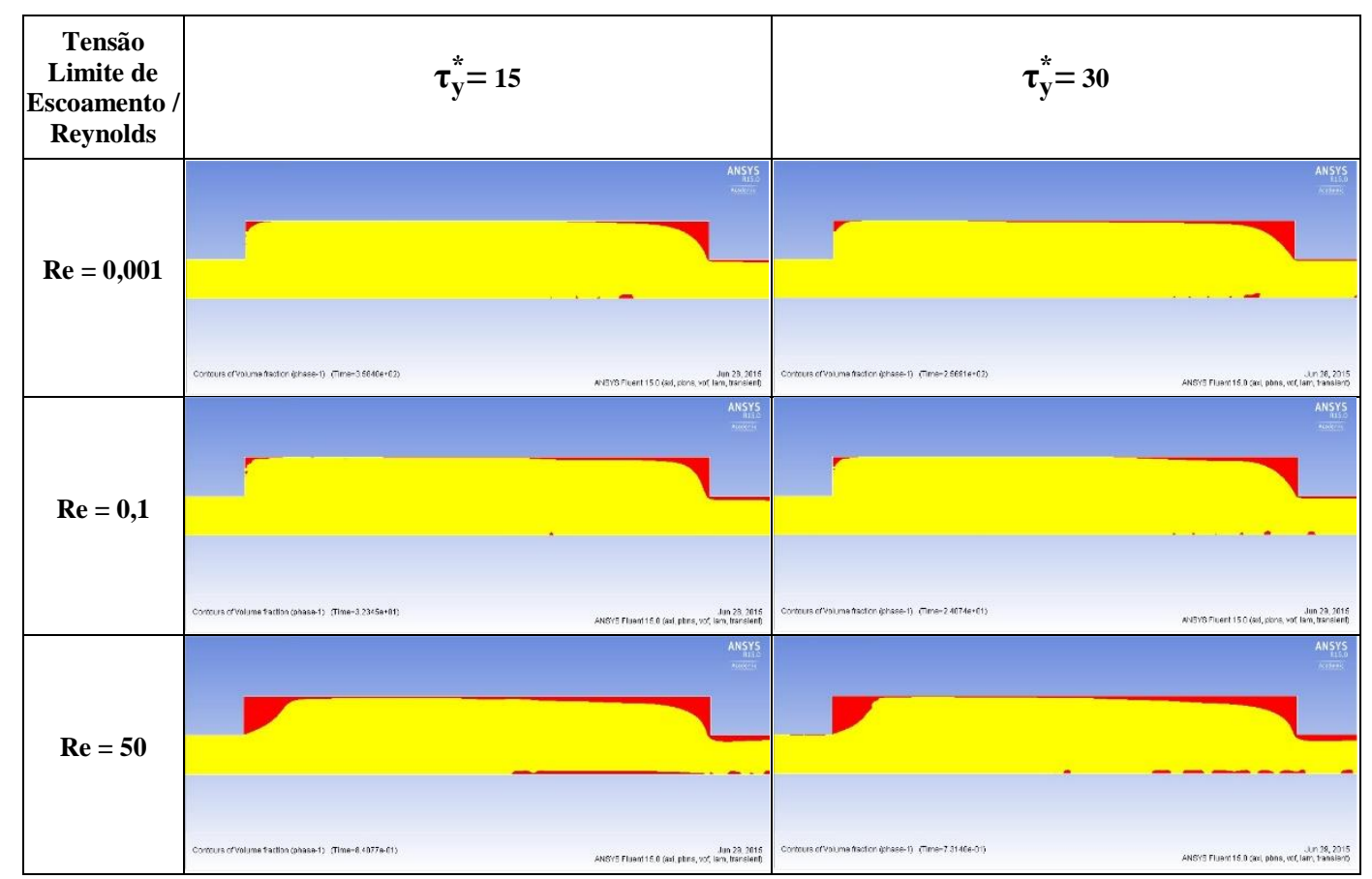

Figura 54 - Deslocamento do Fluido de perfuração pelo Cimento para diferentes Reynolds e tensões limites de escoamento característico na geometria 3.

O processo de deslocamento é similar ao caso anterior (geometria 2). Notase uma remoção quase total do fluido de perfuração para os casos de Reynolds mais baixo $(\operatorname{Re}=0,001$ e $\operatorname{Re}=0,1)$. No caso do maior Reynolds analisado $(\operatorname{Re}=$ 50), nota-se que a remoção desse fluido é muito menor.

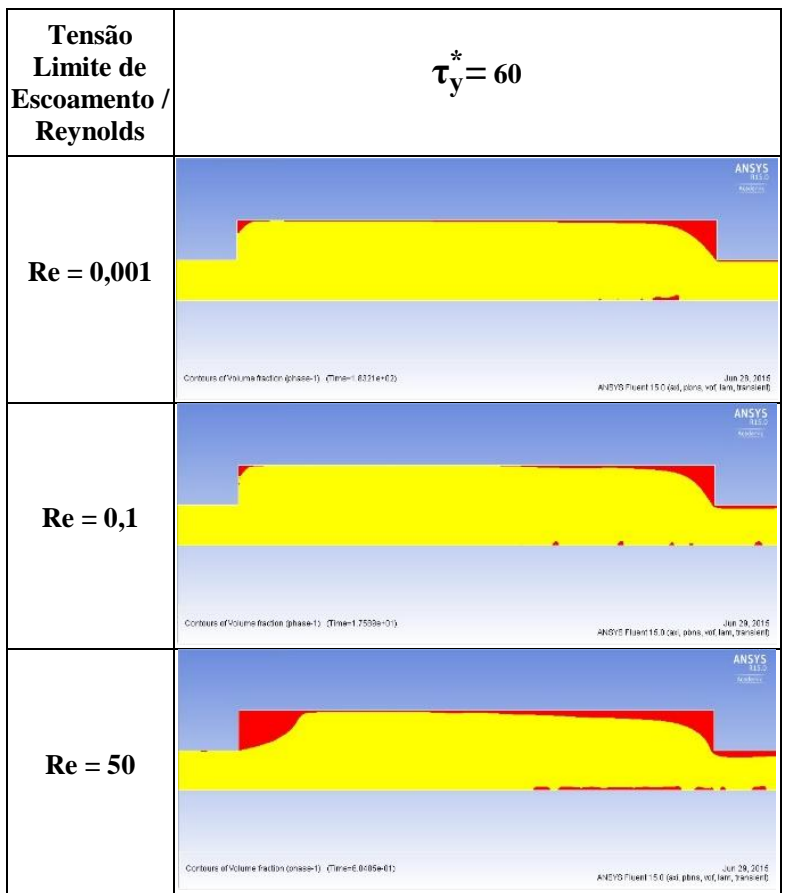

Figura 55 - Deslocamento do Fluido de perfuração pelo Cimento para diferentes Reynolds e tensões limites de escoamento característico na geometria 3. 
As linhas de corrente apresentadas nas Figuras 56 e 57 mostram a existência de recirculação apenas na região a jusante para baixos valores de Reynolds e a montante para Reynolds mais alto, i. e., a recirculação está presente quando o tamanho da região de fluido não deslocado é maior.

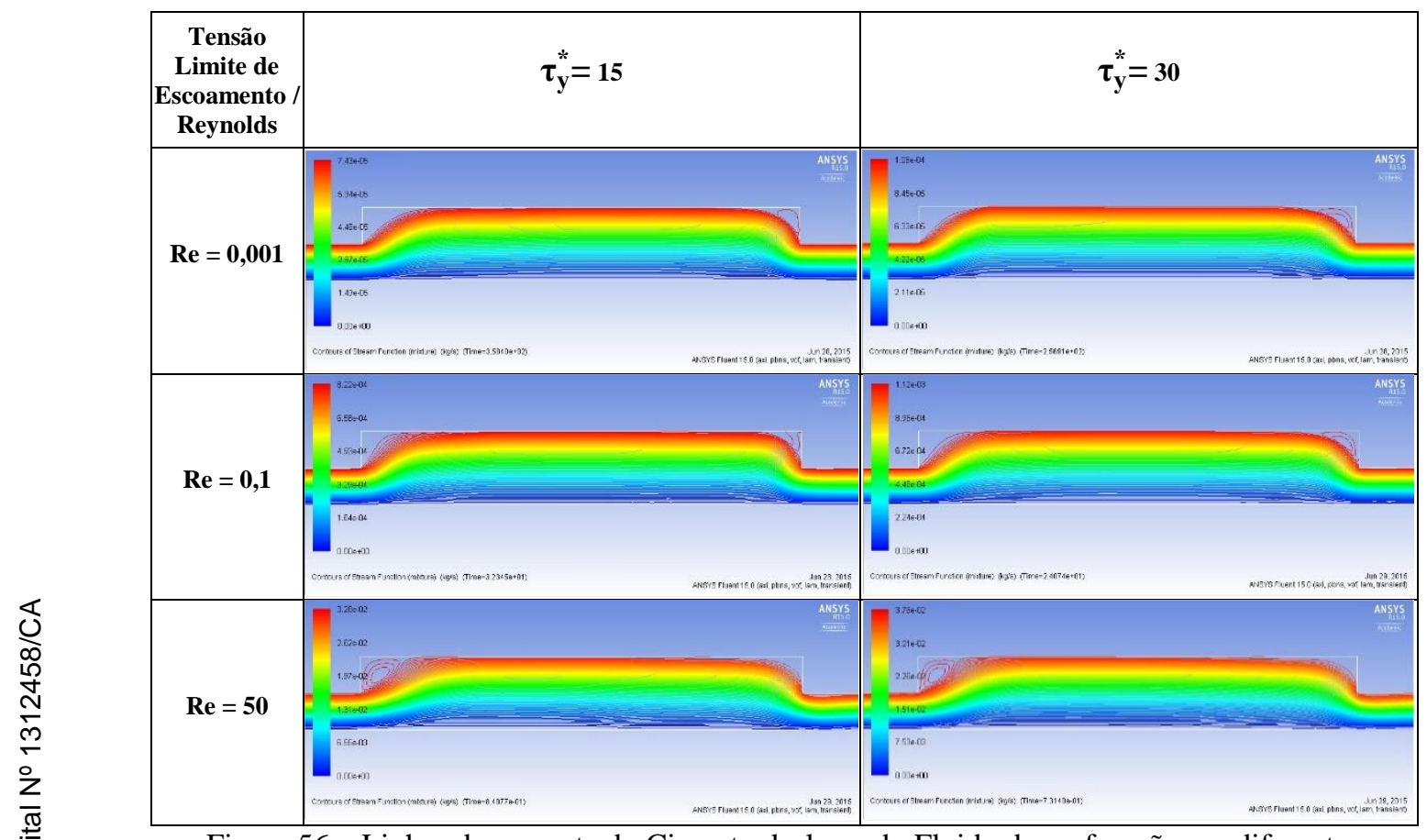

Figura 56 - Linhas de corrente do Cimento deslocando Fluido de perfuração em diferentes Reynolds e tensões limites de escoamento característico na geometria 3.

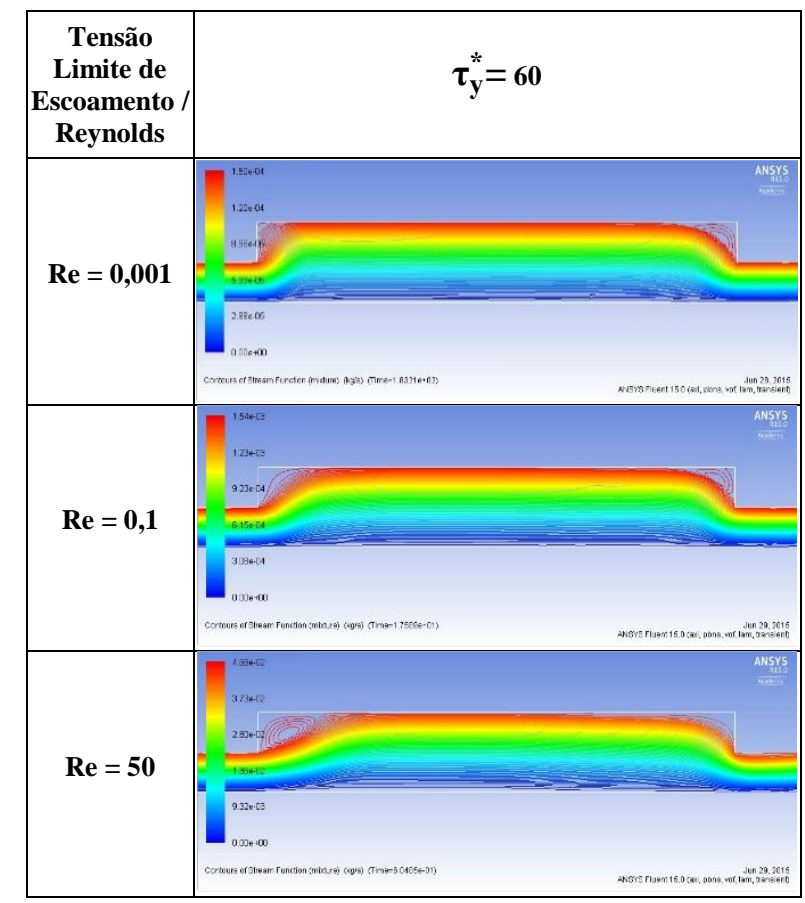

Figura 57 - Linhas de corrente do Cimento deslocando Fluido de perfuração em diferentes Reynolds e tensões limites de escoamento característico na geometria 3. 


\subsection{4 \\ Eficiências do caso Cimento deslocando Fluido de perfuração}

A seguir se apresentam os gráficos da eficiência total, da eficiência na cavidade e as eficiências nas áreas 1 e 2 da região erodida, com o fim de analisar os efeitos causados pela geometria, pelo número de Reynolds e pela razão entre as tensões limite de escoamento.

A Figura 58 mostra o gráfico da eficiência total no tubo para as 3 geometrias, e se pode ver que à medida que o Reynolds aumenta, a eficiência total decresce. Além disso, observa-se que os valores são bem altos, chegando a atingir quase o valor máximo nas situações em que $\operatorname{Re}=0,001$.

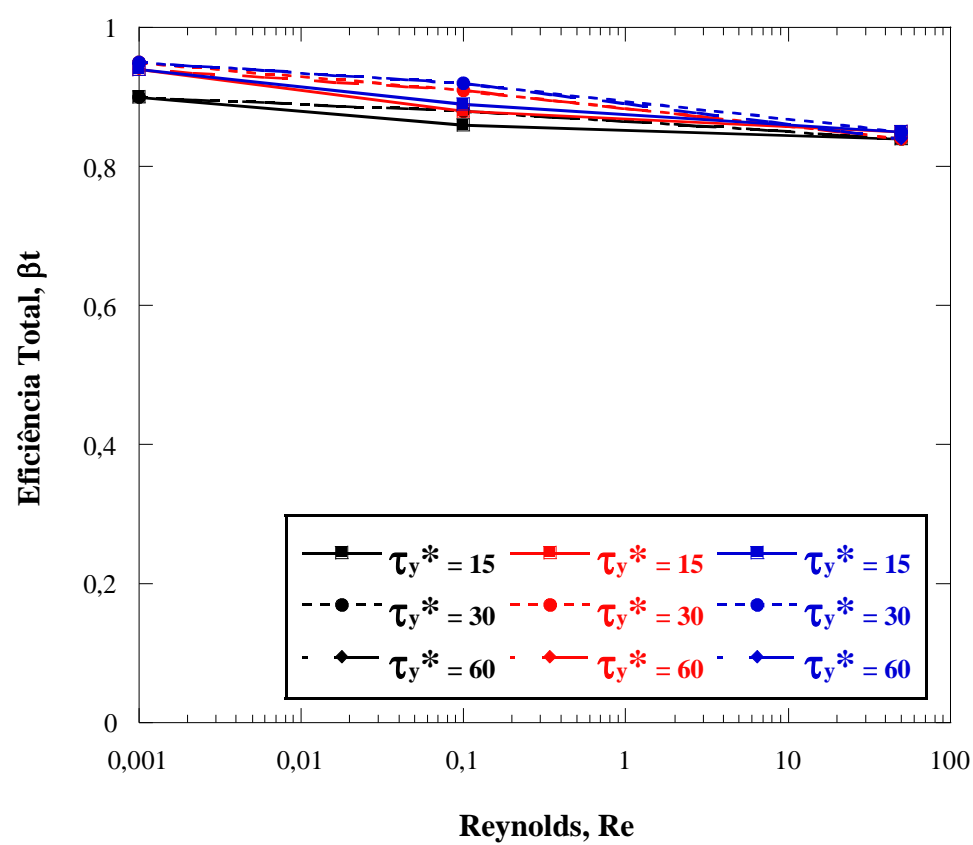

Figura 58 - Eficiência total nas três geometrias para diferentes Reynolds.

A eficiência na cavidade é mostrada na Figura 59, para as mesmas três geometrias. Observa-se novamente que a geometria 1 apresenta o deslocamento bem pior do que as outras geometrias, que apresentam resultados muito próximos. Observa-se que na geometria 1 , a eficiência cresce consideravelmente com $\mathrm{Re}$, na situação em que o escoamento é dominado pelo efeito viscoso. A inércia leva a uma piora no processo de deslocamento. Nota-se também que o aumento na razão entre as tensões limite de escoamento tende a reduzir a eficiência do processo, porém o efeito não é muito significativo. 


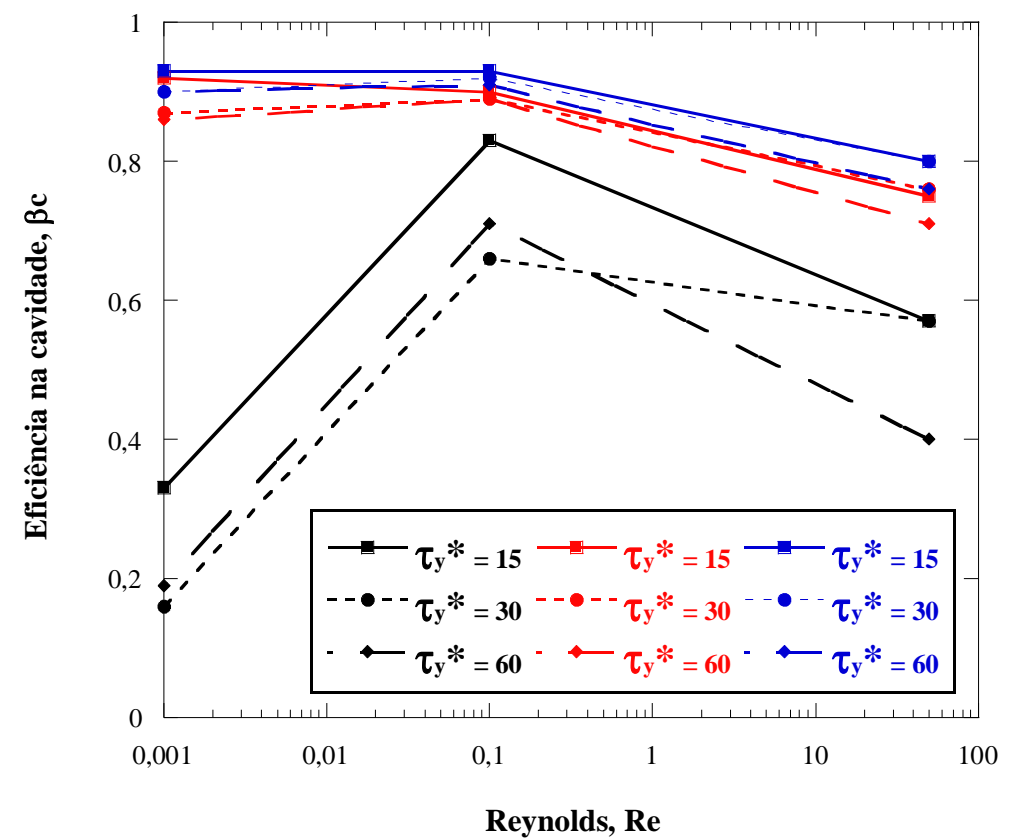

Figura 59 - Eficiência na cavidade nas três geometrias para diferentes Reynolds.

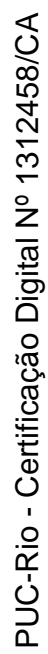

Em adição do gráfico da eficiência na cavidade mostrado na figura anterior, nas Figuras 60 e 61 se apresentam as eficiências nas áreas 1 e 2 da cavidade para as três geometrias.

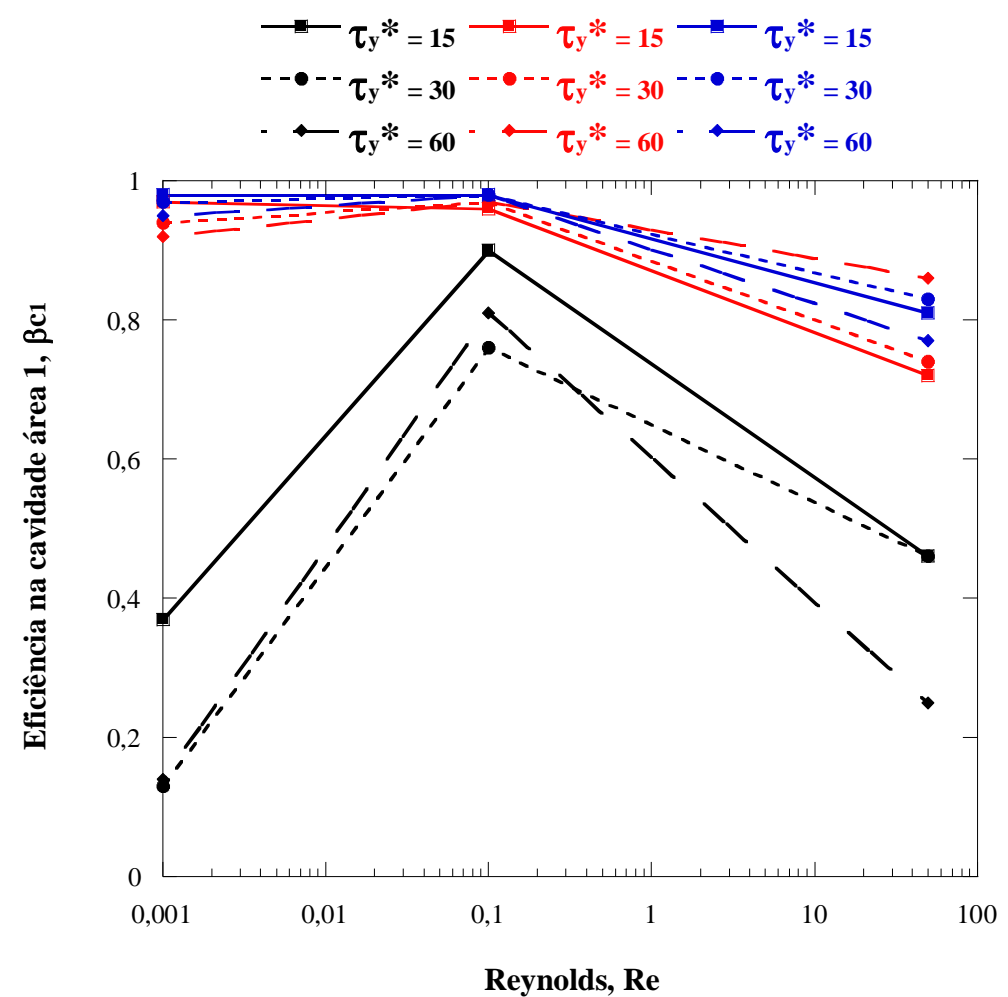

Figura 60 - Eficiência na cavidade da área 1 nas três geometrias para diferentes Reynolds. 


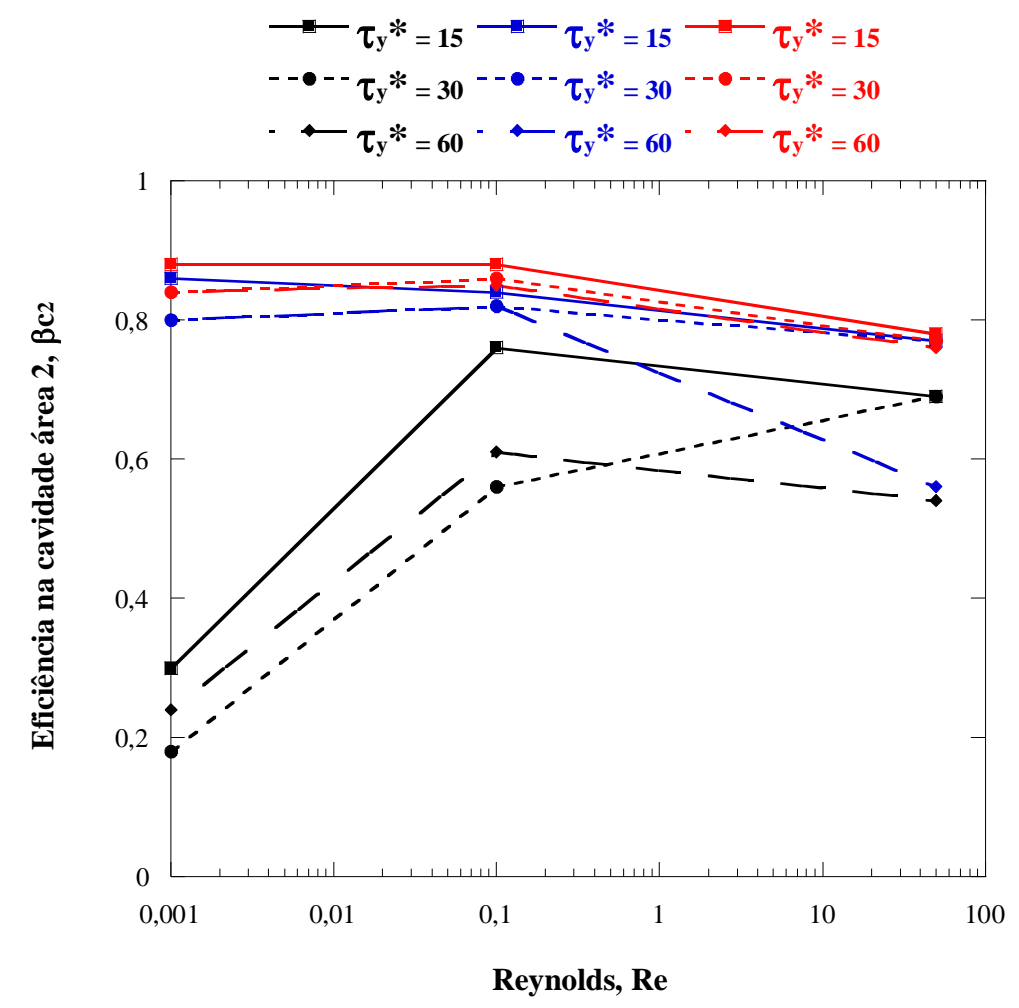

Figura 61 - Eficiência na cavidade da área 2 nas três geometrias para diferentes Reynolds.

Pode-se observar que para as geometrias 1 e 2 e Reynolds baixo $(\operatorname{Re}=0,001$ e $\operatorname{Re}=0,1)$ a eficiência na área 1 da cavidade é maior do que a eficiência na área 2.

À medida que a inércia passa a afetar o escoamento, a frente se move para a direita fazendo com que a eficiência a direita (área 2) se torne maior do que a eficiência a esquerda (área 1). 


\section{5 \\ Conclusões e trabalhos futuros}

\section{1}

\section{Conclusões}

Este trabalho teve como objetivo principal apresentar uma análise numérica rigorosa no processo de deslocamento de fluido que ocorre ao longo do processo de cimentação em poços erodidos. Realizando a análise numérica detalhada através das simulações no Fluent, se conseguiu avaliar a influência de diferentes parâmetros na eficiência da operação, tais como: a relação de viscosidades dos fluidos, a relação de densidades, a geometria e o número de Reynolds.

Foram discutidos nove casos diferentes, com base em dados experimentais. No total, foram feitas mais de cento e trinta simulações para três geometrias distintas e três pares de fluidos.

Os resultados obtidos mostram o efeito da razão de viscosidades no processo de deslocamento. Além disso, eles mostraram que a tensão limite de escoamento afeta suavemente a eficiência de deslocamento no intervalo investigado, enquanto que a inércia e a geometria da área erodida (L/D) tem grande influência sobre a eficiência de deslocamento.

Conclui-se que a eficiência na remoção e limpeza de um poço erodido depende não apenas dos parâmetros reológicos dos fluidos, mas também, e muito fortemente, dos parâmetros geométricos e de escoamento.

\section{2}

\section{Trabalhos futuros}

A análise dos resultados sugere a continuação dos estudos, no sentido de ampliar o entendimento do problema. Assim, propõe-se como continuação do presente trabalho: 
- Realização de simulações com outras formas na geometria da parte erodida, e avaliar o efeito da forma do arrombamento no processo de remoção.

- Fazer comparações dos resultados numéricos com os resultados obtidos na bancada experimental desenvolvida no laboratório de mecânica dos fluidos não Newtonianos na PUC-Rio.

- Analisar a influência de outros parâmetros reológicos, tais como o índice de potência. Efeito relacionados a tixotropia ou elasticidade dos fluidos também podem ser de interesse científico.

- Verificação e comparação dos resultados com dados experimentais, mas utilizando dimensões reais e mudando a injeção dos volumes dos fluidos para apresentar resultados mais perto da realidade do poço. 


\section{6 Referências bibliográficas}

ALEXANDROU, A. N.; MCGILVREAY, T. M.; BURGOS, G. Steady Herschel-Bulkley fluid in three-dimensional expansions. Journal of NonNewtonian Fluid Mechanics, v. 100, n. 1-3, p. 77-96, sep. 2001.

ANSYS FLUENT USERS GUIDE, version 15, Fluent Inc., 2015.

CHIN, W.; ZHUANG, X. Exact Non-Newtonian Flow Analysis of Yield Stress Fluids in Highly Eccentric Borehole Annuli with Pipe or Casing Translation and Rotation. In: INTERNATIONAL OIL AND GAS CONFERENCE AND EXHIBITION IN CHINA, 8-10 June, 2010, Beijing. Conference Paper SPE131234-MS, Beijing, Society of Petroleum Engineers, 2010. P. 1-17.

DEAWWANICH, et al. Displacement of viscoplastic fluids in eccentric annuli: numerical simulation and experimental validation. In: CHEMECA 2008 CONFERENCE, 28 September-1 October, 2008, Newcastle. Conference Paper proceeding of the Chemeca 2008 Conference: Towards a sustainable Australasia, Newcastle, Engineers Australia, 2008. P. 1986-1997.

DUTRA, E. S. S. et al. Liquid displacement through tube-annular transition region inside oil wells. In: ASME 2005 INTERNATIONAL MECHANICAL ENGINEERING CONGRESS AND EXPOSITION, 5-11 November, 2005, Florida. Conference Paper No. IMECE2005-81279, Florida, Fluids Engineering Division, 2005. P. 919-924.

GROESBECK, B. M.; JORDAN, J. C. Deepwater Casing String Deployment for Elimination of Rat Hole Section: Retractable Shoe Joint. In: ASIA PACIFIC OIL AND GAS CONFERENCE \& EXHIBITION, 4-6 August, 2009, Jakarta. Conference Paper SPE-123472-MS, Jakarta, Society of Petroleum Engineers, 2009. P. 1-8.

HAUT, R. C.; CROOK, R. J. Primary Cementing: The Mud Displacement Process. In: SPE ANNUAL TECHNICAL CONFERENCE AND EXHIBITION, 23-26 September, 1979, Las Vegas. Conference Paper SPE-8253-MS, Las Vegas, 
Society of Petroleum Engineers, 1979. 12p.

HAUT, R. C.; CROOK, R. J. Laboratory Investigation of Lightweight, LowViscosity Cementing Spacer Fluids. Journal of Petroleum Technology, v. 34, n. 8, p. 1828-1834, aug. 1982.

LOCKYEAR, C. F.; HIBBERT, A. P. Integrated Primary Cementing Study Defines Key Factors for Field Success. Journal of Petroleum Technology, v. 41, n. 12 , p. 1320-1325, dec. 1989.

PELIPENKO, S.; FRIGAARD, I. A. Mud Removal and Cement Placement During Primary Cementing of an Oil Well. Journal of Engineering Mathematics, v. 48, n. 1, p. 1-26, jan. 2004.

PLANK J. Lehrs für Bauchemie Prof. Dr. Plank. Oil Well Cementing. Disponível em: <http://www.bauchemietum.de/masterframework/data/dynamic/Image/tbzle.gif>. Acesso em: 26 agos. 2014.

SAVERY, M.; CHIN, W.; YERUBANDI, K. B. Modeling Cement Placement Using a New 3-D Flow Simulator. In: 2008 AADE FLUIDS CONFERENCE AND EXHIBITION, 8-9 April, 2008, Houston. Conference Paper AADE-08-DFHO-08, Houston, 2008. P. 1-8.

SAUER C. W. Mud Displacement During Cementing: A State of the Art. Journal of Petroleum Technology, v. 39, n. 9, p. 1091-1101, sep. 1987.

SMITH, T. R.; RAVI, K. M. Investigation of Drilling Fluid Properties to Maximize Cement Displacement Efficiency. In: SPE ANNUAL TECHNICAL CONFERENCE AND EXHIBITION, 6-9 October, 1991, Dallas. Conference Paper SPE-22775-MS, Dallas, Society of Petroleum Engineers, 1991. P. 151-164.

SOUZA MENDES, P. R. et al. Flow of viscoplastic liquids through axisymmetric expansions-contractions. Journal of Non-Newtonian Fluid Mechanics, v. 142, n.1-3, p. 207-217, mar. 2007.

SZABO, P.; HASSAGER, O. Displacement of one Newtonian fluid by another: Density effects in axial annular flow. International Journal of Multiphase Flow, v. 23, n. 1, p. 113-129, feb. 1997.

SZABO, P.; HASSAGER, O. Flow of Viscoplastic Fluids in Eccentric Annular Geometries. Journal of Non-Newtonian Fluid Mechanics, v. 45, n. 2, p. 149169, mar. 1992. 
WACHS, A. Numerical simulation of steady Bingham flow through an eccentric annular cross-section by distributed Lagrange multiplier/fictitious domain and augmented Lagrangian methods. Journal of Non-Newtonian Fluid Mechanics, v. 142, n. 1-3, p. 183-198, mar. 2007. 